\title{
POLICY OPTIONS FOR ADDRESSING CLIMATE CHANGE, WITH A FOCUS ON ECOSYSTEM BASED ADAPTATION: A CASE STUDY OF GUYANA
}

\section{By}

\section{Ramesh Lilwah}

BSc (Agriculture), University of Guyana, (1983)

M.S. (Weed Science), Mississippi State University, (1992)

\author{
A thesis presented to Ryerson University \\ in partial fulfillment of the \\ requirements for the degree of \\ Master of Applied Science \\ in the Program of \\ Environmental Applied Science and Management
}

Toronto, Ontario, Canada, 2015

@ Ramesh Lilwah, 2015 


\section{AUTHOR'S DECLARATION}

I hereby declare that I am the sole author of this thesis. This is a true copy of the thesis, including any required final revisions, as accepted by my examiners.

I authorize Ryerson University to lend this thesis to other institutions or individuals for the purpose of scholarly research.

I further authorize Ryerson University to reproduce this thesis by photocopying or by other means, in total or in part, at the request of other institutions or individuals for the purpose of scholarly research.

I understand that my thesis may be made electronically available to the public. 


\section{ABSTRACT \\ Policy Options for Addressing Climate Change, With a Focus on Ecosystem Based Adaptation (EbA): A Case Study of Guyana}

\section{Ramesh Lilwah \\ Environmental Applied Science and Management Master of Applied Science, Ryerson University, 2015}

Close to ninety percent of Guyana's population live along a low lying coastal plain, which is below sea level and very vulnerable to the impacts of climate change. While the national government has not yet developed a comprehensive climate policy, the potential impacts of climate change is considered in several sectoral policies, much of which emphasize mitigation, with little focus on adaptation. This research examined the current priorities for adaptation by a review of the policies within the natural resource sector to identify opportunities for adaptation, especially ecosystem based adaptation.

A Diagnostic Adaptation Framework (DAF) was used to help identify approaches to address a given adaptation challenge with regards to needs, measures and options. A survey questionnaire was used to support the policy reviews and identified four key vulnerabilities: coastal floods; sea level rise; drought and extreme weather events. The application of the DAF in selecting an adaptation method suggests the need for more data on drought and extreme weather events. Coastal flooding is addressed, with recognized need for more data and public awareness for ecosystem based adaptation. 


\section{ACKNOWLEDGEMENTS}

"It is not the strongest of the species that survive, nor the most intelligent, but the one most responsive to change." Charles Darwin (1859)

This thesis would not have been possible without the guidance and help of my supervisors who contributed and extended their valuable assistance in the preparation and completion of this study. First and foremost my utmost gratitude to Dr. Bernard Fleet for his sincerity, encouragement, knowledge, friendship and for sharing his insights on all the difficult issues related to climate change. I am heartily thankful to Dr. Andrew Laursen, for his tremendous and unselfish support, his patience, motivation and enthusiasm in guiding me through the preparation and completion of this research. It was indeed an honour to work with both of my supervisors and I wish to reiterate my sincere appreciation for their guidance, wisdom and the knowledge they shared with me.

Sincere thanks to the Chair of my defence Committee, Dr. Cory Searcy, to Dr. Christopher Gore and Dr. Carolyn Johns who readily agreed to serve as examiners on my Committee.

Administering a survey in a distant country was not an easy task. I wish to thank all the respondents in Guyana who took the time to fill out my questionnaires and submitted the data and information as requested. Thank you to the staff from the Office of Climate Change in Guyana for your conversations and for responding to my emails.

Sincere thanks to the administrative and laboratory staff of the Department of Chemistry and Biology for your camaraderie and help during my Teaching Assistant (TA) duties for the various undergraduate courses. Thank you Karen, I learned so much from you.

I cannot forget my buddies, Olalekan Onilude, Laura Klien and Paul McKinley, a big thank you for your conversations, friendship and support. Finally, and most importantly, I sincerely thank my family; my wife Donna and two sons, Shawn and Gary. I am forever indebted to you for your encouragement, support, love and inspiration during times when I needed it most and for which I know is always there. 


\section{Dedication}

This thesis is dedicated to my wife, Donna and my two sons, Shawn and Gary, for their love support and constant encouragement 


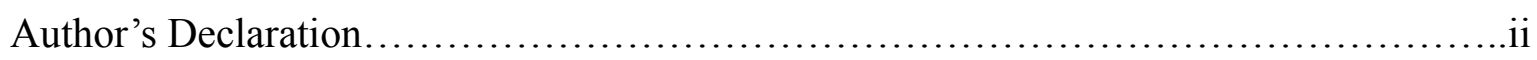

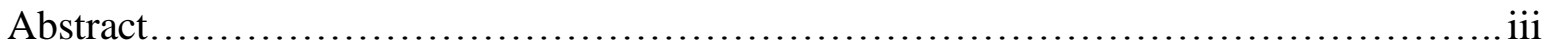

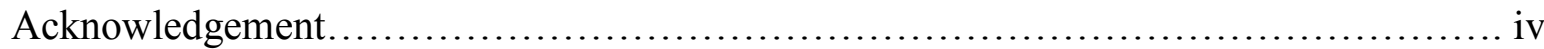

Thesis Dedication.........................................................................

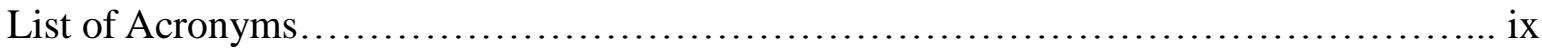

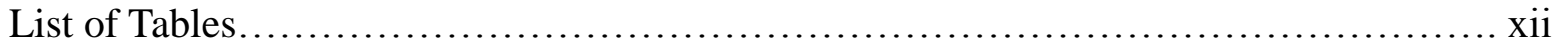

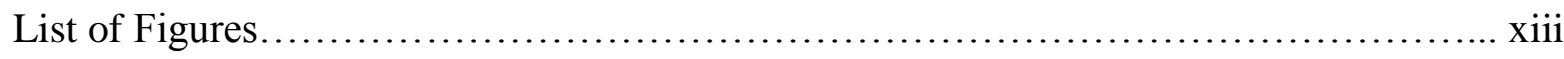

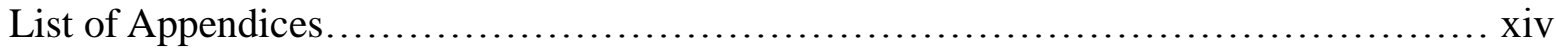

1.0 Introduction and Objectives................................................. 1

1.1 Overview of Global Framework for Addressing

Climate Change................................................................. 8

1.1.1 United Nations Framework Convention on

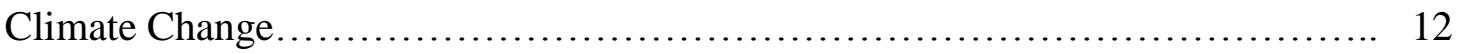

1.1.2 The Kyoto Protocol................................................... 14

1.1.3 The Intergovernmental Panel on Climate Change ......................... 20

1.1.4 The Post Kyoto Agreement.............................................. 21

1.1.5 The Green Climate Fund ............................................... 23

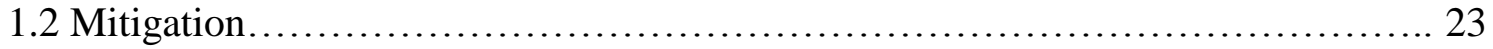

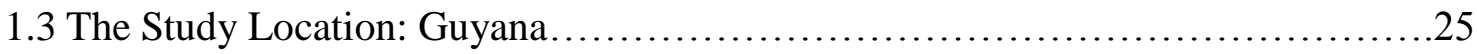

1.3.1 Mitigation in Guyana................................................... 32

1.3.2 Key steps taken by Guyana in Pursuit of its

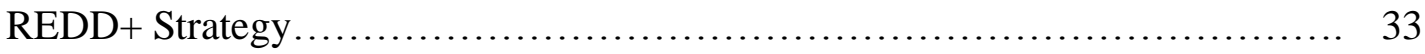

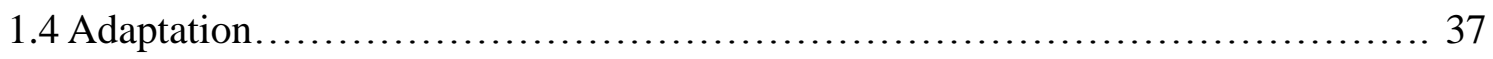

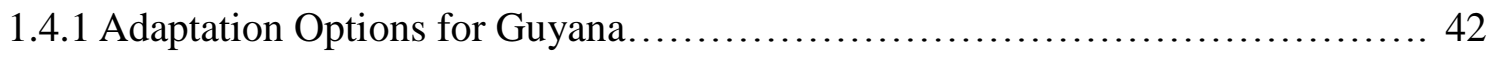

1.4.2 The Adaptation Challenge and its Significance............................... 43

1.4.3 Ecosystem based Adaptation.......................................... 44

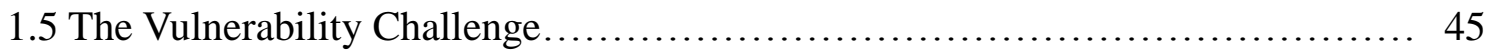

1.5.1 Sea level Rise $\quad$....................................................... 49

1.5.2 Floods in Guyana................................................. 51

1.5.3 Extreme Weather Events (Storms and high precipitation)................. 52 


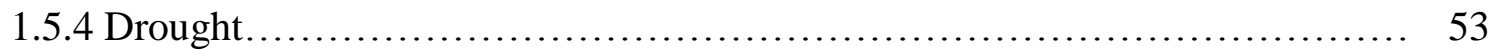

1.6 The Institutional Framework for Climate Change

in Guyana......................................................... 53

1.6.1 Office of Climate Change........................................ 54

1.6.2 The REDD Secretariat............................................ 55

1.6.3 The Guyana Forestry Commission................................ 55

1.6.4 The Environmental Protection Agency................................ 55

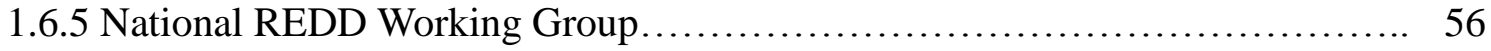

1.6.6 Low Carbon Development Strategy Multi

Stakeholder Steering Committee.................................... 56

1.7 Identifying Adaptation Needs and Opportunities in Guyana.....................57

1.7.1 Selecting an Adaptation Option...................................... 57

1.8 Context of the Research and Specific Research Questions.................. 60

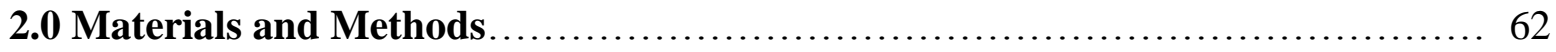

2.1 Overview of the Application of a Diagnostic Adaptation

Framework (DAF) for Guyana........................................ 63

2.2 Identifying Guyana's Adaptation Priorities through

Analytic Review of key Policy and Strategy Documents..................... 65

2.3 Administration of Questionnaires..................................... 69

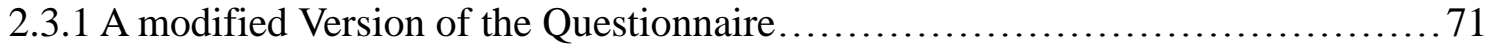

2.4 Impact Analysis........................................................ 75

2.5 Capacity Assessment of Actors...................................... 78

2.6 Assessing Ability of Policy Instruments to enable Necessary Action........... 79

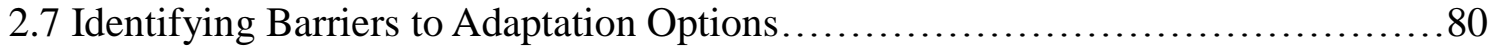

3.0 Results and Discussions............................................. 81

3.1 Identification of Adaptation Needs ..................................... 83

3.1.1 Identification of needs from policy documents.......................... 84

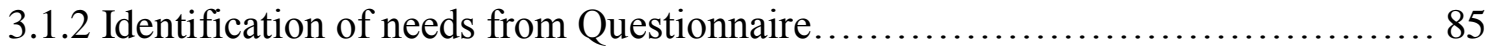

3.2 Impact Analysis..................................................... 86

3.2.1 Impact Analysis for Adaptation Needs: Coastal Flooding .................. 86

3.2.2 Impact Analysis for Adaptation Needs: Drought.......................... 87 
3.2.3 Impact Analysis for Adaptation Needs: Extreme weather Events............. 89

3.2.4 Impact Analysis for Adaptation Needs: Sea Level Rise....................... 89

3.3 Identifying Adaptation Measures for coastal Flooding....................... 91

3.3.1 Identifying Potential measures (hard and ecosystem-based) based on policy reviews..................................................... 91

3.3.2 Identifying Potential measures (hard and ecosystem-based) based

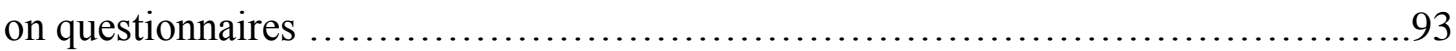

3.4 Capacity assessment of Actors ......................................... 93

3.5 Ability of public policy instruments to enable (or constrain) actors............. 94

3.6 Appraising adaptation options - identification of barriers................... 95

4.0 Summary of Recommendations regarding adaptation Strategies.............. 98

4.1 Results and main findings...........................................99

4.2 Benefits and information of value to Guyana............................... 100

4.3 Directions for further research.......................................... 101

References............................................................... 134 


\section{List of Acronyms}

\begin{tabular}{|c|c|}
\hline $\begin{array}{l}\text { AM } \\
\text { AR }\end{array}$ & $\begin{array}{l}\text { Adaptation Measure } \\
\text { Assessment Report }\end{array}$ \\
\hline AS & Adaptation Situation \\
\hline AN & Adaptation Need \\
\hline BOEM & Bureau of Ocean Energy Management \\
\hline $\mathrm{BP}$ & British Petroleum \\
\hline $\mathrm{CAF}$ & Cancun Adaptation Framework \\
\hline CBD & Convention on Biological Diversity \\
\hline $\mathrm{CCCCC}$ & Caribbean Community Climate Change Centre \\
\hline $\mathrm{CCS}$ & Carbon Capture and Storage \\
\hline $\mathrm{CDM}$ & Clean Development Mechanism \\
\hline $\mathrm{CI}$ & Conservation International \\
\hline $\mathrm{COP}$ & Conference of Parties \\
\hline CRSAP & Climate Resiliency Strategy and Adaptation Plan \\
\hline DAF & Diagnostic Adaptation Framework \\
\hline $\mathrm{EbA}$ & Ecosystem based Adaptation \\
\hline ECLAC & Economic Commission for Latin America and the Caribbean \\
\hline EDWC & East Demerara Water Conservancy \\
\hline ENSO & El Nino Southern Oscillation \\
\hline ET & Emissions Trading \\
\hline EU & European Union \\
\hline FAO & Food and Agriculture Organization \\
\hline GD & Georgetown Datum \\
\hline GCF & Green Climate Fund \\
\hline GDP & Gross Domestic Product \\
\hline GEF & Global Environment Facility \\
\hline GFC & Guyana Forestry Commission \\
\hline GGMC & Guyana Geology and Mines Commission \\
\hline GHG & Greenhouse Gas \\
\hline GLSC & Guyana Lands and Surveys Commission \\
\hline
\end{tabular}




\begin{tabular}{ll} 
GNI & Gross National Income \\
GRIF & Guyana REDD Investment Fund \\
GUYSUCO & Guyana Sugar Corporation \\
ICZM & Integrated Coastal Zone Management \\
IET & International Emissions Trading \\
IFI & International Financial Institution \\
IIC & Iwokrama International Centre \\
INDCs & Intended Nationally Determined Contributions \\
IPBES & Intergovernmental Science-Policy Platform on Biodiversity and Ecosystem \\
& Services \\
IPCC & Intergovernmental Panel on Climate Change \\
ITCZ & Inter-tropical Convergence Zone \\
IUCN & International Union for the conservation of Nature (World Conservation Union) \\
JCN & Joint Concept Note \\
JI & Joint Implementation \\
KC & Keeling Curve \\
LCDS & Low Carbon Development Strategy \\
LDC & Least Developed Country \\
LUCF & Land Use Change and Forestry \\
LULUCF & Land Use, Land Use Change and Forestry \\
MACC & Mainstreaming Adaptation for Climate Change \\
MARAD & Maritime Administration Division \\
MARDS & Mahaicony Abary Rice Development Scheme \\
MEA & Multilateral Environmental Agreement \\
MLG & Ministry of Local Government \\
MOA & Ministry of Agriculture \\
MOAA & Ministry of Amerindian Affairs \\
MOU & Memorandum of Understanding \\
MSE & Medium Scale Enterprise \\
MSL & Mean Sea Level \\
MRSL & Mean Relative Sea Level \\
\hline
\end{tabular}


NAP National Adaptation Plan

NAREI National Agricultural Research and Extension Institute

NCSA National Capacity Self-Assessment

NGO Non-Governmental Organization

NOAA National Oceanic and Atmospheric Administration

NRWG National REDD Working Group

OCC Office of Climate Change

OECD Organization for Economic Cooperation and Development

PROVIA Global Programme of Research on Climate Change Vulnerability, Impacts and Adaptation

REDD Reduced Emissions from Deforestation and Forest Degradation

UNCED United Nations Conference for the Environment and Development

UNDP United Nations Development Programme

UNEP United Nations Environment Programme

UNFCCC United Nations Framework Convention on Climate Change

WWF World Wildlife Fund for Nature 
Table 1: Total aggregate anthropogenic emission of $\mathrm{CO}_{2}, \mathrm{CH}_{4}, \mathrm{~N}_{2} \mathrm{O}$, HFCs, PFCs and $\mathrm{SF}_{6}$ excluding emissions/removals for LULUCF for selected Annex 1 countries

Table 2: Total aggregate anthropogenic emission of $\mathrm{CO}_{2}, \mathrm{CH}_{4}, \mathrm{~N}_{2} \mathrm{O}$, HFCs, PFCs and $\mathrm{SF}_{6}$ excluding emissions/removals for LULUCF for selected Annex 1 countries

Table 3: Aggregate emissions and removals of $\mathrm{CO}_{2}, \mathrm{CH}_{4}, \mathrm{~N}_{2} \mathrm{O}$, in $\mathrm{CO}_{2}$ equivalent by major source / sink category, including and excluding LUCF

Table 4: Key steps taken in pursuit of REDD+ Strategy.

Table 5: Projects currently implemented with GRIF funds

Table 6: UNFCCC Discussions and Policies for financing adaptation in

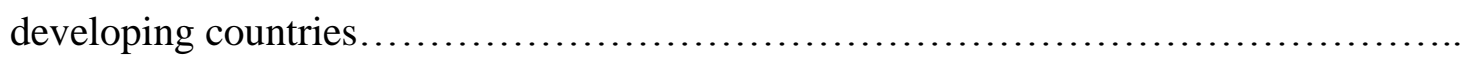


Figure 1: The Keeling Curve showing $\mathrm{CO}_{2}$ current concentration (ppm) at

Mauna Loa Observatory .......................................................... 4

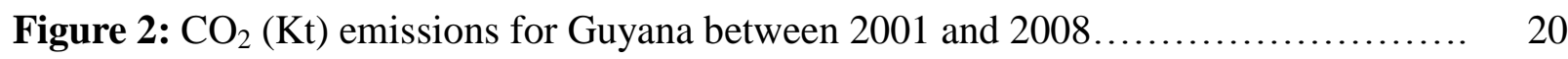

Figure 3: Location map of Guyana showing the capital city of Georgetown and

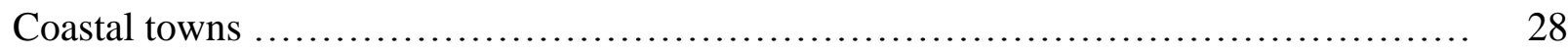

Figure 4: Map showing the administrative Regions of Guyana......................... 29

Figure 5: Mean monthly temperature and rainfall for Guyana from $1900-2009 \ldots \ldots \ldots \ldots . \quad 31$

Figure 6: Schematic diagram and map of the East Demerara Water Conservancy......... 48

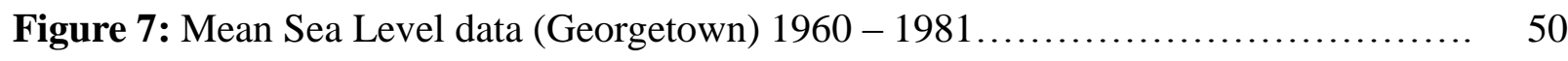

Figure 8: The adaptation cycle.................................................. 60

Figure 9: Identification of adaptation Needs, Measures, and Options and

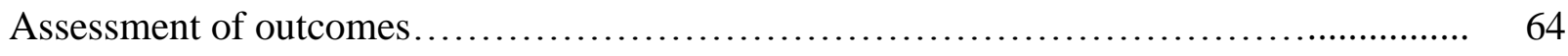

Figure 10: Criteria for choosing salient approaches to impact analysis and for

Identifying adaptation measures............................................... 77

Figure 11: The main vulnerabilities identified in the survey questionnaire............... 80

Figure 12: Barriers identified for community participation.......................... 83 
Appendix I: Ryerson University Consent Agreement for survey in Guyana................102

Appendix II: Joint Concept Note: Guyana and Norway regarding cooperation

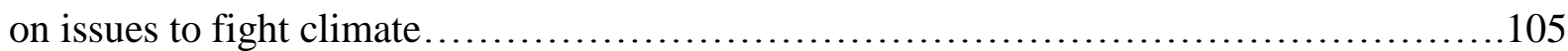

Appendix III: Memorandum of Understanding between the Cooperative Republic of

Guyana and the Kingdom of Norway regarding cooperation on issues to fight climate

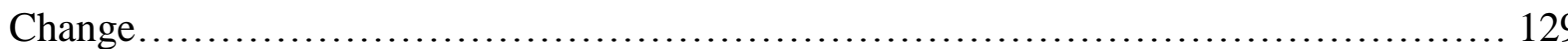




\subsection{Introduction and Objectives}

Climate change is now the foremost emerging environmental challenge that poses an existential threat to humanity's welfare and the survival of our present civilization (Barnett, 2001; Paavola \& Adger, 2006; Solomon, et al, 2007; Ahmad \& Wei, 2012; Hansen, et al, 2013; IPCC, 2014; Goodstein, 2015). The magnitude of this threat is gradually dawning on humanity and because of its global effects it is one of the toughest public policy problems that humanity, on the whole, has ever faced (Buhaug et al, 2014; Sachs, 2015). This is not a local problem where a local community can come up with a solution and resolve the issue. This threat involves the entire world and is centred on the economy which is driven by energy in the form of fossil fuels such as oil, coal and gas. So herein lays the problem: energy in the form of fossil fuels is the driver of the economy and it is also the driver of climate change due to the emission of carbon dioxide $\left(\mathrm{CO}_{2}\right)$, which is the major greenhouse gas responsible for this problem and much of which, will remain in the atmosphere for millennia (IPCC, 2007; Archer, et al, 2009; Solomon, et al, 2009).

The recent fifth Assessment Report (AR) from the Intergovernmental Panel on Climate Change (IPCC) has unequivocally identified humans as the major cause to climate change and states "Human influence on the climate system is clear. This is evident from the increasing greenhouse gas concentrations in the atmosphere, positive radiative forcing, observed warming, and understanding of the climate system" (IPPC, 2014). This position was underscored by other reports from key institutions such as the United Nations (Bierbaum et al, 2007), US Global Change Research Program (Karl et al, 2009), and the Potsdam Institute for Climate Impact Research and Climate Analytics (World Bank, 2012).

This research looks at the situation in a developing country, Guyana, with a coastal plain that lies below sea level and that is highly vulnerable to the effects of climate change such as coastal floods and sea level rise. Even though attempts have been made at mitigating the effects of climate change, little focus is given to adaptation in Guyana. Since mitigation alone will not solve the climate change threat, there is urgent need to direct more attention and resources to adaptation, including ecosystem based adaptation. This thesis considers potential use of ecosystem based adaptation in the context of recognized adaptation priorities and needs in Guyana. The lessons learnt from Guyana can also be used for other jurisdictions within the Caribbean region all of which faced the common threat of climate change. 
As more scientific evidence becomes available, the global policy discussions on mitigating greenhouse gases have intensified in academia, civil society and in the policy circles of both developed and developing countries. Even though carbon dioxide $\left(\mathrm{CO}_{2}\right)$ is the main contributor to climate change, especially through the burning of fossil fuels, there are other greenhouse gases that also contribute to the problem and these include: methane $\left(\mathrm{CH}_{4}\right)$, nitrous oxide $\left(\mathrm{N}_{2} \mathrm{O}\right)$, hydroflurocarbons (HFCs), perflurocarbons (PFCs) and sulphur hexafluoride $\left(\mathrm{SF}_{6}\right)^{1}$.

Many would agree that the concept of climate change is not new, with the origins of awareness of its cause dating back almost two centuries. In 1824, Jean-Baptiste Louis Fourier, a French Mathematician, calculated that an object the size of the earth and distance from the sun should be much colder. He then proposed that the earth's atmosphere was acting as a blanket, allowing it to warm up. Fourier is generally credited with being the first person to describe the "Greenhouse Effect" and calculated that if greenhouse gases were not part of earth's atmosphere then the temperatures would be some $18^{\circ} \mathrm{C}$ lower (Fleming, 1999).

Some fifty (50) years later in 1896, Swedish chemist and Nobel Laureate, Svante Arrhenius was the first to link the increase in carbon dioxide $\left(\mathrm{CO}_{2}\right)$ in the atmosphere to the increased combustion of coal that accompanied the Industrial Revolution (Graham, 2000). He also predicted based on manual calculations that the doubling of the $\mathrm{CO}_{2}$ in the atmosphere would cause a rise in the mean temperature of the earth's atmosphere of about $5^{\circ}$ Celsius and forecasted that this would happen in about 750 years, based on human use of coal, gas and other fossil fuels (Sachs, 2014). Gilbert Plass was a weapons researcher, born in Toronto Canada, but who lived and worked in the United States and pursued climate research in his free time. In 1956, he analyzed how $\mathrm{CO}_{2}$ trapped heat and reported that the impacts of $\mathrm{CO}_{2}$ on climate would be evident by the end of the twentieth century and could pose severe problems on the climate system for future generations (Schmidt, 2010).

One way to get a sense of the current status of $\mathrm{CO}_{2}$ concentration in the atmosphere is from the world famous Keeling Curve, data for which is gathered under the Scripps $\mathrm{CO}_{2}$ Program from the Scripps Institution of Oceanography, San Diego, California. This Program

\footnotetext{
${ }^{1}$ Kyoto Protocol to the United Nations Framework Convention on Climate Change (Annex A) (1998), Available at: http://unfccc.int/resource/docs/convkp/kpeng.pdf (Accessed on: June 2015)
} 
maintains a station at the Mauna Loa Observatory in Hawaii and is the longest running highprecision instrument record for atmospheric $\mathrm{CO}_{2}$ measurements collecting concentration data since $1958^{2}$. The data are gathered at an altitude of $3400 \mathrm{~m}$ in the northern subtropics, and may not be the same as the globally averaged $\mathrm{CO}_{2}$ concentration at the surface ${ }^{3}$, however the data are understood to reflect a general pattern of increase expected globally. Carbon dioxide concentrations have increased at Mauna Loa from 1958 to present (Figure 1). Moreover, the estimated mean rate of growth in $\mathrm{CO}_{2}$ concentrations in the atmosphere has accelerated since the beginnings of the Keeling Curve (KC). The rate has gone from about 0.54 parts per million (ppm) year ${ }^{-1}$ in 1960 to over $2.25 \mathrm{ppm}_{\text {year }}{ }^{-1}$ today $^{4}$. This data is similar to that gathered from other research and from global $\mathrm{CO}_{2}$ emission trends reported from the National Oceanic and Atmospheric Administration (NOAA), which also gave a $\mathrm{CO}_{2}$ level of over $400 \mathrm{ppm}$ so far, for the year 2015 and a growth rate of $\mathrm{CO}_{2}$ of about 2 ppm since 1995 (Battle et al 1996; Butler \& Montzka, 2015). The symbolic 400 ppm CO$~_{2}$ concentration was crossed in 2013 and the average monthly global $\mathrm{CO}_{2}$ concentration is also now 400 ppm (Banerjee, 2013; Gerken 2013; McClendon, 2013; Thompson, 2014; Lazare, 2015; Oh, 2015). As shown in Figure 1 the $\mathrm{CO}_{2}$ concentration at the Mauna Loa Observatory was 403.96 ppm on May 07, 2015.

\footnotetext{
${ }^{2}$ Scripps $\mathrm{CO}_{2}$ data, Mauna Loa Observatory, 2015, available at: co2now.org/Current-CO2/CO2Now/scripps-co2-data-mauna-loa-observatory.html (Accessed on May, 2015)

${ }^{3}$ Earth System Research Laboratory, Global Monitoring Division, 2015, Available at: http://www.esrl.noaa.gov/gmd/ccgg/trends/\#mlo_data

${ }^{4}$ Earth System Research Laboratory, Global Monitoring Division, 2015, Available at: http://www.esrl.noaa.gov/gmd/ccgg/trends/
} 


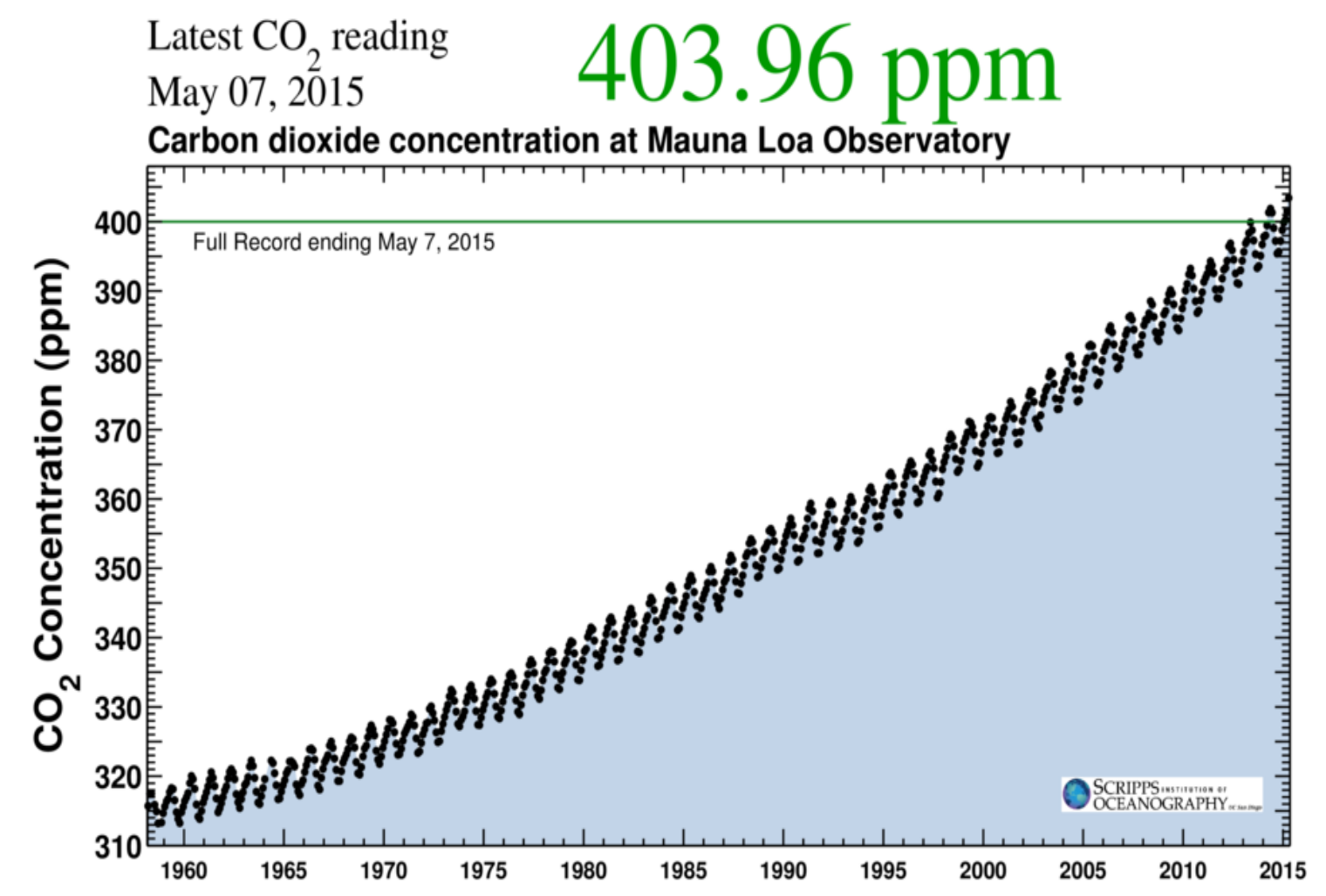

Fig 1: The Keeling Curve showing $\mathrm{CO}_{2}$ current concentration (ppm) at the Mauna Loa Observatory as at May 07, 2015. Source: Scripps Institution of Oceanography, 2015

The real concern today is the current pace at which the $\mathrm{CO}_{2}$ concentration has increased, based on the geometric growth from energy use, compared to earlier times when Arrhenius made his forecast (Waller-Hunter, 2003). According to the British Petroleum (BP) Statistical Review of World Energy 2014 ${ }^{5}$, coal consumption grew by 3\% in 2013 and its share of the global primary energy consumption has now reached 30.1\%, the highest since 1970 . Boden et al (2012), reported that the growth rate of fossil fuel emissions increased from $1.5 \%$ year $^{-1}$ during 1980-2000 to $3 \%$ year $^{-1}$ in 2000-2012, mainly because of increased coal use. So, as argued by Geden (2013) and Hansen et al (2014), even though Parties to the United Nations Framework Convention on Climate Change (UNFCCC, 1992) have agreed to reduce the emission of $\mathrm{CO}_{2}$ and other greenhouse gases, the reality is, these emissions have accelerated. Moreover, as

\footnotetext{
${ }^{5}$ BP Statistical Review of World Energy 2014, available at: http://www.bp.com/content/dam/bp/pdf/Energy-economics/statistical-review-2014/BPstatistical-review-of-world-energy-2014-full-report.pdf (Accessed on May, 2015)
} 
reported by the United States Energy Information Administration ${ }^{6}$, new efforts are underway to expand fossil fuel extraction from drilling, hydro-fracking and coal mining. In May 2015, the US Bureau of Ocean Energy Management (BOEM) gave a conditional approval to Shell Gulf of Mexico Incorporated's exploration plan that proposes the drilling of as many as six wells in the Arctic $^{7}$. During this same period, in May 2015, Exxon Mobil Corporated announced a significant offshore oil find in Guyana, South America, in an area known as the Stabroek Block, 120 miles off the coast of the country ${ }^{8}$. It is now projected that, if we continue with this business as usual, the doubling of $\mathrm{CO}_{2}$ in the atmosphere to cause a $5^{\circ} \mathrm{C}$ rise in temperature is likely to occur roughly 150 years after Arrhenius study, that is around 2050 (Sachs, 2015).

The UNFCCC (1992) does not define a dangerous level for global warming or an emissions limit for fossil fuels but, Article 2 of the UNFCCC states as its objective: the "stabilization of greenhouse gas concentrations in the atmosphere at a level that would prevent dangerous anthropogenic interference with the climate system" (UNFCCC, 1992). In 1996, the European Union introduced and supported a proposal to the UNFCCC to limit global warming to $2^{\circ} \mathrm{C}\left(3.6^{\circ}\right.$ Fahrenheit) relative to pre-industrial times. This was based partly on evidence that many ecosystems are at risk with larger climate change (Hope $\&$ Pearce 2014). The $2^{\circ} \mathrm{C}$ target was reaffirmed in the 2009 "Copenhagen Accord" emerging from the $15^{\text {th }}$ UNFCCC Conference of Parties (COP) Meeting, with specific language "We agree that deep cuts in global emissions are required according to science, as documented in the IPCC Fourth Assessment Report with a view to reduce global emissions so as to hold the increase in global temperature below 2 degrees Celsius..." (Copenhagen Accord, 2009). At the $16^{\text {th }}$ UNFCCC COP Meeting, the $2^{\circ} \mathrm{C}$ target limit was formally adopted in Decision 1/CP.16 which states “ deep cuts in global greenhouse gas emissions are required according to science, and as documented in the

\footnotetext{
${ }^{6}$ International Energy Outlook 2013, U.S Energy Information Administration, available at: http://www.eia.gov/forecasts/ieo/pdf/0484\%282013\%29.pdf (Accessed on May, 2015)

${ }^{7}$ Oil and Gas Journal Online (2015), "Shell gets conditional approval for US Arctic drilling plan”, Available at: http://www.ogj.com/articles/2015/05/shell-gets-conditional-approval-for-usarctic-drilling-plan.html (Accessed on May, 2015)

${ }^{8}$ Dallas Business Journal (2015), "Exxon Mobil makes 'significant' offshore oil find near Guyana", Available at: http://www.bizjournals.com/dallas/news/2015/05/20/exxon-mobilmakes-significant-offshore-oil-find.html, (Accessed on May, 2015)
} 
Fourth Assessment Report of the Inter-governmental Panel on Climate Change, with a view to reducing global greenhouse gas emissions so as to hold the increase in global average temperature below $2^{\circ} \mathrm{C}$ above pre-industrial levels ....." (Cancun Agreements, 2010).

To achieve the $2^{\circ} \mathrm{C}$ target, the IPCC, in its fourth Assessment Report stated this will mean stabilising greenhouse gas (GHG) concentrations in the atmosphere at about 445 to 490 ppm $\mathrm{CO}_{2}$-equivalents $\left(\mathrm{CO}_{2}\right.$-eq) (IPCC, 2007). This includes not only $\mathrm{CO}_{2}$ but all the other greenhouse gases and corresponds to about $400 \mathrm{ppm} \mathrm{CO}_{2}$ alone. A concentration of $350 \mathrm{ppm}$ $\mathrm{CO}_{2}{ }^{9}$ is considered as a safe level by leading climatologists who have concluded that this level is required "to preserve a planet for future generations similar to that in which civilization developed and to which life on Earth is adapted" (Hansen et al, 2008; McKibben, 2008; Vespa, 2009; Kunzig, 2013).

The economic losses from weather and climate related disasters have increased significantly, and estimated from a few US\$ billion to above 200 billion annually from 1980 to 2010 (IPCC, 2012; Liverman \& Glasmeier, 2014), with increased fatality rates and damage to property, especially to people living in developing countries (Sem \& Moore, 2009; IPCC, 2014). Although some researchers argue about the true costs of climate change, the fundamental question not often considered is the cost of not taking action (Carey, 2011). Today world leaders are arriving at the same consensus as atmospheric scientists, that climate change is real and is a threat to our lifestyles, if not our survival, on this planet.

Initially, discussions on a policy to address climate change had significant emphasis on mitigation. Climate change mitigation generally involves reductions in human emissions of greenhouse gases (GHGs). Mitigation may also be achieved by increasing the capacity of carbon sinks, for example, through avoided deforestation or reforestation. Mitigation policies can substantially reduce the risks associated with human-induced global warming (Allen $e t a l$, 2009).

The Kyoto Protocol, adopted in 1997, is an international Agreement linked to the United Nations Framework Convention on Climate Change (UNFCCC) and was designed to achieve reduction in greenhouse gas emissions by committing the developed countries to binding

\footnotetext{
${ }^{9}$ European Environment Agency (2011), "Climate change targets: 350 ppm and the EU twodegree target. Available at: ww.eea.europa.eu/highlights/climate-change-targets-350-ppm-andthe-eu-2-degree-target (Accessed on: May 2015)
} 
emission targets. This strategy has met with varied levels of success, but needs urgent revision and new approaches to strengthen the strategy and increase the likelihood of achieving its goals. This will be the major objective of the crucial UNFCCC meeting scheduled to be held in Paris, France in December, 2015 which is to adopt a universal and legally binding Agreement that will require Parties to reduce GHG emissions, in order to keep global warming below $2{ }^{\circ} \mathrm{C}$.

Over the past ten to fifteen years, reducing the vulnerability to climate change has become one of the most urgent issues for the world's developing countries (Kelly \& Adger, 2000; Heltberg et al, 2009; Mirza, 2011). Sensitive sectors such as agriculture, fishing, and natural resource harvesting have vulnerable public water distribution systems and have concentrated economic activities and people near coastal zones. For these countries, climate change adaptation has become a priority and remains at the forefront of any sustainable development policy agenda. Adaptation means anticipating the adverse effects of climate change and taking appropriate action to prevent or minimise the damage they can cause, or taking advantage of opportunities that may arise. A well planned, early adaptation strategy can saves money and lives.

The process of adaptation is not new; throughout history, people have been adapting and coping with changing conditions, including natural long-term changes in climate (Orlove, 2005). What is new is the discussion occurring within international conventions on climate change regarding how to incorporate future climate risk into policy-making. Although our understanding of climate change and its potential impacts has become clearer, the availability of practical guidance for sound implementation of adaptation to climate change has not kept pace (Klien et al, 1999; Lim et al, 2004). More attention and research needs to be focussed on climate adaptation.

This research looks at Guyana, South America, where the efforts to mitigate climate change can be considered as relatively significant but, like so many other countries, investments in adaptation remains small and in many instances non-existent. The overall objective of this study was to synthesize the information from existing public policy documents that are related to adaptation to climate change and specifically ecosystem based adaptation (EbA) activities.

Healthy ecosystems, such as intact forests and wetlands, are beneficial to local populations for the many livelihood benefits that they provide: fuel, clean water, medicines, shelter and food. They can also form physical barriers against some extreme weather event such 
(such as storm surges). Ecosystems that form natural buffers, such as intact mangrove forests, are often less expensive to maintain, and sometimes more effective than physical engineered structures, such as dykes, levees, or concrete sea walls. This is a means of adaptation that is readily available to the rural poor; it is readily integrated into community-based adaptation, and addresses many of the concerns and priorities identified by the most vulnerable countries and communities.

With little efforts being placed on adaptation to climate change in Guyana, this research examined what is being done or proposed as contained in selected public policy documents within the natural resource sector under which climate change is considered. A particular focus was placed on ecosystem based adaptation to encourage the use of this strategy in the overall adaptation plan. Within the framework of an internationally tested strategy, an analysis was done for opportunities to integrate ecosystem based approaches into national adaptation policies in Guyana. The model used was developed by the Global Programme of Research on Climate Change Vulnerability, Impacts and Adaptation (PROVIA) and is a guidance framework that promotes a more rigorous and systematic approach to assessing vulnerability, impacts and adaptation. One of the key objectives of PROVIA is to facilitate the dissemination and practical application of research for benefit and value of society.

\subsection{Overview of global framework for addressing climate change}

Climate change impacts can affect all sectors and levels of society and does not respect borders. All countries will experience the impacts in one form or the other, as evidenced by the increased incidence of extreme weather and climatic events in both developed and developing countries. A study conducted by German Watch and reported by Roberts (2012), stated that these events are causing both human and economic losses especially in the Least Developed Countries (LDCs) and developing countries. In many instances, the infrastructure of these countries cannot withstand the impacts associated with increased frequency and/or intensity of climate anomalies such as storms, droughts, or heatwaves. These disasters can result in higher fatality rates and significant setbacks to these countries, with already fragile, economies and would therefore require more development aid from developed countries, (Babiker et al, 1999). The control of anthropogenic greenhouse gas emissions is a responsibility of all countries and this must be done by adhering to a global climate policy and regime acceptable to at least a 
plurality of nations. The Kyoto Protocol is the major international agreement intended to achieve greenhouse gas reductions but failures to ratify and enter into the agreement by major emitters, or non-compliance among Parties, have limited progress in reducing emissions (Olawuyi, 2010). Contrary to widespread hopes, the agreement on limiting global temperature increases to a $2^{\circ} \mathrm{C}$ target has contributed little to the implementation of ambitious policy measures even among signatory nations. The target currently serves a primarily symbolic and declarative function and progress toward climate change mitigation largely depends on each country's own motivation and willingness to reduce their levels of emissions.

Twenty years after the original 1992 UN Conference on Environment and Development (UNCED) in Rio de Janeiro, the magnitude of the threat posed by climate change has become much clearer. During these two decades, since the UNFCCC was adopted, progress in the area of international climate policy has been modest at best (Peters \& Hertwich, 2007; Falkner et al, 2010). Annual greenhouse gas emissions have increased by over one-third since 1992 while acute conflicts of interest among industrialized, emerging and developing countries remain a persistent obstacle (Falkner et al, 2010; Haita, 2012; UNFCCC, 2015). A comprehensive global climate treaty will not be concluded until 2015 at the earliest, and it will not enter into force before 2020. There is now cautious optimism that a global treaty may be achieved during the UNFCCC COP 21 Meeting in Paris in December 2015. This will be in the form of a roadmap that will come into full force by 2020 .

To slow, reduce or reverse this threat of climate change, world leaders and the United Nations have launched several initiatives to reduce greenhouse gases, especially carbon dioxide $\left(\mathrm{CO}_{2}\right)$, the gas responsible for almost half of the global warming to date (Hansen et al, 2008; Wallack \& Ramanathan, 2009). Topping the list of initiatives was to get countries, especially the industrialized countries, to agree on fixed emission reduction targets that to achieve a significant lowering of the amount of greenhouse gases entering the atmosphere. Other strategies promoted include cutting emissions from deforestation by Reducing Emissions from Deforestation and forest Degradation (REDD). This initiative was upgraded and is now referred to as the REDD+ mechanism, which goes beyond deforestation and forest degradation, and includes the role of conservation, sustainable management of forests and enhancement of forest carbon stocks (Merger, et al, 2011; Visseren-Hamakers, et al, 2012). 
A major component of success for any strategy is sustainable funding. Although some funding mechanisms exist to support the cutting of emissions, the UN has recognised that more is required to achieve desired impacts on greenhouse gas emissions (Levi, 2009). In an effort to resolve this setback, the UN and the Parties agreed to the creation of the Green Climate Fund. At the sixteenth Conference of Parties Meeting (COP 16), Decision 1/CP.16 Section IV paragraph 102 stated "........ decide to establish a Green Climate Fund, to be designated as an operating entity of the financial mechanism of the Convention under Article 11, with arrangements to be concluded between the Conference of the Parties and the Green Climate Fund to ensure that it is accountable to and functions under the guidance of the Conference of the Parties, to support projects, programmes, policies and other activities in developing country Parties using thematic funding windows"

Significantly reducing greenhouse gases is essential since this is likely to become an even greater cause of global warming by the end of this century (Thompson, 2010; Biello, 2013). However, the task of reducing emissions has proved to be most daunting and difficult since carbon dioxide remains in the atmosphere for centuries (Inman, 2008) and it has been difficult to get governments to agree on how to share the responsibility of reducing carbon emissions. Although the benefits of reducing carbon emissions are shared globally, the costs of doing so and the benefits to be realized are not shared evenly, contributing to the challenge in reaching the Accord. At 400 parts per million (ppm), the current concentration of $\mathrm{CO}_{2}$ in the atmosphere has increased markedly since the industrial revolution from about $280 \mathrm{ppm}$ and is now higher than it has been for the past 650,000 years (Amos, 2006: Wayman, 2013). Apart from $\mathrm{CO}_{2}$, methane and nitrous oxide are also of primary concern because they are associated with human activities. Methane is produced naturally when vegetation is burned or decomposed anaerobically, and large amounts of this gas are emitted from cattle and rice farming and from the production of oil and gas (Dittrick, 2014). Nitrous oxide is released by burning of fossil fuels and by natural microbial activity (nitrification and denitrification), greatly enhanced by the application of chemical fertilizers. These three $\left(\mathrm{CO}_{2}, \mathrm{CH}_{4}\right.$ and $\left.\mathrm{N}_{2} \mathrm{O}\right)$ are responsible for about 50, 18 and 6 percent, respectively of the overall global warming effect arising from human activities (Lashof \& Ahuja, 1990; Climate Action, 2013).

The developed countries have committed to cut greenhouse gas emissions by a paltry $3 \%$ from 2011 to 2020, according to a new analysis by the United Nations Framework Convention 
on Climate Change (Rogelj et al, 2010; UNFCCC, 2013). This is less than a third of the emission cuts developed countries have achieved between 1990 and 2011. A review by the UNFCCC Secretariat of the commitments made by developing countries for emission cuts (by 2020), shows that these countries have collectively committed themselves to a reduction of only 13-19 per cent relative to 1990 levels. This falls far short of the 25-40 per cent reduction expected of the developed countries, by the UNFCCC, so as to keep temperatures from rising more than $2^{\circ} \mathrm{C}$ above the pre-industrial era, a tipping point that leads to dangerous climate change consequences.

The UNFCCC analysis shows that the European Union (EU), which has always projected itself as a leader on the issue, has set such a low target for 2020 that it has almost achieved it. It had committed to cut emissions down by 20 per cent below the 1990 levels, but, by 2011, it had achieved an 18 per cent cut. China is the world's biggest greenhouse gas emitter (Murray, 2011, Olivier et al, 2012) but the U.S. is still way ahead as the highest per capita $\mathrm{CO}_{2}$ emitter in the world, (Parker \& Blodgett, 2008; Rohekar, 2014), while refusing to ratify the Kyoto Protocol, and increasing emissions by eight per cent between 1990 and 2011 (Ibrahim \& Uke, 2013). The US and Canada have both committed to cut emissions by $17 \%$ by 2020 using 2005 as their base year. $^{10,11}$ The analysis also warns that it is difficult to figure out how much of these emission reduction actions will be executed by the developed countries as many have not explained or clarified their dependence on offsets, buying credits for work done to cut emissions in the developing world. The probability of Canada achieving its target has been the subject of much speculation. Statistics have shown that the global carbon market value rose from 3 billion Euros in 2005 to 85 billion Euros in 2012. ${ }^{12}$ For the EU, it has been argued that it can only meet its emissions targets provided that member states buy international emission credits and carry out

\footnotetext{
${ }^{10}$ Letter to UNFCCC Secretariat from Todd Stern, US Special Envoy for Climate Change, United States Department of State, Washington, D.C, Available at:

http://unfccc.int/files/meetings/cop_15/copenhagen_accord/application/pdf/unitedstatescphaccor d_app.1.pdf

${ }^{11}$ Letter to UNFCCC Secretariat, from Michael Martin, Chief Negotiator and Ambassador for Climate Change, Government of Canada, Available at:

http://unfccc.int/files/meetings/cop_15/copenhagen_accord/application/pdf/canadacphaccord_ap p1.pdf (Accessed on June, 2015).

${ }^{12}$ Statista: Global carbon market value from 2005 to 2012 (billion Euros), Available at: http://www.statista.com/statistics/223516/global-carbon-market-value-forecast/ (Accessed on June, 2015)
} 
afforestation and reforestation activities as planned. Existing policies would not deliver the intended emission reductions (EurActiv, 2010.)

The UNFCCC negotiations have been running on two tracks. One is to press the countries to take higher emission cuts between now and 2020 so as to prevent the atmosphere from accumulating higher levels of emissions. The second is meant to deliver a new deal by 2015, which will put in place a formula for all countries to cut emissions from 2020 onward.

In as much as all Parties to the UNFCCC have a crucial role to play, the major tussle is usually among the developed countries on the one hand and those emerging economies and developing countries on the other. The developed countries, mainly the US, propagate the view that countries like China, India, Brazil and a few others are major emitters and should therefore bear a fair or equal share of the burden in reducing emissions. Also the decision to set legally binding targets has not been agreeable to some developed countries that would rather prefer voluntary, individualized reductions, resulting in their weak support for the Kyoto Protocol.

Internationally, adaptation has generally had lower priority than mitigation. In part, this has been due to optics, as adaptation may appear an admission of defeat in mitigation, or appeasement of parties opposed to emission reductions. Progress in developing adaptation strategies has, consequently, been limited by low funding support. Even though there has been some funding support from international financial institutions for adaptation, it has not been enough and most of this has come through traditional development aid (Hallegate, 2011).

The sixteenth Conference of Parties Meeting in Cancun, Mexico developed a Cancun Adaptation Framework (CAF) to raise the prominence of adaptation measures in the UNFCCC's efforts. The CAF also represented the first formal agreement to establish guidelines concerning capacity building in communities vulnerable to the effects of climate change, and even though adaptation financing remains inadequate, this is a step in the right direction to encourage action on adaptation.

\subsubsection{United Nations Framework Convention on Climate Change}

Serious steps and an international political response to climate change began with the adoption of the United Nations Framework Convention on Climate Change (UNFCCC) when the United Nations Conference on Environment and Development (UNCED) (Earth Summit) was held in Brazil in 1992. This international treaty set out a framework for action aimed at 
stabilizing atmospheric concentrations of greenhouse gases (GHGs) to avoid further interference with the climate system. The key objective of the UNFCCC is:

"to achieve, in accordance with the relevant provisions of the Convention, stabilisation of greenhouse gas concentrations in the atmosphere at a level that would prevent dangerous anthropogenic interference with the climate system. Such a level should be achieved within a time frame sufficient to allow ecosystems to adapt naturally to climate change to ensure that food production is not threatened and to enable economic development to proceed in a sustainable manner." ${ }^{13}$

To do this Article 3 of the Convention stipulates that:

"the Parties should protect the climate system for the benefit of present and future generations of humankind, on the basis of equity and in accordance with their common but differentiated responsibilities and respective capabilities. Accordingly, the developed country Parties should take the lead in combating climate change and the adverse effects thereof". 14

The UNFCCC entered into force on March 21, 1994, and with its current membership of 196 Parties, the Treaty has near universal membership. The goal is, for countries to work cooperatively to limit the average global temperature increases and to cope with the impacts caused by climate change. Delegates from the Parties have met annually since 1995 at various locations around the globe to negotiate multilateral responses to climate change and to agree on commitments for different groups of countries according to their circumstances and needs. It is important to point out, that the Convention itself sets no binding limits on greenhouse gas emissions for individual countries and contains no enforcement mechanisms. In that sense, the Treaty is considered legally non-binding, and therefore countries can default on their commitments without penalties or sanctions. A key strategy of the Convention is that it divides countries into three main groups according to differing commitments. The industrialized countries such as the United States of America, Canada, Germany, the United Kingdom, and those with economies in transition such as the Russian Federation, Baltic States and Central and

\footnotetext{
${ }^{13}$ United Nations Framework Convention on Climate Change, 'Article 2,' available at http://unfccc.int/resource/docs/convkp/conveng.pdf (Accessed on May, 2015)

${ }^{14}$ Ibid, Article 3 (Accessed on May, 2015)
} 
European States are listed as Annex I, while the developing countries such as Argentina, Guyana, the Philippines and the Maldives are listed as Non-Annex I to the Convention. There is also the group of 34 countries that currently comprise the Organization for Economic Cooperation and Development (OECD). These countries are classified as Annex II and include Australia, Japan, Israel, the Netherlands, Spain, Sweden and other states. The Parties are expected to provide financial and technical support to developing countries and those with economies in transition, to assist them in reducing their greenhouse gas emissions and manage the impacts of climate change.

From the first Conference of the Parties (COP) Meeting in Germany in 1995, the Parties recognized and agreed that the commitments in the Convention were inadequate to meet the objectives of the Convention. This led to the development of the Berlin Mandate (1995) which was the precursor for discussions and negotiations for strengthened commitments from developed countries and it laid the groundwork for the Kyoto Protocol.

\subsubsection{The Kyoto Protocol}

Keeping in mind that the UNFCCC simply sets an overall framework for international efforts to tackle the challenge of climate change, the Convention places no binding targets on Parties. Therefore achieving the agreed emissions reduction, especially from Annex I countries, proved to be very difficult. After two and a half years of intensive negotiations, a substantial extension to the UNFCCC was adopted in Kyoto, Japan in December 1997. Known as the Kyoto Protocol (KP), this extension of the Framework became the world's first greenhouse gas reduction treaty. Guyana acceded to the Kyoto Protocol on August 5, 2003 (UNFCCC, 2014).

The Protocol entered into force on February 16, 2005 and currently has 192 Parties. Both the Convention and its Protocol created a framework for the implementation of an array of national climate policies and established legally binding emissions targets for industrialized countries. It supported these countries in meeting targets through innovative mechanisms such as Emissions Trading (ET), Joint Implementation (JI) and the Clean Development Mechanism $(\mathrm{CDM})$ projects in developing countries which created opportunities to earn carbon credits (Gang, 2007). The process leading up to the Kyoto Protocol has been difficult and slow because it has to be effective against a complicated worldwide problem and it also has to be politically acceptable (Bohringer, 2002; Gang, 2007). As a result, panels and committees have multiplied 
to monitor and referee its various programmes, and even after the agreement was approved in 1997, further negotiations were deemed necessary to hammer out instructions on how to "operate" it. In 2001 at the seventh Conference of Parties Meeting the rules, referred to as the "Marrakesh Accords", were adopted which set the stage for ratification of the Protocol. This formalized an agreement on International Emissions Trading (IET), the Clean Development Mechanism (CDM), and Joint Implementation (JI) (UNFCCC, 2014). Under the Protocol's Clean Development Mechanism (CDM), the Guyana Sugar Corporation (GuySuCo) benefited from funds provided for the Skeldon Bagasse Cogeneration Project ${ }^{15}$. This project commenced in 2007 and consists of the addition of a more efficient co-generation plant to the ongoing Skeldon Sugar Modernization Project, a modern sugar factory that will manufacture high quality raw sugar. Bagasse is a renewable fuel source, residue from sugarcane processing. The cogeneration project is the CDM project, which is expected to receive financial payments to be made under the Clean Development Mechanism of the Kyoto Protocol

The first commitment period was for five years between 2008 and 2012 and required thirty seven (37), industrialized countries and the European community (Annex 1) to reduce their greenhouse gas emissions at an average of five per cent (5\%) compared to 1990 levels. There are currently forty three (43) member countries classified as Annex 1. Due to the lengthy period to acquire the number of ratifications to enter into force, the protocol didn't become international law until more than halfway through the 1990-2012 period by which point, global emissions had risen substantially (Parry et al, 2013). Even though some countries and regions, including the European Union, were on track by 2011 to meet or exceed their Kyoto goals, other large nations were falling woefully short. The two biggest emitters of all, the United States and China, generated more than enough extra greenhouse gas to erase all the reductions made by other countries during the Kyoto period ${ }^{16}$.

So the main difference between the two Agreements is the Kyoto Protocol "operationalizes" the Convention and commits industrialized countries to stabilize greenhouse

${ }^{15}$ Guyana Chronicle, online (Dec. 2014), “Government accepts Doha Amendment to Kyoto Protocol-exemplifies commitment to fight climate change" Available at: http://guyanachronicle.com/govt-accepts-doha-amendment-to-kyoto-protocol-exemplifiescommitment-to-fight-climate-change/ (Accessed on June, 2015)

${ }^{16}$ Statista, (2015), The largest producers of $\mathrm{CO}_{2}$ worldwide in 2014 based on their share of global $\mathrm{CO}_{2}$ emissions, Available at: http://www.statista.com/statistics/271748/the-largestemitters-of- $\mathrm{CO}_{2}$-in-the-world 
gas emissions based on the principles of the Convention, whereas the Convention itself only "encourages" countries to do so. The Kyoto Protocol came to an end on December 31, 2012, but at the Conference of Parties (COP) Meeting in Doha, 2012, the Parties agreed to a second commitment period after they adopted the Doha Amendment, which commenced on January 1, 2013 and will end on December 31, 2020. It is noteworthy to mention that another GHG, Nitrogen Trifluoride $\left(\mathrm{NF}_{3}\right)^{17}$ was added to the Protocol and became applicable from the beginning of the second commitment period. Almost all Parties renewed their commitments for a second period except for Canada which opted out of the Protocol, thus making its emission targets and commitments obsolete (Jull, 2012; Laybourn et al, 2012; Sheargold, 2012). However, Canada pursuant to a letter to the Executive Secretary of the UNFCCC, expressed its commitment to reduce its GHG emissions by $17 \%$ by 2020 with 2005 at its base year ${ }^{18}$.

Annex I countries are required to submit an annual inventory of data on GHG emissions by source and removals by sink including aggregate emissions both including and excluding net GHG emissions and removals from land use, land-use change and forestry (LULUCF). The report for 2014 shows that for the first commitment period, (1990-2012), total aggregate GHG emissions for all Annex I countries, excluding emissions and removals from LULUCF, decreased by $10.6 \%$, (Table 1). The total GHG emissions and removal including LULUCF decreased by $16.2 \%$ (Table 2 ) (UNFCCC, 2015) ${ }^{19}$.

\footnotetext{
${ }^{17}$ Doha Amendment to the Kyoto Protocol (2012), Available at: https://treaties.un.org/doc/Publication/CN/2012/CN.718.2012-Eng.pdf (Accessed on: June 2015) ${ }^{18}$ Letter to UNFCCC Secretariat, from Michael Martin, Chief Negotiator and Ambassador for Climate Change, Government of Canada. Available at: http://unfccc.int/files/meetings/cop_15/copenhagen_accord/application/pdf/canadacphaccord_ap p1.pdf (Accessed on June, 2015). ${ }^{19}$ UNFCCC, (2015) FCCC/SBI/2005/18/Add.2, Available at: http://unfccc.int/documentation/documents/advanced_search/items/6911.php?priref=600003580\# beg (Accessed on May, 2015)
} 
Table 1: Total aggregate anthropogenic emissions of $\mathrm{CO}_{2}, \mathrm{CH}_{4}, \mathrm{~N}_{2} \mathrm{O}, \mathrm{HFCs}, \mathrm{PFCs}$ and $\mathrm{SF}_{6}$ excluding emissions/removals from land use, land-use change and forestry, for 1990, 2000 2010, 2011 and 2012 for selected Annex 1 countries in $\mathrm{Gg} \mathrm{CO}_{2}$ equivalent. Source: Modified from UNFCCC, FCCC/SBI/2014/20

Party

$1990 \quad 2000 \quad 2010 \quad 2011$

$2012 \%$ Change (1990 to 2012)

\begin{tabular}{lllllll}
\hline Australia & 414974 & 489813 & 540211 & 541543 & 543648 & 31.0 \\
Belgium & 142952 & 145857 & 130611 & 120146 & 116520 & -18.5 \\
Canada & 590908 & 721362 & 699302 & 701212 & 698626 & 18.2 \\
Denmark & 70020 & 69955 & 63007 & 58052 & 53118 & -24.1 \\
European Union & 5626260 & 5121652 & 4751060 & 4603245 & 4544224 & -19.2 \\
Germany & 1248049 & 1040367 & 946388 & 928695 & 939083 & -24.8 \\
Japan & 1234320 & 1340523 & 1256095 & 1306518 & 1343118 & 8.8 \\
Netherlands & 211850 & 213023 & 209286 & 195064 & 191669 & -9.5 \\
New Zealand & 60641 & 70899 & 73491 & 74393 & 76048 & 25.4 \\
Norway & 50409 & 54058 & 54347 & 53294 & 52733 & 4.6 \\
Russian Federation & 3363342 & 2053321 & 2221342 & 2284293 & 2295045 & -31.8 \\
United Kingdom & 783412 & 704435 & 613218 & 569273 & 586357 & -25.2 \\
United States & 6219524 & 7075609 & 6854728 & 6716993 & 6487847 & 4.3
\end{tabular}


Table 2: Total aggregate anthropogenic emissions of $\mathrm{CO}_{2}, \mathrm{CH}_{4}, \mathrm{~N}_{2} \mathrm{O}$, HFCs, PFCs and $\mathrm{SF}_{6}$ including emissions/removals from land use, land-use change and forestry, for 1990, 2000 2010, 2011 and 2012 for selected Annex 1 countries in $\mathrm{Gg} \mathrm{CO}_{2}$ equivalent. Source: Modified from UNFCCC, FCCC/SBI/2014/20

Party

$$
\begin{gathered}
1990 \\
(1990 \text { to 2012) }
\end{gathered}
$$

\begin{tabular}{lccccccc}
\hline Australia & 545495 & 513027 & 568802 & 480894 & 558809 & 2.4 \\
Belgium & 142118 & 145264 & 129345 & 118978 & 115139 & -19.0 \\
Canada & 519888 & 669850 & 775045 & 778022 & 739487 & 42.2 \\
Denmark & 75303 & 73190 & 62684 & 55310 & 52281 & -30.6 \\
European Union & 5367940 & 4819245 & 4439385 & 4291788 & 4240671 & -21.0 \\
Germany & 1223531 & 1016400 & 941694 & 924608 & 935595 & -23.5 \\
Japan & 1167502 & 1254874 & 1183737 & 1230930 & 1268052 & 8.6 \\
Netherlands & 214863 & 215395 & 212593 & 198468 & 195205 & -9.1 \\
New Zealand & 23391 & 38549 & 41741 & 44799 & 49450 & 111.4 \\
Norway & 40262 & 30152 & 27577 & 25682 & 26056 & -35.3 \\
Russian Federation & 3527913 & 16468191654100 & 1710856 & 1753029 & -50.3 \\
United Kingdom & 785291 & 702343 & 605969 & 561788 & 579379 & -26.2 \\
United States & 5402124 & 64148395906734 & 5772687 & 5546304 & 2.7
\end{tabular}

The UNFCCC (2014) also reported on GHG inventory data from non-Annex1 countries (Table 3) the majority of which reported for the year 1994. The aggregate total GHG emissions, excluding land use change and forestry (LUCF) sector, reported by 122 non-Annex I Parties, were 11.7 billion tonnes of $\mathrm{CO}_{2}$ equivalent. Carbon dioxide is the primary gas emitted, with a total of 7.4 billion tonnes ( $63 \%$ ), followed by $\mathrm{CH}_{4}$, with 3 billion tonnes $\mathrm{CO}_{2}$ equivalent (26 per cent), and $\mathrm{N}_{2} \mathrm{O}$ with 1.3 billion tonnes $\mathrm{CO}_{2}$ equivalent (11 per cent). Total emissions for non- 
Annex I Parties was $61 \%$ that of selected Annex I Parties (Table 1), interpolating for the year 1994.

Table 3: Aggregate emissions and removals of $\mathrm{CO}_{2}, \mathrm{CH} 4$ and $\mathrm{N}_{2} \mathrm{O}$ in $\mathrm{CO}_{2}$ equivalent by major source/sink category, including and excluding land-use change and forestry ( $\mathrm{Gg} / \mathrm{region})$, from non-Annex 1 countries for 1994. Source: Modified from UNFCC, (2005), FCCC/SBI/2005/18

\begin{tabular}{llll} 
Region & Total (without LUCF) & Total (with LUCF) & \% LUCF in GHG \\
\hline Africa & 1612904.22 & 1201794.07 & -25.5 \\
Asia and Pacific & 7929689.69 & 7614071.57 & -4.0 \\
$\begin{array}{l}\text { Latin America \& } \\
\text { the Caribbean }\end{array}$ & 2058599.43 & 2986460.11 & -45.1 \\
$\begin{array}{l}\text { Other } \\
\text { Totals for }\end{array}$ & $\mathbf{1 1 7 3 5 4 3 6 . 9 0}$ & 129170.10 & -3.8 \\
for non-Annex 1 & & $\mathbf{1 1 9 3 1 4 9 5 . 8 5}$ & $-\mathbf{1 . 7}$
\end{tabular}

Guyana is largely a producer and exporter of primary products such as timber, rice, bauxite ore and sugar. Industrialization is very low and fuels such as gasoline, diesel oil, kerosene, aviation kerosene and liquefied petroleum gas are imported for local use and consumption. Greenhouse gas emissions are produced through the combustion of these fuels for power generation, transport, agriculture, mining, fishing, and the commercial, manufacturing and residential sectors. Biomass is also used in the form of bagasse in the sugar industry and rice husks in the rice industry as cogeneration for heat and electricity. Wood products in the form of firewood and charcoal are used in the residential sector for cooking purposes. From estimations, carbon dioxide emissions between 2001 and 2008 stayed around $1520 \mathrm{Kt}$ (Figure 2) with a slight increase in 2002 to just over $1540 \mathrm{Kt}$.

Guyana's Second National Communication (SNC) to the UNFCCC reported on it its GHG emissions based on inventory data for the period 1990-2004. From the data submitted it was evident that in so far as $\mathrm{CO}_{2}$ emissions and removals are concerned, Guyana can be considered as a net carbon sink country, that is, the country absorbs more $\mathrm{CO}_{2}$ than it emits. The 
bulk of the $\mathrm{CO}_{2}$ emissions were derived from the energy sector while all the $\mathrm{CO}_{2}$ removals were attributable the land use change and the forestry sector (LUCF). ${ }^{20}$

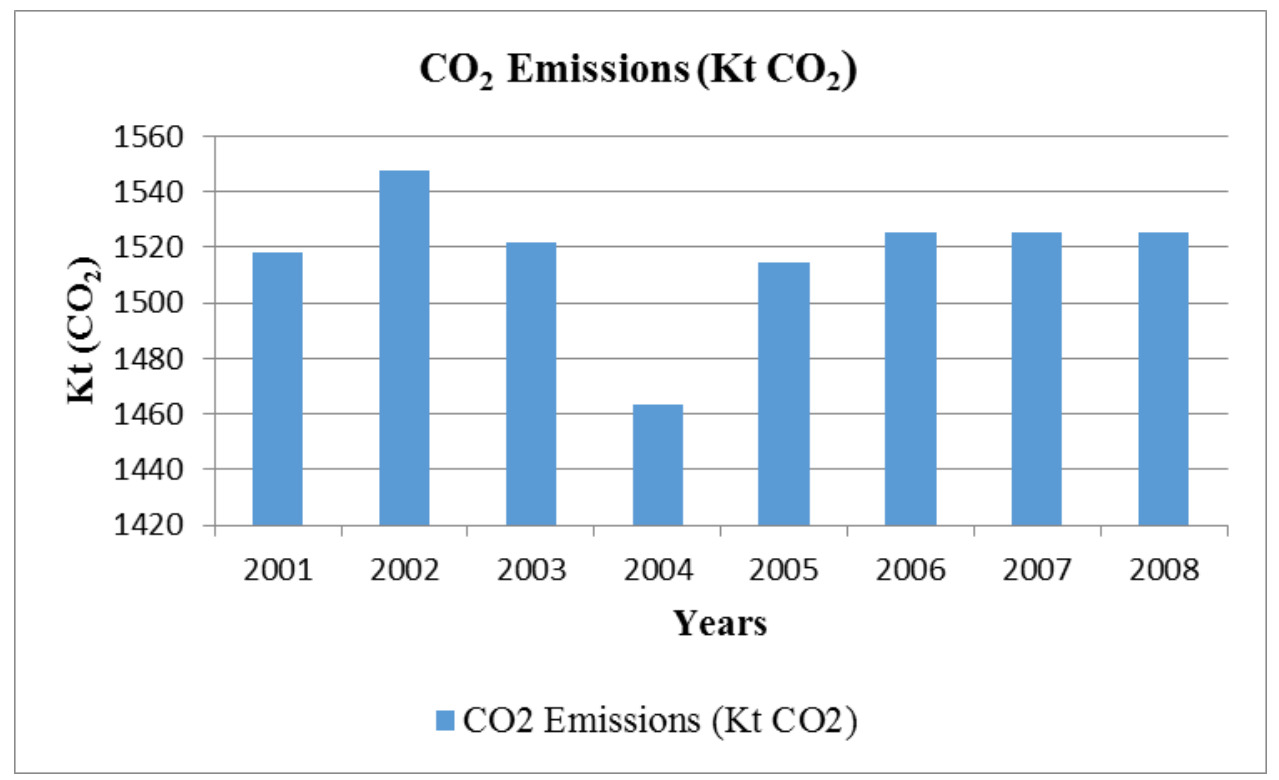

Fig 2: $\mathrm{CO}_{2}\left(\mathrm{Kt}^{21}\right)$ Emissions for Guyana between 2001 and 2008. Source: Adapted from the World Bank Group, 2015

\subsubsection{The Intergovernmental Panel on Climate Change (IPCC)}

The IPCC is the leading international body, under the auspices of the United Nations, with a focus on the assessment of climate change. It was established in 1988, by two other UN bodies, the United Nations Environment Programme (UNEP) and the International Maritime Organization (IMO) to assess "the scientific, technical and socioeconomic information relevant for the understanding of the risk of human-induced climate change." (IPCC, 2013). The first major assessments done by the IPCC formed the basis for negotiating the UNFCCC and since then it has continued to play a key role in influencing decisions of both the Convention and the Kyoto Protocol. The Second Assessment Report of the IPCC, released in 1996, caused many to take heed when it first stated that "the balance of evidence suggests that there is a discernible

\footnotetext{
${ }^{20}$ Guyana's Second National Communication to the UNFCCC, 2012. Available at: www.lcds.gov.gy (Accessed on June, 2015).

${ }^{21} \mathrm{Kt}$ means kilotonnes or kiloton. $1 \mathrm{Kt}=1000$ metric tonnes
} 
human influence on global climate." (IPCC, 1996). In its Fifth Assessment Report the IPCC mentioned a key finding which states that human interference with the climate system is occurring and climate change poses risks for human and natural systems. Further, it reported that "It is extremely likely that human influence has been the dominant cause of the observed warming since the mid-20 $0^{\text {th }}$ century" (IPCC, 2014).

The relationship between the UNFCCC and the IPCC has become a model for interaction between science and decision makers and attempts have been made to translate this relationship to other environmental issues such as biodiversity.

\subsubsection{The Post Kyoto Agreement}

A new international agreement to combat climate change is due to be adopted in December 2015 at the 21st Conference of the Parties (COP) to the United Nations Framework Convention on Climate Change (UNFCCC), scheduled to be held in Paris, France. The current Kyoto agreements commit developed countries to binding targets for GHG emissions, but not developing countries, some of which, for example, China and India, have become major emitters of greenhouse gases (Mufson, 2014). After the 2009 Copenhagen climate conference failed to adopt a new agreement, the 2011 Durban conference decided that a new agreement applicable to all countries should be concluded in 2015 and enter into force in 2020. COP 20, held in December 2014 in Lima, concluded with the adoption of the 'Lima Call for Climate Action', a document inviting all Parties (countries) to communicate their intended contributions, known as the Intended Nationally Determined Contributions (INDCs), to post-2020 climate action well before the Paris conference. Importantly, besides action to counter global warming, the submission should also cover plans for adaptation to climate change. The 'Lima Call' contains elements of a draft negotiating text for the Paris Agreement (revised in February 2015). The text contains many options reflecting the divergent negotiating positions of the various countries and country groups. A new negotiating text for the Paris Agreement should be made available by May 2015.

The Lima Conference left a number of important issues unresolved. First of all, the nature of the countries' contributions is not clearly specified, with regards to the legal nature, comparisons, evaluation, monitoring and reporting. This will make them hard to compare and assess and it is likely that they will not add up to the emissions reductions required to keep global 
warming below the internationally agreed limit of $2^{\circ} \mathrm{C}$. A process for the periodic assessment and strengthening of national efforts will therefore be an important element of the Agreement. Processes for monitoring, reporting and verification of national contributions will also have to be agreed. While some negotiators favour a strong, legally binding agreement, others prefer a bottom-up approach based on voluntary contributions. Finally, issues of fairness and equity need to be addressed, acknowledging that developed countries have a greater historical responsibility for climate change and stronger capabilities for taking action. They can, therefore, be expected to make larger contributions to emissions reductions as well as to providing finance for developing countries' climate action. The probable shift from a legally binding environmental treaty, such as the Kyoto Protocol, towards a 'soft' agreement based on national contributions presents both risks and opportunities. Continued engagement with international partners is needed to achieve the transformations of the economies and energy systems required to make sure that the risks of global warming remain manageable.

It is important to note that "Adaptation" was not specifically discussed in the Kyoto Protocol but is now receiving some consideration in the negotiating text for the new climate agreement referred to as the Paris Agreement ${ }^{22}$. Three proposed clauses for adaptation measures are included in the negotiating text of the Paris Agreement which awaits ratification in December 2015.

"Option (a): Emphasizing that adaptation is a global challenge and a common responsibility that requires global solidarity and must be addressed with the same urgency as, and in political / legal parity with, mitigation"

"Option (b): Emphasizing that adaptation is a global challenge that must be addressed with the same urgency as, and in balance with, mitigation, and that enhanced action and international cooperation on adaptation is urgently required in order to enable and support the implementation of adaptation actions [and recognizing that both climate-resilient development and adaptation to the impacts of climate change will be essential]"

"Option (c): Emphasizing that enhanced action and international cooperation on adaptation is urgently required to enable and support the implementation of adaptation actions aimed at

\footnotetext{
${ }^{22}$ Negotiating text (Advance unedited version), 2015. Available at: http://unfccc.int/files/bodies/awg/application/pdf/negotiating_text_12022015@2200.pdf (Accessed on: Aug, 2015)
} 
reducing vulnerability and building resilience in [developing country Parties][Parties not included in annex X], taking into account the urgent and immediate needs of those [developing countries][Parties not included in annex X] that are particularly vulnerable" (UNFCCC, 2015).

Guyana has not yet submitted its INDCs for the Meeting in Paris, but several countries have already done so, such as the Canada, Mexico, USA, and European Union. Canada intends to achieve an economy-wide target to reduce GHG emissions by 30\% below 2005 levels by 2030 (UNFCCC, 2015). However, plans to continue development of the Alberta Tar Sands would seem to make achieving this target difficult.

\subsubsection{The Green Climate Fund}

The Green Climate Fund was established by a Decision (1/CP16) at the sixteenth COP Meeting and "Recognizes that developed country Parties commit, in the context of meaningful mitigation actions and transparency on implementation, to a goal of mobilizing jointly USD 100 billion per year by 2020 to address the needs of developing countries". The fund is within the framework of the UNFCCC and is a facility to redistribute funds from developed countries to developing countries to assist with adaptation and mitigation practices to combat the effects of climate change. It is expected that the Fund will promote climate resilient development by supporting developing countries to limit or reduce their greenhouse gas emissions and adapt to the impacts of climate change. This Fund is crucial for countries such as Guyana and other developing countries since it is intended to play a key role in channelling new and additional financial resources, at the public and private levels for efforts geared towards climate adaptation and mitigation. As of April 30, 2015, the Fund has received \$US 4 billion equivalent in contributions representing $42 \%$ of what was initially pledged at its conference in 2014 (Green

Climate Fund, 2015). Other Funds under the UNFCCC are; the Global Environment Facility (GEF), the Least Developed Countries Fund (LDCF), Special Climate Change Fund (SCCF), and the Adaptation Fund.

\subsection{Mitigation}

Measures to mitigate climate change and to adapt to it complement each other and should therefore be pursued together. Mitigation means action to limit dangerous climate change, notably by reducing the emission of GHGs into the atmosphere. It is important to note that emissions from one country contribute to climate change for the entire planet. Conversely, 
mitigation efforts by one country benefit all others, whether they contribute or not. A country that unilaterally adopts ambitious mitigation measures may be at an economic disadvantage compared with countries with lower ambition.

Measures to reduce carbon emissions from energy use include promoting low-carbon energy sources (renewables, nuclear), energy conservation and energy efficiency. Carbon capture and storage (CCS) can help reduce emissions from the continued use of fossil fuels, but some argue that CCS capacities should be preserved to build carbon-negative power plants (bioenergy with CCS) in the future (Haszeldine, 2009). CCS has been used Norway, Canada and the United States. The International Energy Agency proposes a decarbonisation strategy based on energy efficiency, electrification of transport and heating, and low-carbon electricity generation. Emissions from existing high-carbon assets, which have a lifetime of many decades, must also be reduced, and subsidies for fossil fuels phased out. Outside the energy sector, reducing meat consumption can lead to reduced emissions, according to a recent Chatham House report (Bailey et al, 2014). Land use, agriculture and forestry are other sectors that can achieve significant emissions reductions or even net carbon removal. Nations around the world take different approaches to dealing with climate change.

A number of organisations have analysed the approaches and performances of individual countries. The Climate Change Performance Index ranks countries every year according to emissions level, emissions trend, renewable energy development, energy efficiency and climate policy. In the 2015 ranking, 11 of the 12 best-performing countries were European countries (Burck et al., 2014). Mitigation benefits arise from reduced climate impacts. Arnell et al (2013) concluded that strong mitigation can reduce the impacts expected for the year 2100 by up to $65 \%$. The Stern Review argued that losses from climate impacts would amount to 5-20\% of global GDP if GHG emissions are not reduced (Stern Review, 2006). Apart from reducing climate change, mitigation is considered to bring further benefits such as less air pollution (a major public health problem in China and India), technology leadership, 'green' jobs and reduced dependence on energy imports (for countries without primary energy resources). However, it is far from clear that such co-benefits outweigh the cost of mitigation action under current policies. The fact that many countries and companies continue to invest in fossil-fuel assets suggests they consider these as more advantageous technically and economically than 
pursuing a low-carbon transition. The EU, which has implemented strong mitigation policies, has higher energy costs than some economies with less ambitious mitigation targets.

Deforestation and other land-cover changes typically release carbon from the terrestrial biosphere to the atmosphere as $\mathrm{CO}_{2}$, while recovering vegetation in abandoned agricultural or logged land removes $\mathrm{CO}_{2}$ from the atmosphere and sequesters it in vegetation biomass and soil carbon. It is estimated that deforestation and forest degradation make a significant contribution to global greenhouse gas emissions (Ramankutty, et al, 2007; Miles \& Kapos, 2008; Gari, 2011).

\subsection{The study location: Guyana}

Guyana is located in the neo-tropical zone of northeastern South America and lies between latitudes $2^{\circ}$ and $8^{\circ} \mathrm{N}$, and longitudes $56^{\circ}$ and $62^{\circ} \mathrm{W}$. The country is home to a vast expanse of tropical rain forests, freshwater, dry savannahs, wetlands and other unique ecosystems. It is a part of the Guiana Shield region which forms part of the Amazon Biome and is one of eight countries that share the extensive Amazon Basin. The Amazon Biome, spanning 6.7 million $\mathrm{km}^{2}$ is the single largest remaining tropical rainforest in the world and is home to at least $10 \%$ of the world's known biodiversity, including many endemic and endangered flora and fauna (WWF-Guiana, 2012).

The size of Guyana is 214,970 square kilometers and it is bounded by the Atlantic Ocean on the north, Suriname on the East, Venezuela on the West, and Brazil on the West and South (Figure 3). The coastline along the Atlantic Ocean extends for 430 kilometers and represents less than $7 \%$ of the total land area or 15,000 square kilometres (Dalrymple, 2006). The portion that is developed and occupied along this belt is about 270 kilometres long and about 25 kilometres in width. It is a low lying zone, consisting of clay deposits, and averages about 2.4 metres (8 feet) below mean sea level. With its relatively flat topography, the area is particularly vulnerable to flooding, erosion and salinization from Atlantic swells on a year-round basis, together with intense precipitation and breaches of the sea defences (Khan and Sturm, 1995). The coastal belt is protected by concrete and earthen sea-defence structures, with remaining areas covered by mangroves, sand and shell beaches. The land is drained by gravity by a system which comprises an extensive network of drainage and irrigation channels linked to sluices which regulates inflow and outflow from and to the ocean. However, according to Khan \& Sturm (1995), due to the lack of adequate maintenance of existing sea defenses, and the 
gradual destruction of mangrove forests, coastal protection has been drastically reduced. Moreover, continued groundwater extraction, soil compaction, impediments to groundwater recharge, and drainage of wetlands have resulted in coastal subsidence in some areas to the magnitude of $10 \mathrm{~mm} \mathrm{yr}^{-1}$ (Dalrymple \& Pulwarty, 2006).

The country is physically divided into four major ecological zones, the Coastal Clay belt, the Hilly Sand and Clay Region, the Interior Plains and Savannahs and the Highland Region. The Coastal Plain has been formed partially through the alluvial deposits of the main rivers of the country (Berbice, Mahaica, Demerara and Essequibo Rivers) and this zone is a fertile agricultural area where the major crops such a sugar cane, rice, coconuts and vegetables are grown.

The second zone is the Hilly Sand and Clay Region, which lies to the south of the coastal clay belt and includes some of the intermediate savannahs. The third ecological zone, the Interior Plains and Savannahs, comprises over half of the country's land area encompasses vast areas of tropical forests and extensive mineral deposits, in addition to extensive savannahs, which continues into Brazil. The fourth zone is the Highland Region which includes the Pakaraima Mountains which forms part of the extensive Guiana Highlands that cover an area of 1,300,000 square kilometres in Guyana, Venezuela and Brazil (WWF-Guiana, 2012).

These ecosystems support diverse species to the extent that as of 2010, Guyana's species status was estimated as 8,000 species of plants (Boggan et al, 1997), 467 fish; 130 amphibians; 179 reptiles; 814 birds; 225 mammals; 1,673 arthropods, and over 1,200 fungi (FAO, 2005). The Food and Agriculture Organisation (FAO) further estimated that Guyana has a total of 1,182 native tree species of which 1 species, Vouacapoua americana Aubl., is listed by the IUCN Red List as Critically Endangered. Three species; Trichilia surumuensis C. DC., Aniba rosaedora Ducke, and Virola surinamensis (Rolander) Warb, are listed as Endangered and a total of 18 species are listed as Vulnerable.

Guyana's biodiversity provides an important basis for climate regulation, poverty reduction, provisioning of freshwater, economic growth and development in areas such as agriculture, forestry and fisheries, payment for forest climate services, and community based economies, particularly in hinterland communities. Loss of biodiversity and any disruption in the provision of ecosystem services would impact negatively on the economy, and more 
particularly on the quality of life in the hinterland and indigenous communities. These communities use a variety of non-timber products for food, shelter, medicine and trade.

Climate change, deforestation and land degradation have recently received greater recognition as current and future drivers of environmental change and threats to Guyana's biodiversity. These pressures have been increasing over the past decade. In addition emerging threats that will affect biodiversity in the future include (i) overfishing, (ii) depletion of the mangrove fringe and (iii) expansion of extractive industries (WWF-2012).

About 8.5 million hectares of tropical rainforests cover approximately eighty-five percent of the total land area. Through sustainable forest management Guyana has had relatively low historical rates of deforestation at about 0.1 to 0.3 percent (FAO, 2012), therefore it is a net sink for carbon.

Guyana's environmental policy is formulated and implemented by the Environmental Protection Agency (EPA) which was established by an Act of Parliament. The EPA has a list of functions and responsibilities and these include the effective management of the natural environment so as to ensure the conservation, protection, and sustainable use of its natural resources. It coordinates environmental management activities of all persons, organisations and agencies and assists in establishing and coordinating institutional linkages especially in the preparation and implementation of environmental cross-sectoral programmes. It is also responsible for prevention and control of pollution, the undertaking of environmental impact assessments and advising on general environmental policy and the impact of development. 


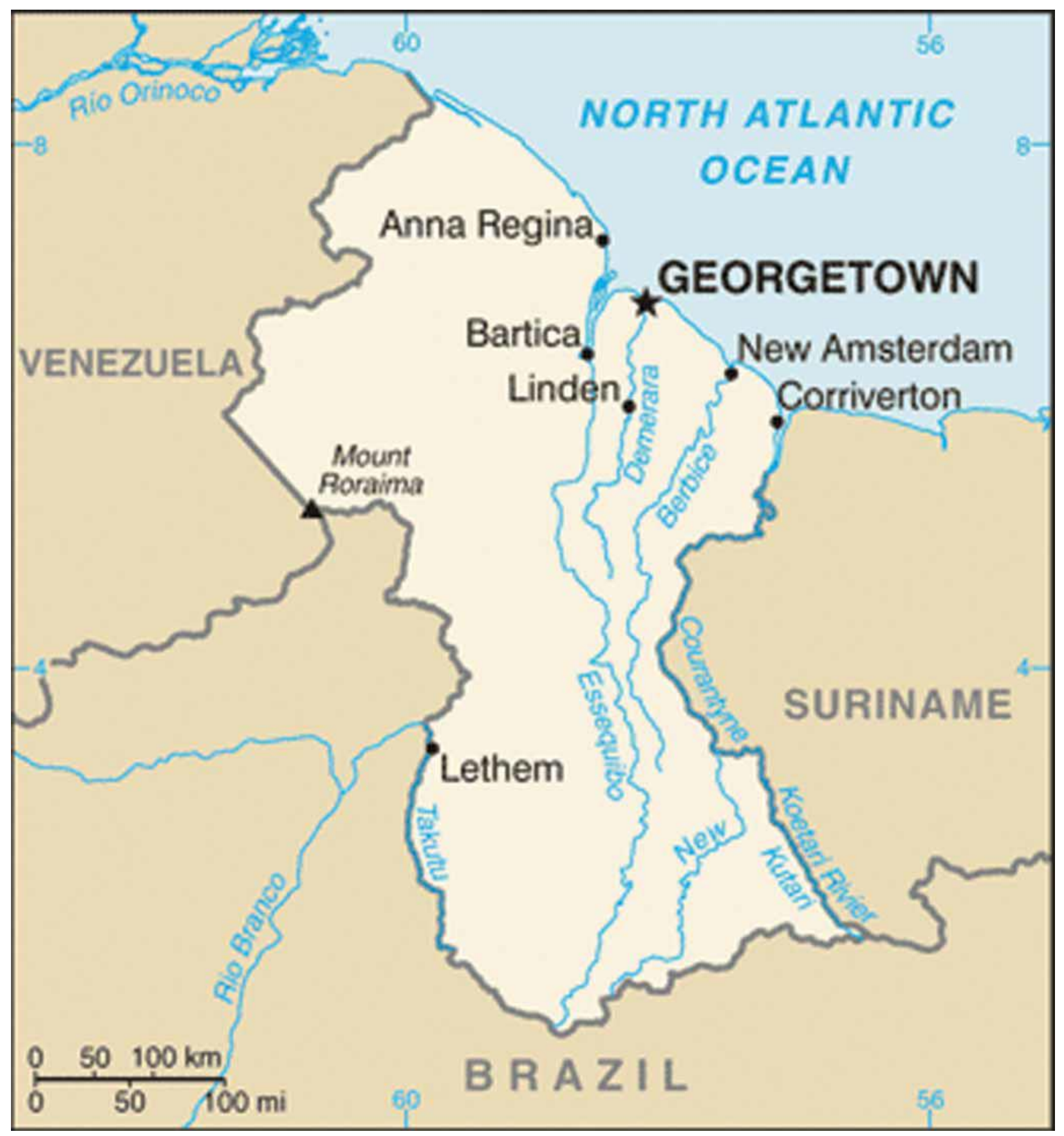

Fig 3: Location map of Guyana showing the capital city of Georgetown and coastal towns

The country is divided into 10 administrative regions, each having varying levels of population and development (Figure 4). The most populous of these is Region 4 (309,059 people), which includes the capital, while the least populated is Region 8 (9,211 people). In the last national census conducted in 2012, the country recorded a total population of 
approximately 747,883 persons which differs slightly from the World Bank's figure of 799,613 reported for 2013 (World Bank, 2015). The majority of the people, nearly 90\%, live along the narrow coastal strip of land, approximately $25 \mathrm{~km}$ wide, facing the Atlantic Ocean. Although this area comprises only 5\% of the land area, it is the administrative, agricultural, commercial and industrial centre of the country. The country is classified as a lower middle income state with a Gross Domestic Product per capita (GDP/capita) of US \$3,847 in 2013 and a Gross National Income per capita (GNI/capita) of US $\$ 6,550$. There has been continued economic growth for the past nine years with an average of about $3 \%$ annually. The debt to GDP ratio is about sixty percent (60\%) and the GINI index was 0.4 in 1998 (World Bank, 2013). In 2013, the UNDP calculated the Human Development Index (HDI) as 0.638.
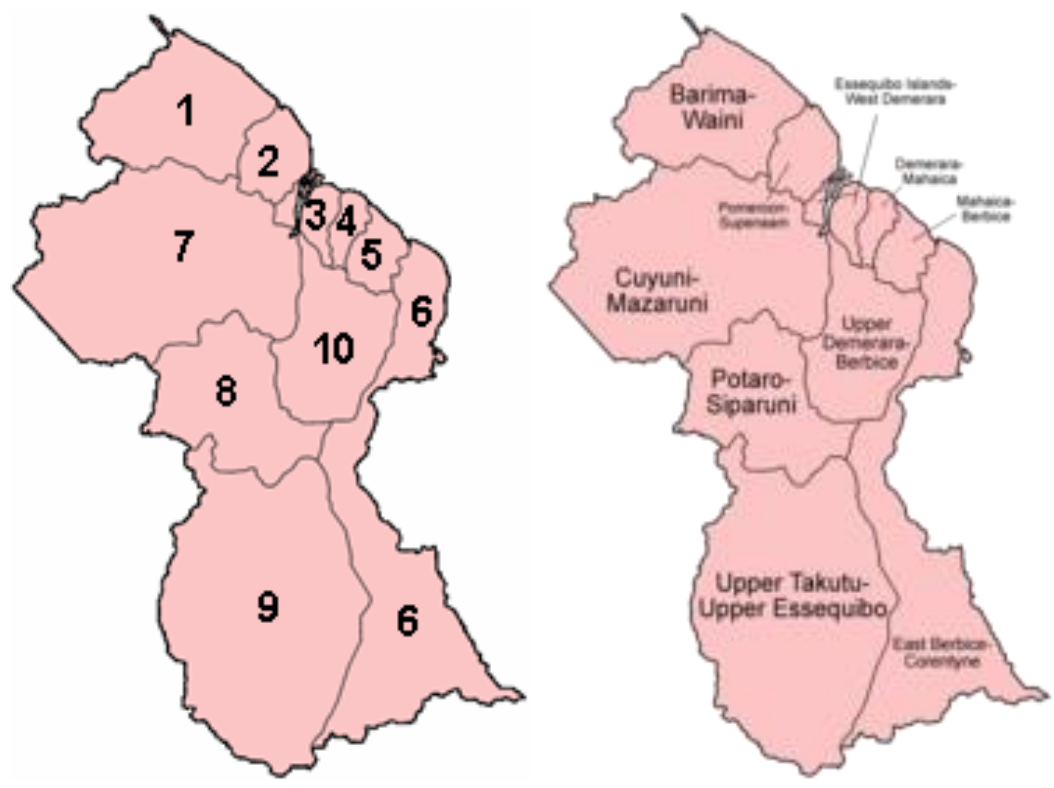

Fig 4: Map showing the Administrative Regions of Guyana, Source: Guyana Graphic, 2012

The country became a signatory to the United Nations Framework Convention on Climate Change (UNFCCC) at the United Nations Conference on Environment and Development (UNCED) in Rio de Janiero on June 13, 1992 and attained ratification on August 29, 1994. The Convention entered into force for Guyana on November 17, 1994. The country is also Party to fourteen (14) other Multilateral Environmental Agreements (MEAs). 
Guyana has an equatorial climate and is generally hot and humid throughout the year, though moderated by northeast trade winds along the coast. There are two rainy seasons, the first from May to mid-August, and the second from mid-November to mid-January. There are also two dry seasons the first from February to April and the second from mid-August to midNovember (Figure 5). Over the past twenty five years, high variability with this pattern has been observed and recently there has been an increase in the incidences of extreme weather events, particularly dangerous storms (Pereira, et al, 2014). The average daily temperature is about $26.7^{\circ} \mathrm{C}$, and annual precipitation of 2500-3200 $\mathrm{mm}$ (Figure 5).

Guyana's weather system is influenced by the meridional migration of the Inter-Tropical Convergence Zone (ITCZ) which is predominantly responsible for the annual cycle observed with its climate (Shaw, 1986). On the Guyana coast northward movement of the ITCZ brings the heavy and prolonged wet seasons (Gu \& Adler, 2009). The weather is also affected by the climate system known as the El Niño Southern Oscillation (ENSO). As observed by MacDonald (2006) the La Niña events are clearly associated with significantly higher rainfall than normal, and El Niño events with significantly lower rainfall.

As a result of Guyana's proximity to the equator there is little variation in the hours of daylight. It varies from a minimum of 11.6 hours per day in December to a maximum of 12.5 hours per day in June. Bright sunshine is inversely proportional to rainfall and this varies from an annual average of 4.5 hours per day in the hinterland mountainous regions to 7.0 hours per day on the coast. During the wet seasons, it can average as low as 3.0 hours and 6.0 hours per day respectively at these locations.

Over the last century, Guyana has experienced significant changes in its climate. The records suggest an increase by $1.0^{\circ} \mathrm{C}$ of the mean annual temperature within the last century (Second National Communication, 2012). Over this same period Keller et al (2011) reported an increasing temperature trend of an estimated $0.07^{\circ} \mathrm{C}$ per decade since 1960 , while Sweeney et al (2010) stated that rainfall has increased at an average rate of 4.8 millimetres per month per decade since 1960. In recent years, there have been many extreme weather events that have resulted in high levels of flooding, especially along the coast and in some inland areas. In Guyana, it is projected that by the end of this century, temperatures can increase by up to $4^{\circ} \mathrm{C}$ 
and weather patterns will become more extreme. ${ }^{23}$ Sea level is projected to rise at a rate of $1 \mathrm{~cm}$ $\mathrm{y}^{-1}$, about $40 \mathrm{~cm}-60 \mathrm{~cm}$ by the end of the $21 \mathrm{st}$ century (Bovolo, 2013). Such a rise in sea level will inundate wetlands and lowlands, accelerate coastal erosion, exacerbate coastal flooding, threaten or destroy coastal structures, raise water tables, and increase the salinity of rivers and aquifers (Second National Communication, 2012).

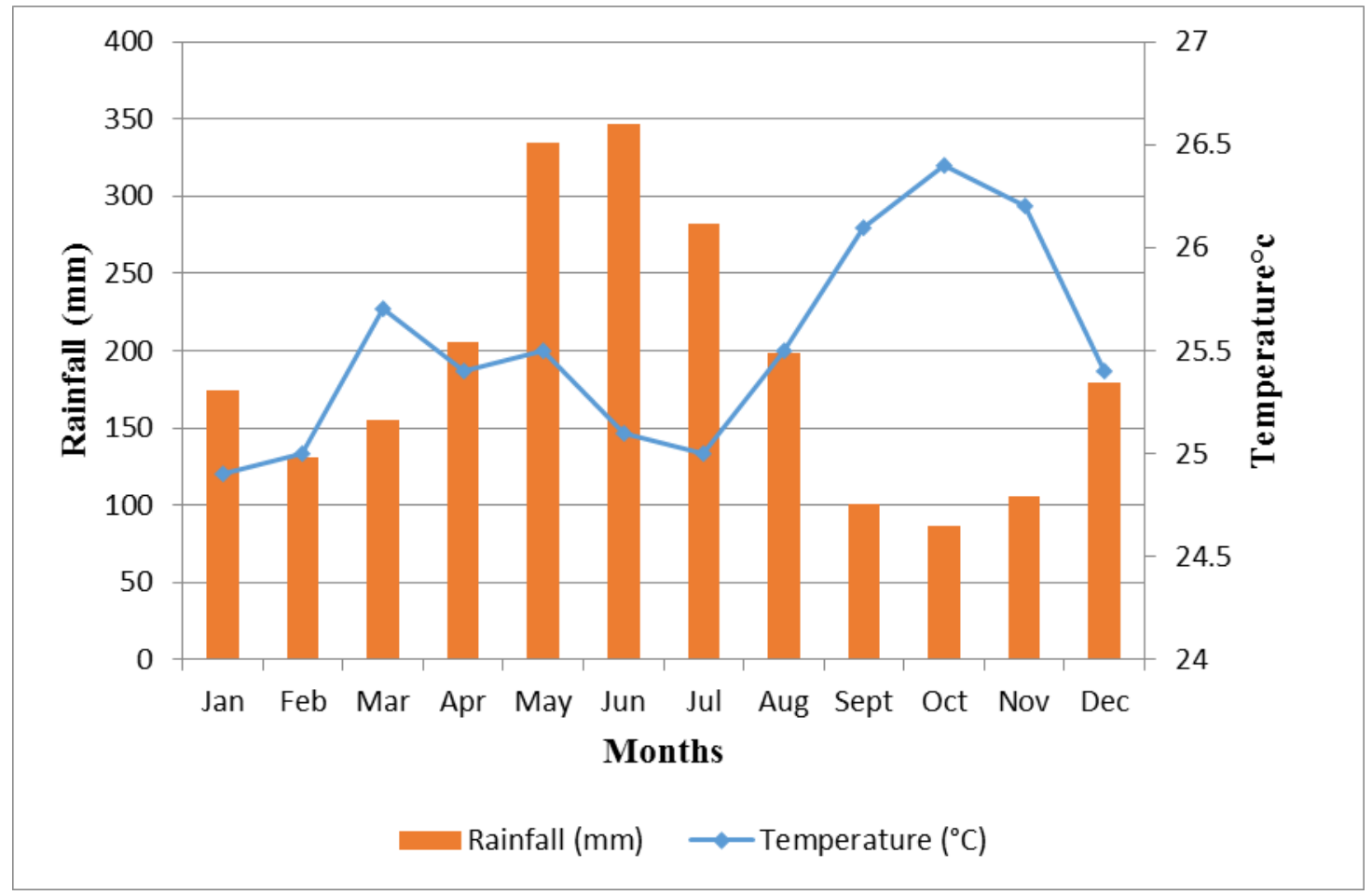

Fig 5: Mean monthly Temperature and Rainfall for Guyana from 1900 - 2009. Source: Adapted from the World Bank Group, 2015

Diurnal variation of temperature is smallest on the coast where the maritime effect is mostly pronounced. In that area daily maximum temperatures average $29.6^{\circ} \mathrm{C}$ while daily minimum temperatures average $24.0^{\circ} \mathrm{C}$. However, the lowest temperatures occur in the mountainous regions. At the peak of Mount Roraima (Fig 3), daily minimum temperatures are expected to average about $5.0^{\circ} \mathrm{C}$ (Khan, 2001).

${ }^{23}$ McSweeney, et al., 2010. UNDP Climate Change Country Profiles: Guyana. Available at: http://country-profiles.geog.ox.ac.uk/ (Accessed June 2015). 


\subsubsection{Mitigation in Guyana}

Guyana's mitigation efforts are outlined in its Low Carbon Development Strategy (LCDS) which supports an economy with less emphasis on fossil fuels. The country's pristine rainforests are its most valuable asset, the protection of which is essential for carbon sequestration to support the fight against climate change. The governments of Guyana and Norway signed a Memorandum of Understanding (MOU) (Appendix 3) on November 9, 2009 regarding cooperation on protecting the rainforest through the Reducing Emissions from Deforestation and Forest Degradation Plus (REDD+) mechanism.

Under the Norway agreement, Guyana is being financially compensated for its cooperation in the fight against climate change, biodiversity protection and enhancement of lowcarbon development. The country's performance is assessed through an incentive structure that rewards the country for keeping deforestation below an agreed reference level, as well as avoiding increased forest degradation. Norway has committed to providing Guyana up to US\$250 million to 2015, depending on the country's delivery of results as measured against two sets of indicators: those referred to as Enabling Activities, and REDD+ performance indicators (Appendix 2).

In summary, Guyana is using an interim reference level for deforestation under its MOU with Norway until a standard level is agreed at the UNFCCC. The reference level is a combination of average deforestation rates for Guyana between 2000 and $2009(0.03 \%)$ and the average deforestation rates for developing countries between 2005 and 2009 (0.52\%). This gives a reference level of $0.275 \%$ and this is used to determine payments under the MOU with Norway. If this deforestation rate is exceeded Guyana will receive a reduced payment, on a sliding scale, up to $100 \%$ at a level of $0.1 \%$ (The REDD Desk, 2013).

In 2011, the Joint Concept Note (JCN) for the MOU was revised to modify the reference level and included a sliding payment scale (Appendix 2). This showed a strengthening of and interchange between Guyana and Norway and a flexible "learning by doing" approach to the partnership (Birdsall \& Busch, 2014). 
Considerable progress has been made in the Guyana-Norway cooperation and in other related efforts. Guyana has met all the requirements specified within the agreement and has since earned four sets of payments totalling US\$195 million. Funds generated from this arrangement are used to strengthen village economies by supporting economic activities such as Amerindian land titling, small enterprise development and tourism for rural and hinterland communities (Table 5).

The funds are administered through an institutional mechanism known as the Guyana REDD+ Investment Fund (GRIF) which became operational in 2010. This is multi-contributor Trust Fund for financing activities identified under the Government of Guyana's Low Carbon Development Strategy (LCDS). The World Bank serves as the Trustee for GRIF and the InterAmerican Development Bank (IDB), the United Nations Development Programme (UNDP) and the World Bank (WB) are the partner Agencies responsible for release of the funds for the various projects to be undertaken (Gruning \& Shuford, 2012).

GRIF is also designed to support global efforts to devise a UNFCCC REDD+ mechanism and is intended to be a model for REDD+ payments for ecosystem services. The lessons learnt from this mechanism will help to refine the UNFCCC REDD+ efforts to ensure adherence to internationally accepted safeguards for fiduciary, social and environmental standards (World Bank \& UNDP, 2015).

Even though not outlined in the MOU or the JCN, local and foreign observers of this partnership have concluded that Norway will treat any avoided deforestation or degradation of Guyana's pristine forests as its contribution to global targets set for its reduction of dangerous greenhouse gas emissions. In other words, it is buying carbon offset rights for its own emissions from Guyana. ${ }^{24}$

\subsubsection{Guyana and the REDD+ Strategy}

Historically Guyana has experienced very low rates of deforestation with almost zero forest extraction rates back to $1990 .^{25}$ In 2011, the Guyana Forestry Commission and the Consultancy Group POYRY, identified deforestation rates of $0.06 \%$ for 2009-2010, rising from

\footnotetext{
${ }^{24}$ University of Guyana, Institute of Development Studies, 2009, Norway and Guyana's rainforest: why beggars do not choose., Available at: http://www.idsguyana.org/lcds/6-norwayand-guyanas-rainforest-why-beggars-do-not-choose.html (Accessed on: June 2015)

${ }^{25}$ FAO, 2010. Global Forest Assessment, Available at: http://www.fao.org/docrep/017/i3110e/i3110e.pdf (Accessed on June, 2015)
} 
$0.02 \%$ per annum between 2005 and 2009. ${ }^{26}$ For many years, successive governments have made efforts to limit the number of extraction concessions granted to investors in an effort to protect the vast rainforest reserves. With the launch of the LCDS in 2009, the Government sought opportunities to benefit financially for it standing forests and lobbied internationally for establishment of the REDD mechanism. Guyana's efforts which are embodied in its LCDS, are based on the REDD approaches. Table 4 illustrates the key actions taken to protect the forest resources and the financial benefits received based on the MOU and the JCN signed between Guyana and Norway. Table 5 lists the current projects implemented, in a number of communities throughout Guyana, with the funds earned from Norway.

${ }^{26}$ GFC \&POYRY, 2011. Guyana REDD+ MRVS, Interim Measures Report. 
Table 4: Key steps taken in pursuit of the REDD+ Strategy. Source: Adapted from Mary Robinson Foundation Climate Justice, 2011

1990s Low deforestation maintained by Government and indigenous communities

1996 Iwokrama International Centre (IIC) established to manage the Iwokrama forest reserve of 371,000 hectares

2006 Government of Guyana stepped up efforts to further address deforestation and proposed placing forests under long term protection if the right economic incentives were created.

2008 Guyana estimated value of its forests, if harvested and land put to subsequent use, to be equivalent to an annual annuity payment of US\$580 million

2009 Informal working group for interim financing for REDD established; Government of Guyana launched its Low Carbon Development Strategy (LCDS); National consultations begin on LCDS and Governments of Guyana and Norway sign Memorandum of Understanding. Norway to contribute US\$250 million for forest climate services to Guyana through to 2015

2010 REDD partnership launched at the Oslo and Climate conference in Norway; Guyana's REDD investment Fund (GRIF) established as the intermediary for performance based payments. First payment of US\$30 million transferred from Norway to GRIF

2011 GRIF received second tranche of US\$40 million from Norway

2012 GRIF received third tranche of US $\$ 45$ million from Norway

2015 GRIF received fourth tranche of US\$80 million from Norway 
Table 5: Projects currently implemented with GRIF funds. Source: Office of Climate Change, Office of the President, Guyana, 2015

\begin{tabular}{|l|c|}
\hline \multicolumn{1}{|c|}{ PROJECTS IN IMPLEMENTATION } & $\begin{array}{c}\text { US\$ / } \\
\text { M }\end{array}$ \\
\hline $\begin{array}{l}\text { Amerindian Land Titling - seeks to enable Amerindians to secure their lands and } \\
\text { natural resources with a view towards sustainable social and economic development. } \\
\text { Titling of communities will strengthen land tenure security and expand the asset base } \\
\text { of Amerindians. }\end{array}$ & 10.8 \\
\hline $\begin{array}{l}\text { Amerindian Development Fund (Phases 1 and 2) - supports the socio-economic } \\
\text { development of approximately 187 Amerindian communities and villages through the } \\
\text { implementation of their Community Development Plans. Phase 1 of the project } \\
\text { provided funding and technical assistance to 26 villages and is near completion. Phase } \\
\text { 2 has commenced implementation. }\end{array}$ & 8.2 \\
\hline $\begin{array}{l}\text { Micro and Small Enterprise Development - addresses two of the major bottlenecks } \\
\text { that constrain the development of micro and small enterprises and the ability of } \\
\text { vulnerable groups to build alternative livelihoods, which are limited access to finance, } \\
\text { and limited technical and business skills. }\end{array}$ & 5.1 \\
\hline $\begin{array}{l}\text { Climate Resilience Strategy and Action Plan - establishes a climate resilience } \\
\text { framework for Guyana that addresses direct and indirect impacts associated with } \\
\text { extreme weather events, as well as emerging, indirect, slow-onset climate impacts and } \\
\text { hazards }\end{array}$ & 0.5 \\
\hline $\begin{array}{l}\text { Monitoring Reporting Verification System Development - further builds capacity } \\
\text { in the Guyana Forestry Commission to carry out forest cover and change monitoring } \\
\text { and forest carbon monitoring/measurement in fulfilment of the MRVS Roadmap. }\end{array}$ & 1.9 \\
\hline $\begin{array}{l}\text { Institutional Strengthening (Phase 1) - enhances national institutional capacity in } \\
\text { Guyana to address the impacts of Climate Change, ensure the effective } \\
\text { implementation of the LCDS, and help Guyana meet its commitments under interim } \\
\text { REDD+ partnerships. }\end{array}$ & 6.4 \\
\hline $\begin{array}{l}\text { LCDS Outreach and Communication - aimed at increasing understanding and } \\
\text { awareness on climate change and Guyana's LCDS, both nationally and internationally. }\end{array}$ & 1.2 \\
\hline Sub-Total & $\mathbf{3 4 . 1}$ \\
\hline
\end{tabular}

\footnotetext{
${ }^{27}$ This project has been prepared by a Consultant in collaboration with Conservation International (Guyana). Shyam Nokta, Head of Climate Change, Office of the President (Personal Communication)
} 


\subsection{Adaptation}

For climate policies to be effective and efficient a mix of both greenhouse gas mitigation and adaptation is required and the two efforts must be seen as complementary to each other. Despite the stringency of mitigation efforts it is argued that the near-term impacts of climate change are already "locked-in", and this makes adaptation inevitable (Wheaton \& Maciver, 1999; de Bruin et al, 2009). Additionally, without mitigation, the magnitude and rate of climate change will likely exceed the capacity of many systems and societies to adapt (IPCC, 2007). So from an economic perspective a climate policy that encourages a mix of both mitigation and adaptation is encouraged (Burton et al, 2002; McKibbin \& Wilcoxen, 2002).

The United Nations Framework Convention on Climate Change (UNFCCC) of 1992 refers to two types of political responses to the impacts of climate change. The first is, mitigation, that is: "strategies to reduce greenhouse gas sources and emissions and enhance greenhouse gas sinks" and, second, adaptation: "the initiatives and measures taken to reduce the vulnerability of natural and human systems against actual or expected climate change effects" (IPCC, 2007). A more inclusive definition of adaptation was given by Moser \& Ekstrom (2010) which states:

"Adaptation involves changes in social-ecological systems in response to actual and expected impacts of climate change in the context of interacting on climatic changes. Adaptation strategies and actions can range from short-term coping to longer-term, deeper transformations, aimed to meet more than climate change goals alone, and may or may not succeed in moderating harm or exploiting beneficial opportunities".

From a purely rational perspective, these two strategies are complementary and, adaptation and mitigation should be considered as two sides of the one coin (Stehr \& von Storch, 2008).

Adaptation to climate change did not receive much attention in the first years of the international climate change studies; instead there was more focus on mitigation and impacts or what some described as preventive measures (Kates, 2000; Mees et al, 2012). However, adaptation planning is emerging as a new area of public policy across various geopolitical scales (Pielke jr., 1998; Biesbroek et al, 2010; Preston et al, 2011) with an increased interest in this adaptation mainly for two reasons: first, people, including politicians are realising that some climate change impacts are inevitable. Also, as mentioned previously, even if emissions of all greenhouse gases were to stop immediately, average temperatures could continue to rise for 
some time. As a result, adaptation and mitigation are not alternative strategies but rather, complementary ones and both need to be pursued together. Second, while scientists are clear on the need to reduce greenhouse gas emissions to stop global warming, action on the ground by politicians, businesses and individuals can best be described as slow. Inadequate mitigation, therefore, makes the need to adapt to climate change impacts all the more urgent (Smit, et al, 1999; Linham \& Nicholls, 2010; Uittenbroek, et al, 2013).

The IPCC distinguishes between adaptation as actions that operate upon the system itself, and mitigation as actions that operate upon the origin and attributes of the perturbation (i.e., reducing greenhouse gases emissions). Many authors and researchers disagree with this concept since in this case; adaptive capacity is clearly limited to coping with changes in the environment of the system (actually to climate change) and seems to exclude the element of increasing "adaptedness" when the environment does not change.

The anthropogenic emissions of greenhouse gases associated with the use of fossil fuels are largely from the rich industrialized countries, but with the increased growth and expansion of economies of the BRICS (Brazil, Russia, India, China, South Africa) countries, especially China and India, have now become significant sources of greenhouse gas emissions to the atmosphere, and will certainly contribute to the negative effects of global warming (Leal-Arcas, 2013). The impacts of climate change will be more severe in poor, developing countries. This is because the physical impacts are relatively larger in developing country regions. For example, increases in the already high temperatures are likely to lead to large evaporation losses and in many developing countries precipitation is not likely to increase as is expected in many high-latitude regions (Tol et al, 2004; Mertz, et al, 2009). Coupled with higher evaporative loss, droughts are likely to become more frequent and prolonged. Secondly, in many developing countries, the national income and employment rely heavily on agriculture that is directly affected by climatic change (Howden, et al, 2007; Millner \& Dietz, 2011). Also the high number of poor people in these countries is generally more vulnerable and likely to feel the negative effects of climate change. Finally, the economic and technological capacity to adapt to climatic change is often very limited in developing countries.

The Third IPCC Assessment Report (IPCC, 2001), defines vulnerability as "the degree to which a system is susceptible to, or unable to cope with, adverse effects of climate change, including climate variability and extremes. Vulnerability is a function of the character, 
magnitude, and rate of climate variation to which a system is exposed, its sensitivity, and its adaptive capacity.',

However, Smit \& Wandel (2006) describe vulnerability as the "degree to which a system is susceptible to injury, damage, or harm and the ability or capacity or resilience of the system to cope, adapt or recover from the effects of those conditions. Adaptations are therefore manifestations of adaptive capacity, and they represent ways of reducing vulnerability.

Adaptive capacity is similar to, or closely related to a host of other commonly used concepts, including adaptability, coping ability, management capacity, stability, robustness flexibility, and resilience (Smit \& Wandel, 2006; Klien, 2010). At the local level the ability to undertake adaptations can be influenced by such factors as managerial ability, access to financial, technological and information resources, infrastructure, the institutional environment within which adaptations occur, and political influence (Adger, et al, 2004; Haddad, 2005). This means that adaptive capacity is context-specific and varies from country to country, from community to community, among social groups and individuals, and over time (Brooks, et al, 2005). It varies not only in terms of its value but also according to its nature and the scales of adaptive capacity are not independent or separate. To better understand the diversity of adaptation measures and to be able to develop a framework of analysis, it is useful to classify adaptive responses and to distinguish different generic types of adaptation such as reactive and anticipatory adaptation and autonomous and planned adaptation.

The distinction between reactive and anticipatory adaptation is of particular importance. Reactive adaptation measures are those that institutions, individuals, plants and animals are likely to make in response to climate change, after the fact. Anticipatory adaptations are deliberate decisions to prepare for potential effects of climate change (Smith, 1997). Anticipatory measures are taken in advance of climate change, before the fact. Intuitively, the distinction between reactive and anticipatory adaptation is clear. Climate change is a continuous process, however, and so is adaptation. In practice, it may therefore be hard to delineate before and after. Anticipation requires foresight and planning, whereas reaction does not require but may involve foresight and planning.

Carter et al (1994) define autonomous adaptation as "natural or spontaneous adjustments in the face of a changing climate". Planned adaptation, on the other hand, requires conscious intervention. Migration of species to new locations in response to climate change is clearly an 
example of autonomous adaptation. Farmers switching crops and management practices is autonomous adaptation from the perspective of their government, but planned from a farmer's viewpoint. A research project to improve long-term weather forecasting would be a form of planned adaptation. Planned adaptation can directly reduce the negative impacts of climate change. One example is building sea walls. In addition, planned adaptation may also be used to influence (autonomous) adaptation by other actors (Smith \& Lenhart, 1996).

Funding is always a decisive factor for successful implementation for adaptation options since this would mean additional costs for the public and the private sectors. Assessing the costs and the benefits of adaptation is more complicated than that for mitigation since the benefits of adaptation are usually long term and not always easy to measure. The Bali Action Plan, adopted in 2007 attached equal weight to mitigation and adaptation and identified technology and finance as key mechanisms to enable developing countries to respond to climate change. The UNFCCC commits developed countries to assist developing countries to meet the costs of adaptation, especially for those countries most vulnerable to the impacts of climate change. Funds established by the COP to support adaptation includes: (a) The Least Developed Countries Fund (b) The Special Climate Change Fund (c) The Adaptation Fund and (d) The Green Climate Fund $^{28}$ (Table 6).

${ }^{28}$ Stockholm Environment Institute (SEI), 2008. Financing adaptation to climate change (Policy Brief), Available at: http://www.seiinternational.org/mediamanager/documents/Publications/Climate/financing_adaptation_climate_ change.pdf (Accessed on June, 2015). 
Table 6: UNFCCC Discussions and Policies for financing adaptation in developing countries

\begin{tabular}{|c|c|}
\hline UNFCC COP & Discussions on Policies for financing adaptation in developing countries \\
\hline $\begin{array}{l}\text { COP } 13(2007) \\
\text { Bali }\end{array}$ & $\begin{array}{l}\text { Discussions stressed the need for providing financial resources and } \\
\text { investment for developing countries to support mitigation and adaptation }\end{array}$ \\
\hline $\begin{array}{l}\text { COP } 15(2009) \\
\text { Copenhagen }\end{array}$ & $\begin{array}{l}\text { The need for US } \$ 100 \text { Billion } \mathrm{yr}^{-1} \text { by } 2020 \text { first noted to meet the needs of } \\
\text { developing countries }\end{array}$ \\
\hline $\begin{array}{l}\text { COP } 16(2010) \\
\text { Cancun }\end{array}$ & $\begin{array}{l}\text { The establishment of the Green Climate Fund noted to support projects, } \\
\text { programs and policies on Adaptation }\end{array}$ \\
\hline $\begin{array}{l}\text { COP } 17(2011) \\
\text { Durban }\end{array}$ & $\begin{array}{l}\text { The Green Fund designated as an operating entity. Aimed to raise US\$ } 30 \\
\text { Billion before } 2020 \text { as start-up funding. }\end{array}$ \\
\hline $\begin{array}{l}\text { COP } 19(2013) \\
\text { Warsaw }\end{array}$ & $\begin{array}{l}\text { The institutional framework was set up for effective delivery of climate } \\
\text { finance via the Green Fund. The need for oversight was stressed to avoid } \\
\text { corruption and fraud }\end{array}$ \\
\hline $\begin{array}{l}\text { COP } 20(2014) \\
\text { Lima }\end{array}$ & $\begin{array}{l}\text { More planning, strategy and policy for the Green Fund. Discussions on the } \\
\text { need to limit global temperatures to } 1.5^{\circ} \mathrm{C} \text { and defined the need for Intended } \\
\text { Nationally Determined Contributions (INDCs). The Green Fund to start } \\
\text { operating when } 50 \% \text { of the pledges were received. Calls for private sector } \\
\text { co-funding. }\end{array}$ \\
\hline $\begin{array}{l}\text { COP } 21(2015) \\
\text { Paris }\end{array}$ & $\begin{array}{l}\text { Two major objectives: (i) Bind all nations in a global effort to reduce } \\
\text { emissions sufficiently to achieve < } 20 \mathrm{C} \text { by } 2050 \text { and (ii) stimulate faster } \\
\text { action on finance for Green Fund. }\end{array}$ \\
\hline
\end{tabular}

It is estimated that the amount of climate finance needed to support carbon neutral energy is 1US\$ Trillion $\mathrm{yr}^{-1}$ with only US\$356 Billion received in 2012. ${ }^{29}$

${ }^{29}$ International Energy Agency, 2012. Plugging the energy efficiency gap with climate finance. The role of International Financial Institutions and the Green Climate Fund to realize the potential of energy efficiency in developing countries. Available at:

https://www.iea.org/publications/insights/insightpublications/PluggingEnergyEfficiencyGapwith ClimateFinance.pdf (Accessed on June, 2015). 
Guyana was one of the first countries that benefitted from the Special Climate Fund in 2007 under the administration of the Global Environment Facility (GEF). A grant in the amount of US\$3.8 million was disbursed to Guyana, from the Implementing Agency, the World Bank, for the Conservancy Adaptation Project (CAP). Implementation was done through the World Bank's Sustainable Development Department, Caribbean Country Management Unit for Latin America and the Caribbean. ${ }^{30}$ The funding arrangements for the Green Fund are now being developed and Guyana intends to access funds through this facility as a member of the Caribbean Community (CARICOM).

\subsubsection{Adaptation Options for Guyana}

In Guyana through the performance-based payment for carbon services mechanism under the Low Carbon Development Strategy (LCDS), funds received have been used for economic projects. These projects are inclusive of adaptation, especially in the hinterland communities. A number of projects have commenced and a few are in the pipeline. The projects currently being implemented with resources earned from Norway as well as other funding sources are (i) The Conservancy Adaptation Project; (ii) Cunha Canal Rehabilitation Project; (iii) Amerindian Development Fund that supports socio-economic development in Amerindian Communities through the implementation of community development plans. These plans, in some villages, include community projects such as diversification in agriculture using climate tolerant crop varieties, shade houses / green houses and other adaptation techniques, and ecotourism; (iv) Micro \& Small Enterprise (MSE) and Vulnerable Groups Low Carbon Livelihood Project that aim to address two major challenges which hinder the development of micro and small enterprises and the ability of vulnerable groups to build alternative livelihoods in Guyana. It will address limited access to financing by assisting those outside of the scope of the banking sector, while also addressing limited access to technical and business skills. This project indirectly will address adaptation through the support for low carbon MSE projects; (v) The development of an overarching Climate Resilience Strategy and Action Plan for Guyana. In summary the plan will, among other things, (a) assess Guyana's current adaptation initiatives,

\footnotetext{
${ }^{30}$ Project Appraisal document, 2007. The World Bank, Proposed Grant from the Global Environment Facility, Special Climate Fund. Available at: http://wwwwds.worldbank.org/external/default/WDSContentServer/WDSP/IB/2007/09/27/000310607_2007 0927095909/Rendered/PDF/39120main.pdf (Accessed on June 2015)
} 
plans and capacity; (b) identify current climate change risks and scenarios and measures to address these risks; (c) identify the overall economics of climate resilience in order to transform and maintain resilience; (d) develop a climate resilience framework for Guyana that addresses direct and indirect impacts associated with extreme weather events, as well as, emerging, indirect, slow-onset climate impacts and hazards; (e) identify priority climate resilience projects and measures along with a plan of execution and associated costs; (f) identify global financing options for the implementation of the Strategy, inclusive of all projects and identified measures to support the transformation of a low carbon, climate resilient economy; (g) analyse and present scenarios of the impacts of implementing the climate resilience projects and measures in the longer term (by 2030). It also intends to examine ecosystem based adaptation initiatives and potential. The plan is currently being developed consistent with the UNFCCC requirements and guidance in preparing national adaptation plans.

The former President of Guyana, Donald Ramotar, emphasized his commitment to adaptation to climate change in his speech to the United Nations Climate Summit in New York in 2014. At this meeting he said "We are ready to take actions to develop along low carbon and climate resilient paths, but the global financial system makes such actions difficult”. He further stated that "As a low lying coastal state, we are particularly vulnerable to devastating climate impacts. Adaptation activities and building resilience to improve our ability to cope are indispensable elements of our climate strategy". 31

\subsubsection{The adaptation challenge and its significance}

The impacts of climate change will be felt by developed and developing countries and will affect people across many economic sectors. These impacts are likely to include increased water stress, flood risks, food insecurity and loss of biodiversity, (inclusive of important crop genetic resources), loss of livelihoods and health risks (Klien, 2015). Developing countries will be particularly affected, due to their relatively low adaptive capacity and therefore higher social and economic vulnerability. It is therefore expected that the net costs of climate change to the developing countries will be larger than the global average.

\footnotetext{
${ }^{31}$ Donald Ramotar, (former President of Guyana), speech at the United Nations Climate Summit in New York, 2014.
} 
In 1996, the Intergovernmental Panel on Climate Change (IPCC) wrote that adaptation offers a "very powerful option" for responding to climate change and ought to be viewed as a "complement" to mitigation efforts. The Fifth Assessment report from the IPCC further reinforces the urgency of supporting adaptation, whether among the urban poor exposed to climate hazards or among poor rural communities that depend on rainfed agriculture and other climate-sensitive resources (IPCC, 1996).

\subsubsection{Ecosystem Based Adaptation (EbA)}

Ecosystem-based adaptation (EbA) is an emerging approach which recognizes that ecosystem services play an important role in reducing the vulnerability to climate change (CBD, 2009; Turner et al., 2009). EbA is the use of biodiversity and ecosystem services as part of an overall adaptation strategy to help people to adapt to the adverse effects of climate change (Folke 2006; Jones et al, 2012; Mccarthy, 2012). As one of the possible elements of an overall adaptation strategy, ecosystem-based adaptation uses the sustainable management, conservation, and restoration of ecosystems to provide services that enable people to adapt to the impacts of climate change. It aims to maintain and increase the resilience and reduce the vulnerability of ecosystems and people in the face of the adverse effects of climate change. Further it takes into account, the multiple social, economic and cultural co-benefits for local communities (Doswald \& Osti, 2011; Lugnot \& Martin, 2013).

EbA can generate significant social, economic and cultural co-benefits, contribute to the conservation of biodiversity, and build on the traditional knowledge and practices of indigenous peoples and local communities, including the important role of women as custodians of local knowledge (Munang et al, 2013). In addition, healthy, well-managed ecosystems have climate change mitigation potential, for example, through the sequestration and storage of carbon in healthy forests, wetlands, and coastal ecosystems. Through the EbA, communities benefit from the maintenance and enhancement of ecosystem services that are crucial for livelihoods and human well-being, such as provision of clean water, food, fibre and maintenance of soil fertility (Promova et al., 2014; Sutton-Grier., et al., 2014).

Essentially, EbA addresses the crucial links between climate change, biodiversity, ecosystem services and sustainable resource management. However, despite the apparent success and recognition of EbA in the adaptation toolbox, its use in adaptation programs is 
considered inadequate (Munang, et al, 2013). This may be due to the increased emphasis on gaining 'evidence of effectiveness' of EbA so establishing an evidence base for decision making with respect to EbA remains a challenge. According to Naumann et al (2011) and Travers et al (2012), robust information on quantitative benefits of EbA and the conditions under which those benefits are likely to be received is generally not available. Gathering additional information through research and wider use of EbA is of vital importance, to support the integration of $\mathrm{EbA}$ in national adaptation programmes and to raise awareness of its benefits.

The 'Ecosystem Approach' was first used in the early 80s, but became formally accepted at the Earth Summit in Rio in 1992 where it became an underpinning concept of the Convention on Biological Diversity (CBD). A few examples include the restoration of mangroves for protecting coastal settlements against storm surges, the conservation of upstream forests to regulate water flow and control erosion, for the benefit of vulnerable communities, and sustainable forest management for the provision of safety nets to livelihoods (Munang, 2013). In this respect, the concept of using ecosystems as a basis to adapt to the impacts of changes in climate has gained momentum in recent years and has now emerged as an important technology in the adaptation 'toolbox'.

\subsection{The vulnerability challenge}

The concept of vulnerability is of great importance in the context of climate change since the UNFCCC commits developed countries to "assist the developing country Parties that are particularly vulnerable to the adverse effects of climate change in meeting costs of adaptation"

(UNFCC, 1992). In ordinary language vulnerability can simply be described as a measure of future harm (Wolf, et al, 2012). The IPCC (2007) defines vulnerability as "the degree to which a system is susceptible to, and unable to cope with, adverse effects of climate change, including climate variability and extremes." Further the IPCC states that it "is a function of the character, magnitude, and rate of climate change and variation to which a system is exposed, its sensitivity, and its adaptive capacity." From a social and natural science perspective, Adger (2006) concludes that vulnerability is constituted of components that include exposure to perturbations or external stresses, sensitivity to perturbation and the capacity to adapt. From a natural hazard perspective Blaikie, et al (1996) and Gallopin (2006), compared vulnerability to resilience and 
described it as generally specific to perturbations that impinge on a system; in other words, a system can be vulnerable to certain disturbances and not to others.

Adapting to climate change is one of the biggest challenges for Guyana, now that the threats, sea level rise, flooding, extreme weather events and drought, are more evident and are becoming more frequent. The costs of achieving total adaptation are projected to exceed about US\$1B, a conservative estimate (ECLAC, 2011). In protecting the coast from the Atlantic Ocean, the government needs to fortify $360 \mathrm{~km}$ of sea defences at an approximate cost of US\$4.4-6.4 million per kilometre. ${ }^{32}$ Guyana's vulnerability is further amplified with $90 \%$ of its population residing on the low-lying coastal plain, along with most agriculture lands and all major administrative, economic, service and infrastructure facilities. Although the country is very rich in natural resources, its economic base is very narrow with a strong dependence on a very small range of primary products, rice, sugar, rum, bauxite and timber for export. The coastal lowland between the Demerara and Mahaica Rivers is the most populous area of Guyana and houses the capital city of Georgetown (Figure 3). Apart from the settlements, it is also a major agricultural district for sugar cane, fruits and vegetables. This relatively narrow strip of land is located between the sea and the East Demerara Water Conservancy (EDWC).

The EDWC traps surface water flowing to the coast, both for use in irrigation and to protect against flooding when river levels are high, with canals serving as control structures allowing water levels to be managed behind the conservancy dam (ECLAC, 2005). Water from the land is drained through rivers and canals by gravity towards the ocean. Since the land is below sea level the drainage system consists of a system of kokers (out flow or sluice gate) which is closed during the high tide and opened when the tide is low for water to drain out to the sea. Figure 6 shows a schematic diagram and map of the drainage system. Over the past decades the system suffered from poor maintenance and investments, and with the added impacts from sea level rise there is increasing stress on the drainage system (World Bank 2007; Hickey \& Weis, 2012).

In 2005, extreme rainfall caused severe flooding along the coastal lowlands and affected more than half of Guyana's population. The floods highlighted the vulnerability of the EDWC

\footnotetext{
${ }^{32}$ Former President Bharat Jagdeo (2008); Stabroek News online, Guyana "Adaptation to climate change will cost billions" Available at: http://www.stabroeknews.com/2008/archives/08/03/adaptation-to-climate-change-will-costbillions/ (Accessed on; June, 2015)
} 
earthen dam to overtopping and the potential for breaching. In 2008 to 2013, with support from the World Bank, the Government of Guyana carried out the Conservancy Adaptation Project (CAP), the aim of which was to reduce the likelihood of catastrophic flooding along Guyana's low-lying coastal areas which are also threatened by sea level rise. ${ }^{33}$

\footnotetext{
${ }^{33}$ Project Appraisal document, Global Environment Facility, Special Climate Change Fund. Conservancy Adaptation Project, 2007 (Report no.39120-GY), Available at: http://wwwwds.worldbank.org/external/default/WDSContentServer/WDSP/IB/2007/09/27/000310607_2007 0927095909/Rendered/PDF/39120main.pdf (Accessed on June 2015)
} 
(a)
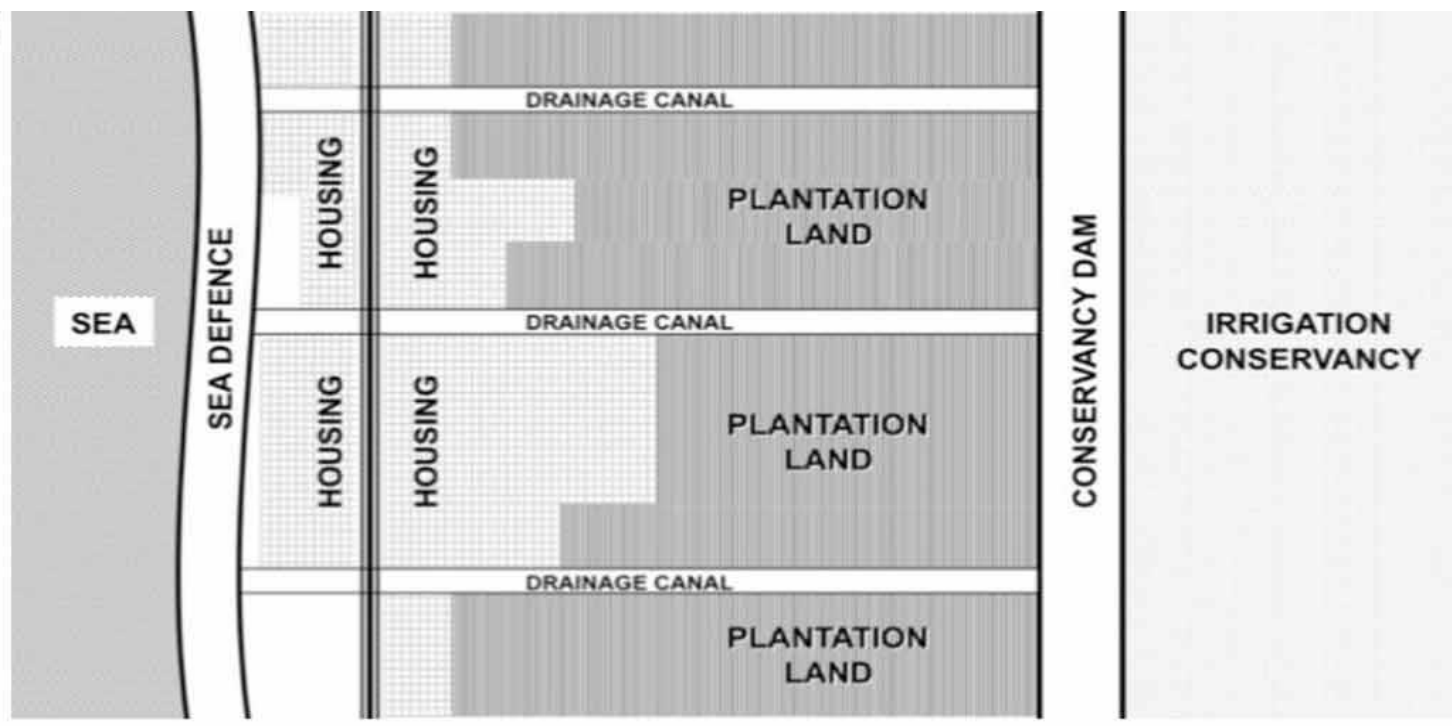

(b)

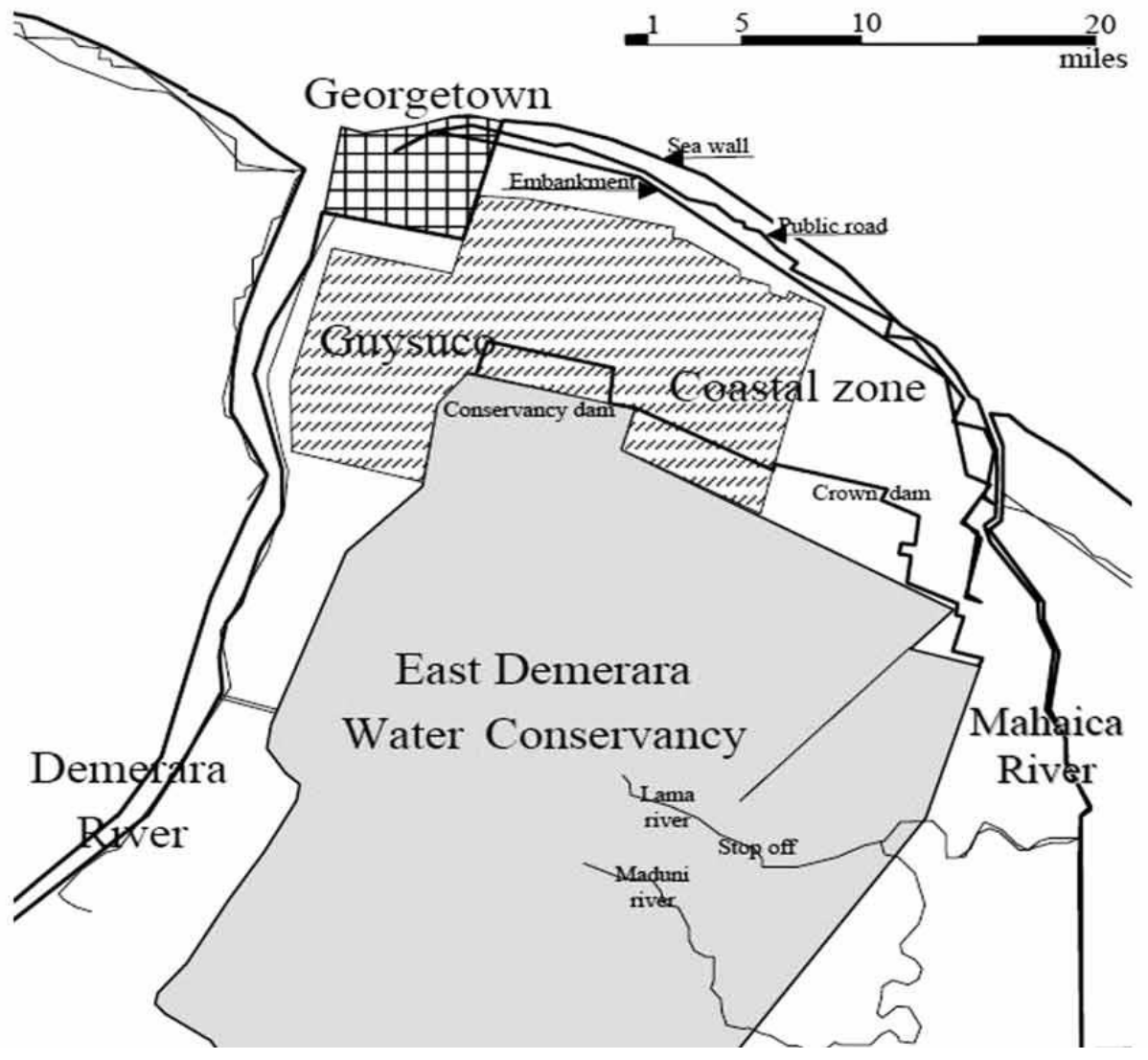

Fig 6: Schematic diagram and map of the East Demerara Water Conservancy. Source: Hickey and Weis, 2012. 
Despite its high vulnerability to the impacts of climate change, Guyana has been undertaking significant efforts at the national and international level to combat this phenomenon in the context of sustainable development. In 2010, the Government of Guyana launched a pioneering and historic, national-scale model for addressing climate change - Guyana's Low Carbon Development Strategy (LCDS). The LCDS is a comprehensive approach to addressing climate change focusing on both mitigation and adaptation priorities while simultaneously promoting economic growth and development (LCDS, 2010).

\subsubsection{Sea Level Rise}

Rising sea levels vary from region to region, which leads to different impacts. Sea level rise has been attributed to greenhouse gas induced temperature rise which creates thermal expansion of the oceans and melting sea ice (Wigley \& Raper, 1987) leading to increased volumes of water in the seas.

Guyana is extremely vulnerable to sea-level rise and intense tropical storms (EPA Guyana, 2002; Dasgupta et al 2009) because the coastal strip sits below mean sea level and depends on an ageing infrastructure to keep the sea at bay and for proper drainage of the land. The settlement pattern reflects Guyana's long colonial history as does the country's narrow, commodity-dependent economy and its predominant association with the Caribbean region rather than South America. Both episodic floods and persistent saltwater intrusion ${ }^{34}$ threaten the availability of potable water along the coast, the viability of the irrigation system and the salinization of soils, which would endanger the sugar and the rice industries (Second National Communication, 2012). Within the coastal zone, the issues of sea level rise, destruction of mangroves and coastal subsidence add to the pressures on coastal sea defense system. Additionally, some of the vegetative cover on the coastal zone and the sandy plains further inland has been lost to competing activities such as, agriculture, human settlements, and harvesting for fuel wood to make charcoal.

The imperative of climate change adaptation in Guyana is overwhelmingly conceived in terms of the populous coastal strip and the rehabilitation and enhancement of the sea and river defences which are crucial adaptation investment priorities. Already, the ocean regularly

\footnotetext{
${ }^{34}$ Narayan, Kailas, 2006. Climate change impacts on water resources in Guyana. World Friend Conference Proceedings, Havana, Cuba.
} 
overtops many areas of the sea-wall and, in addition to waves cresting more frequently over the wall, rising sea levels would put it under greater general physical stress and compromise the effectiveness of the entire coastal drainage system (Hickey \& Weis, 2012). An analysis of the tide gauge data from 1960 to 1981 (Figure 7) for the Mean Sea Level (MSL) shows an average increase of $1.27 \mathrm{~mm}$ for the following twenty one years after 1960. This is very close to the global average sea level rise of $1.7 \mathrm{~mm} \mathrm{yr}^{-1}$ as estimated by the IPCC. ${ }^{35}$

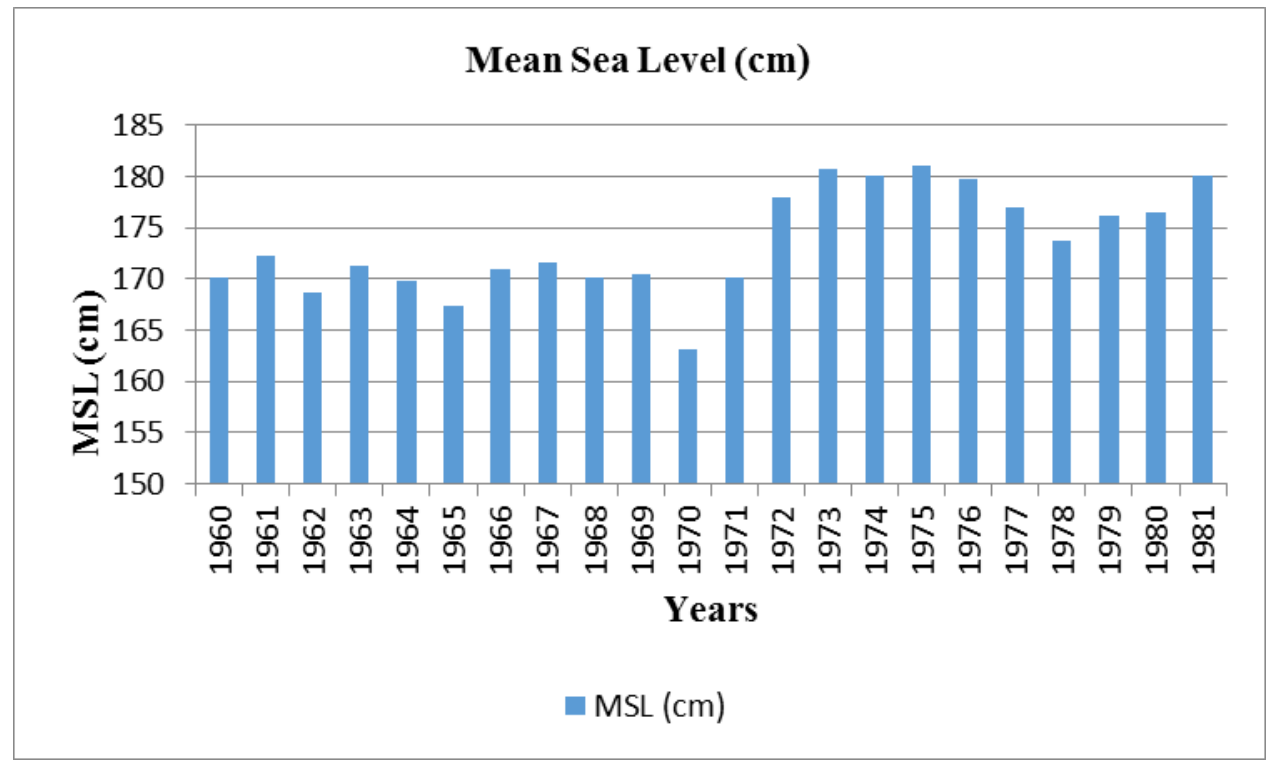

Fig 7: Mean Sea Level data (Georgetown) 1960 -1981 Source: Adapted from Persaud, 2014

The tide gauge data for relative mean sea level was taken at two locations: Stabroek Market, Georgetown and at the Lighthouse in Kingston (Table 5). For Stabroek Market, data for fifty years (1960-2010) indicated a difference in Mean Relative Sea Level (MRSL) of 9.25 inches $(234.95 \mathrm{~mm})$ while the data for the location at the Lighthouse in Kingston indicated a drop in MRSL of 1.60 inches $(40.64 \mathrm{~mm})$ over a period of thirty eight years. The total increase over eighty eight years is 7.65 inches $(194.31 \mathrm{~mm})$. This is equivalent to a MRSL of $2.2 \mathrm{~mm} \mathrm{yr}^{-1}$

${ }^{35}$ IPCC, 2007. Climate Change 2007, Working Group 1: The Physical Science Basis. Is Sea Level rising, Available at: http://www.ipcc.ch/publications_and_data/ar4/wg1/en/faq-5-1.html (Accessed on June 2015) 
which is close to the global average but much lower than projections made by Dalrymple (2006) of $7.1 \mathrm{~mm} \mathrm{yr}^{-1}$.

Table 7: Mean Relative Sea Level, Georgetown. Source: Persaud, 2014

A. Tide Gauge at Stabroek Market, Georgetown

Date

August 2010

August 1960

Difference (50 years)

B. Lighthouse, Kingston, Georgetown

Date

2008

1970

Difference
Height (ft)

6.36

5.59

\subsection{5 in}

Height ( $\left(\mathrm{ft}^{37}\right.$ )

56.9763

57.1100

\section{Reference}

MARAD $^{36}$

MARAD

Other reports used data available for the period 1951 to 1979 for Port Georgetown, and reported a MRSL, using linear extrapolation, of $10.2 \mathrm{~mm} \mathrm{yr}^{-1}$. High tide change was calculated to be $9.7 \mathrm{~mm} \mathrm{yr}^{-1}$ with the low tide change being $11.1 \mathrm{~mm} \mathrm{yr}^{-1} .{ }^{39}$ These projections are nearly five times the global estimates of about 2.2 to $2.4 \mathrm{~mm} \mathrm{yr}^{-1}$.

\subsubsection{Floods in Guyana}

Floods are the most frequent natural hazard in Guyana, often caused by heavy rainfall, overtopping the sea defences or an overflow of the Conservancies used to store water flowing by gravity from the backlands. Flooding is also exacerbated by blocked drains and malfunctioning kokers or sluice gates or silted up outfalls along the Coast of Guyana.

\footnotetext{
${ }^{36}$ Georgetown vertical Datum, set at 56 feet below MSL

${ }^{37}$ Maritime Administration Division, Ministry of Public Works, Guyana

${ }^{38}$ Guyana Lands and Surveys Commission, Guyana

${ }^{39}$ Guyana's coastal vulnerability and risk assessment, Technical Report 5C/CPACC-02-01-1, CPACC, 2014.
} 
Annual precipitation has increased over the years in Guyana. From 1966 to 2006, the average annual rainfall was estimated at 3,088 $\mathrm{mm} \mathrm{yr}^{-1}$. The maximum annual rainfall was 3,800 $\mathrm{mm}$ over the period and this was recorded in the year 2000. From the year 2000 onwards the number of flood events increased dramatically with an average of just 4 events $\mathrm{yr}^{-1}$ in the 1990s to about 20 flood events annually in the $2000 \mathrm{~s} .{ }^{40}$ When there is such high unexpected rainfall and the EDWC is full to capacity, the potential for floods along the coastal lowlands is always there. The situation becomes worse at high tides when there is overtopping of the sea defences. Dalrymple and Pulwarty (2006) projected a significant overtopping of $0.027 \mathrm{~m}^{3} \mathrm{~s}^{-1} \mathrm{~m}^{-1}$ by 2020 , and suggested that the current infrastructure be upgraded to keep the sea out. In 2005 Guyana experienced one of its worst flood disasters, caused by a combination of heavy rainfall, breaches and overtopping of the EDWC and overtopping of the sea defences. Losses were estimated at $60 \%$ (US\$ 450 million) of the country’s GDP (LCDS, 2010), with heaviest losses incurred from cash crops followed by sugar and rice ${ }^{41}$.

\subsubsection{Extreme weather events (Storms and high precipitation)}

Extreme weather can have devastating impacts, not only on immediate loss of lives and assets, but also longer-term damage to livelihoods and economies. During the period 1972 to 1994 extreme weather and storms were virtually absent from Guyana. This changed from around 1995, when Guyana began to experience about 2 to 4 extreme storm events every year. In 2006 there were 7 extreme storm events which affected the lives of almost 1000 people. ${ }^{42}$ In 2013, hail and strong winds caused millions of dollars' worth of damage in the mining town of Linden. ${ }^{43}$ Hail falling in Guyana was a historic event. Data from circulation models predict an increase in the frequency of high intensity storms over the next 100 years with an increase of category 4 and category 5 storms. ${ }^{44}$

\footnotetext{
${ }^{40}$ Desinventar, online: An inventory system of the effects of disasters (Accessed on June 2015). ${ }^{41}$ ECLAC/UNDP, 2005. Socio-economic assessment of the damages and losses caused by the January-February, 2005 flooding

${ }^{42}$ Desinventar, online: An inventory system of the effects of disasters (Accessed on June 2015 ${ }^{43}$ Guyana Chronicle, 2013. Hail falls on Blueberry Hill, Accessed on June 2015 and available at: http://guyanachronicle.com/hail-falls-on-blueberry-hill/

${ }^{44}$ ECLAC, An assessment of the economic impact of climate change in the coastal and human settlement sector of Guyana. (Accessed on June 2015)
} 


\subsubsection{Drought}

While much of the weather that we experience is brief and short-lived, drought is a more gradual phenomenon, slowly taking hold of an area and tightening its grip with time. In severe cases, drought can last for many years, and can have devastating effects on agriculture and water supplies. The incidences of drought have increased since late 1990s and are mostly concentrated in southern Guyana (Region 9), which is neighbouring to Brazil. Prior to this period, a drought in Guyana was virtually unheard of but in 1997 and 2003 there were 2 incidences of severe drought for each of the respective years in which over 20,000 residents were affected. ${ }^{45}$ Guyana's climate is highly influenced by the El Niño Southern Oscillation (ENSO) and drought in Guyana is attributed to the El Niño phenomenon. In its El Niño phase, ENSO provokes dry periods throughout the year and higher temperatures in July and August; whereas it's La Niña phase leads to the opposite situation. The droughts in 1997 and 1998 caused a severe shortage of drinking water throughout the country and a significant drop in agricultural production especially for rice and sugar.

Farmers experienced a major water shortage in August 2009 to May 2010 due to the occurrence of El Niño weather conditions. Rice as well as cattle and food crops were severely affected, with large acreages of paddy fields left unsown due to the absence of water. High levels of salt in the water were also reported by farmers ${ }^{46}$.

\subsection{The institutional framework for climate change in Guyana}

Politically, Guyana can be described as a representative democratic republic, whereby the President of Guyana is the head of government, and of a multi-party system of representation. The government exercises executive power while legislative power is vested in both the government and the National Assembly of Guyana. The Judiciary is independent of the executive and the legislature.

Elections are conducted according to the Constitutional provisions which are supplemented by the laws made by Parliament. The major laws among those are the Representation of the People Act (1964) which deals with all aspects of the conduct of elections and the National Registration Act (1967) which deals mainly with the preparation and revision of

\footnotetext{
${ }^{45}$ Desinventar, online: An inventory system of the effects of disasters (Accessed on June 2015

${ }^{46}$ United Nations, 2011. Guyana: Common country analysis
} 
electoral rolls. The president is not directly elected; each party presenting a slate of candidates for the assembly must designate in advance a leader who will become president if that party receives the largest number of votes. The president has the authority to dissolve the parliament, or any other institutions he creates to address a particular issue such as climate change. The president is not a member of the National Assembly but may address it at any time or have his address read by any member he may designate at a convenient time for the Assembly. Under Guyana's constitution the President is both the Head of State and Head of Government of the Cooperative Republic of Guyana.

Climate change is considered a serious threat to the economic well-being of Guyana and it is being given a high priority by the Government. Despite this, a national policy on climate change is still to be developed. In the meantime it comes under the direct supervision of the President of the country and the Office of Climate Change (OCC) is housed within the Presidential complex for maximum attention and to cut the usual bureaucracy if necessary so that key projects can be smoothly implemented. This office plays a coordinating role especially with regards to access of funds from external donors and enabling collaboration with the respective institution under whose supervision a particular project may fall. It was set up just after negotiations were complete for the Guyana-Norway REDD Agreement. The OCC draws on the collaborative input and efforts of several organisations within the environmental and natural resources sector all of which may be affected in one way or another by the effects of climate change. This collaborative effort also encourages synergy and free flow of information on climate change on projects that are being implemented by the various institutions.

\subsubsection{Office of Climate Change}

The Office of Climate Change (OCC) works across Government to support work on climate adaptation, mitigation and forest conservation and it is sited at the Office of the President. It is the entity with overall responsibility for consultations on Guyana's Low Carbon Development Strategy and works closely with the REDD Secretariat. Its key role is one of coordination for local climate change projects and for Government engagements with international forestry programmes including the Forest Carbon Partnership Facility, the Forestry Investment Programme and UN-REDD. It has no responsibility for finances with REDD+ or any other programme. 


\subsubsection{The REDD Secretariat}

The REDD Secretariat (RS) is responsible for the coordination of all national REDD+ activities, under the direction of the Guyana Forestry Commission, and for overseeing the implementation of REDD+ activities under the Low Carbon Development Strategy framework. The main areas of work are the execution of consultation and outreach activities, and the dissemination of results of the assessment of the carbon stock potential of Guyana's forests. The Secretariat reports directly to the Guyana Forestry Commission as well as the National Climate Committee.

\subsubsection{The Guyana Forestry Commission}

The Guyana Forestry Commission (GFC) is responsible for the administration and management of all State Forest Land in Guyana. In addition it advises the Government on issues of forest policy, forestry laws and regulations. It is responsible for overseeing all forestry concessions from initial granting to monitoring and enforcement. The GFC has been at the forefront of the development of a national Monitoring, reporting and Verification System leading the formation of the Monitoring, Reporting and Verification System Roadmap. The GFC is at the forefront of Guyana's developments under the Forest Carbon Partnership Facility. The GFC houses the REDD Secretariat.

\subsubsection{The Environmental Protection Agency}

The Environmental Protection Agency (EPA) was established by an Act passed in 1996. The EP Act mandates the EPA to oversee the effective management, conservation, protection and improvement of the environment, the prevention and control of pollution, the assessment of the impact of economic development on the environment and the sustainable use of natural resources. The mission of the Environmental Protection Agency (EPA) is to "take measures necessary for effective protection and management of the natural environment, coordination of conservation programmes, sustainable use of natural resources, assessment of the impact of development activities on the environment and the integration of appropriate environmental provisions into development planning". In working towards achieving its mandate, the EPA enables Guyana to contribute to global environmental protection and conservation. To achieve its mandate, the Agency implements education, regulation and enforcement programmes and uses 
partnership and collaborative approaches to strengthen the impact of its interventions. Although the details have yet to be finalized, it is likely that the EPA will be the lead agency for ensuring that national and international social and environmental standards are met in all Guyana REDD+ Investment Fund funded projects.

\subsubsection{National REDD Working Group}

The National REDD Working Group (NRWG) forms a component of the Readiness Preparation Proposal, comprising representatives of the following agencies and organizations: REDD Secretariat, Guyana Forestry Commission (GFC), Ministry of Amerindian Affairs, Office of Climate Change, Office of the President, National Toshaos Council, University of Guyana and some other institutions

The NRWG, while being coordinated and chaired by the GFC, involves the input of key stakeholders. It is intended that the NRWG would also have the involvement of relevant agencies/bodies. This will be required both during consultation and outreach, as well as in the development and implementation of REDD+ activities. Social accountability for REDD+ activities will be closely monitored by the National REDD Working Group (NRWG).

\subsubsection{Low Carbon Development Strategy Multi-Stakeholder Steering Committee}

The Low Carbon Development Strategy Multi-Stakeholder Steering Committee was established in 2009 by the office of climate change to oversee the consultation and awareness process for Guyana's Low Carbon Development Strategy. The committee's functions are to:

- Provide input and guidance to the planning and execution of the sub-national consultations and education and awareness activities

- Assist in information dissemination to constituencies; and

- Assist in convening fora within constituencies to promote and discuss the Strategy

- Provide feedback on Guyana's Low Carbon Development Strategy

The committee comprises senior governmental ministers and civil servants including representatives from the Environmental Protection Agency, Guyana Forestry Commission, Guyana Geology and Mines Commission (GGMC), Ministry of Amerindian Affairs and the Office of Climate Change. It also includes non-governmental representatives from private sector 
NGOs, environmental NGOs, including Conservation International (CI) Guyana and World Wildlife Fund, Amerindian NGOs, and associations of foresters and miners.

\subsection{Identifying Adaptation Needs and Opportunities in Guyana}

The Government of Guyana is cognizant of the negative impacts posed by climate change, the precarious nature of its coastal zone and the country at large, but it has limited capacity to make the necessary investments in response to the heightened threats posed by extreme weather events associated with climate change. Particular focus was centred on the coastal plain where the majority of the people live and work. Additionally, the coastal zones are ecologically productive and economically important ecosystems which support diverse habitats including agricultural systems, a variety of species, grasslands, wetlands and mangroves, as well as employment, recreation, water-borne commerce and energy production. In general, adaptation strategies can be divided into two categories, the first of which is hard adaptation and this includes construction of sea walls or dykes, reinforcement of earthen dams and the use of sluices for drainage and irrigation, measures that are capital intensive and usually involve complex technology and infrastructure. The second is referred to as soft adaptation and this relies on natural capital, community control, simplicity and appropriateness (Grothmann \& Patt, 2003; Clark et al, 2012). This refers to how the local community use the available natural resources in a way that fits within the needs of the local people and at the same time builds resilience to climate change.

Ecosystem-based adaptation is the soft approach and involves a wide range of ecosystem management activities to increase resilience and reduce the vulnerability of people and the environment to climate change. This study examined some of the initiatives that support the ecosystem based approach and how this can be integrated into the overall adaptation strategy for managing climate change in Guyana, especially with regards to combatting the effects of coastal floods which have become increasingly frequent.

\subsubsection{Selecting an adaptation option}

Integrating adaptation within development planning is essential to achieve medium and long term targets especially at the local levels. The central idea that underpins adaptation planning is that it is a continuous and iterative series of actions to account for climate change and 
decision making. It requires regular revision as more knowledge and information becomes available and as capacities and institutions change over time. Importantly, it involves a wide range of stakeholders, not only with the Ministry of Environment but across many other Ministries at all levels, especially at local levels.

The ability to adapt to climate change depends on the extent of climate change, as well as on the availability of technical, financial and institutional capacity among other requirements. Therefore, the adaptive capacity of a location or area is a function of education, health care, financial resources, scientific information, understanding climate change, availability of technologies and scientific information (Grothmann \& Patt, 2003; Thomas \& Twyman, 2005).

The IPCC has documented that many groups, sectors, ecosystems and places are highly vulnerable to today's weather and climate and that climate change is likely to exacerbate such vulnerabilities (IPCC, 2007; IPCC, 2012). However, vulnerability assessments to date are based on a range of disparate methodologies, which makes it challenging to integrate results. Furthermore, comparable climate events can lead to dramatically different levels of impact across regions or groups. For example, communities with weak governance, little local participation, limited land-use planning and no access to insurance may be particularly vulnerable to flood damage. This suggests that if amplifiers / dampeners of vulnerability and impacts can be identified and tracked, it may be possible to better prioritize and target the most vulnerable regions, subpopulations and sectors, both for emergency preparedness and adaptation. At the same time, adaptive capacity does not guarantee adaptation actions. Adaptation occurs when the available adaptive capacity is supported by the political will and formal mechanisms that enable the adoption of planned adaptation.

Countries prepare National Adaptation Plans (NAPs) to outline a framework aimed at reducing vulnerability to climate change impacts by building adaptive capacity and resilience, and to help integrate adaptation into relevant policies, programmes and activities. Technical guidelines for preparation of such plans are available, but there are also some accompanying guidelines that are helpful in ensuring that the appropriate adaption choices are made. One such guideline is the PROVIA (Programme of Research on Climate Change Vulnerability, Impacts and Adaptation) guidance which has been approved for uses internationally by the United Nations Environment Programme (UNEP). 
The goal of the PROVIA guidance (PROVIA, 2013) is to provide clear technical guidance that combines science with what is needed locally and is meant to be useful to a wide array of audiences in both developing and industrialized countries, including researchers, consultants, policy analysts and sectoral planners (Bisaro et al, 2014).

The PROVIA guidance is structured along a five stage iterative adaptation learning cycle Fig 8).

(a) Identifying adaptation needs: What impacts may be expected under climate change? What are actors' vulnerabilities and capacities? What major issues need to be addressed?

(b) Identifying adaptation options: How can the specific risks and opportunities that were identified be addressed? There may be several options available to achieve the desired goals.

(c) Appraising adaptation options: What are the pros and cons of the different options, and which best fit the adaptation objectives?

(d) Planning and implementing adaptation actions: After an option is chosen, implementation can begin. The focus here is on practical issues, such as planning, assigning responsibilities, setting up institutional frameworks, and taking action.

(e) Monitoring and evaluation of adaptation. As measures are implemented, the process is monitored and evaluated to ensure it goes as planned, identify any problems, document the outcomes achieved, change course as needed, and draw lessons from the experience.

The adaptation process in Guyana is not expected to be as straightforward as represented in the model and in fact may require refinement through iteration. The PROVIA guidance therefore provides several entry points at various stages or sub-stages of the process, and allows users to directly access the material that meets their immediate needs. The model also differentiates adaptation situations based on the stage in the adaptation cycle, and whether the situation is public or private, and individual or collective. In addition, the guidance highlights three other key sets of empirical criteria: the characteristics of the climate risks (or opportunities) involved, such as whether they are already present; the characteristics of those affected, such as whether they are aware of the risks and have the capacity to adapt; and the characteristics of the available adaptation options, such as their relative cost and flexibility. In addition, the model also allows for use of other types of criteria such as economic theory or social psychology or for more pragmatic options such as time, skill or funding constraints. 


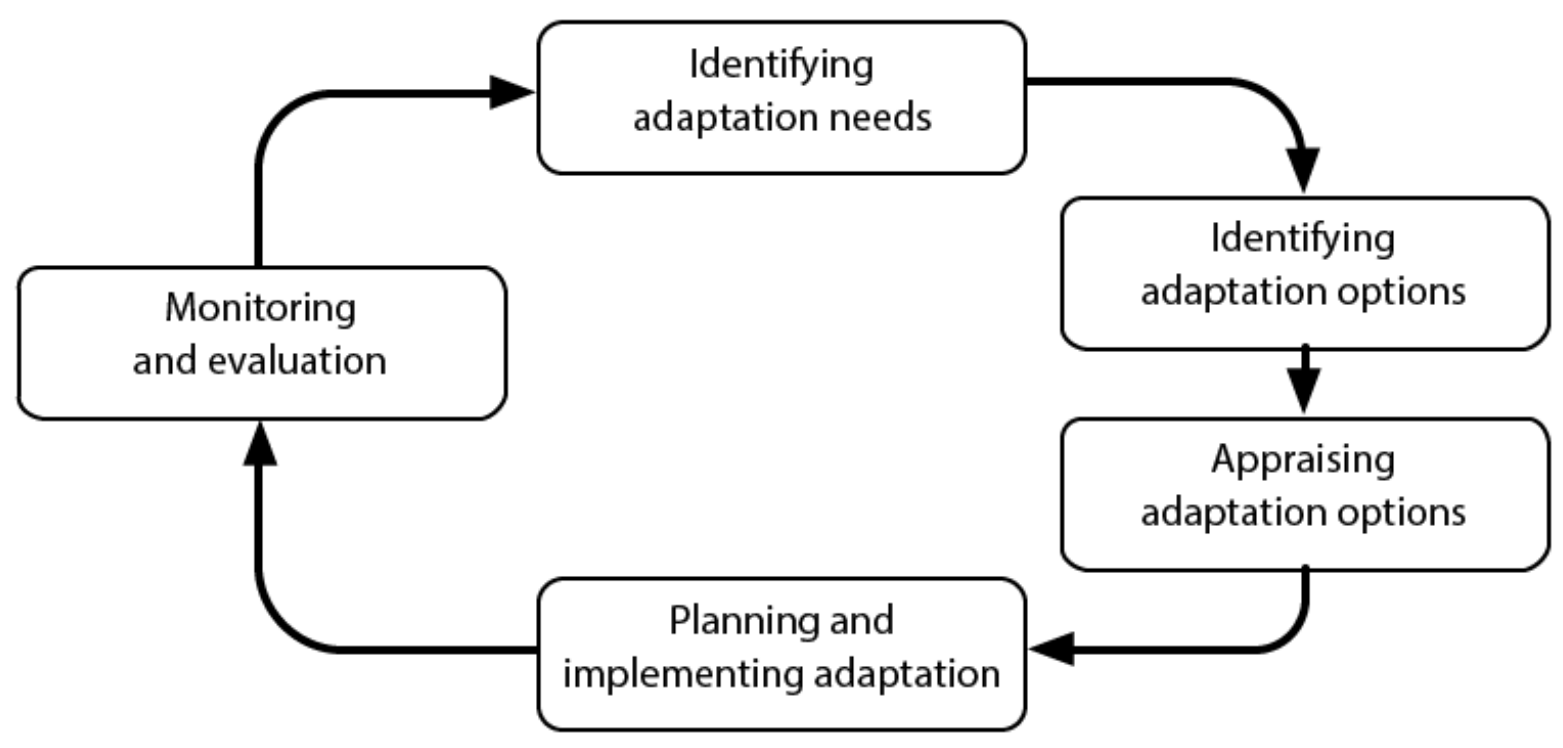

Figure 8: The adaptation cycle. Source: Hinkel and Bisaro, 2014

\subsection{Context of the Research and Specific Research Questions}

As national policies influence local adaptive capacity, the mainstreaming of adaptation into wider national development agendas is of critical importance. Ecosystem based adaptation is highlighted in this study since it has been largely missed in the design of national adaptation strategies. Additionally, information on Ecosystem based Adaptation will refine its use and help to convince decision makers by showing evidence that 'environmental infrastructure' is capable of meeting their adaptation objectives which would require a systematic consideration of the applicability, limitations and risks of Ecosystem based Adaptation options when compared to traditional approaches such as construction of dams and irrigation facilities.

The research will explore the current status of ecosystem-based adaptation within the broader adaptation strategy of Guyana, and will identify additional opportunities for inclusion of ecosystem-based adaptations. The research will consider the specific questions within the current context and status of adaptation to climate change in Guyana.

1) What are the current activities and priorities for adaptation and how can the Diagnostic Adaptation Framework (DAF) be used to guide selection of salient case-specific adaptation research in Guyana? 
2) How can ecosystem based adaptation be incorporated into the Adaptation Need (AN) and integrated into the overall adaptation response based on identified ecosystem-based projects in Guyana? 


\subsection{Materials and Methods}

The IPCC Technical Guidelines for Assessing Climate Change Impacts and Adaptations (Carter et al., 1994; Parry \& Carter, 1998) provide the basis for a large number of national climate-change vulnerability and adaptation studies. They offer a generic framework comprising seven main steps of analysis, designed to be applicable to any natural and socioeconomic system potentially affected by climate change. The IPCC guidelines are more than two decades old and have been critically analysed by many researchers over years for their suitability and applicability in addressing the complex interface between human adaptation and environmental variation (Smithers \& Smit, 1997; Klien, et al 1999; Heltberg, et al, 2009). Decision makers urgently need more science based information to help them respond to climate impacts and opportunities for adaptation and to provide more decision support for policies (Dessai, et al, 2004; Werner, et al, 2015). To help identify approaches suitable for specific adaptation challenges the Diagnostic Adaptation Framework (DAF) was developed for adaptation research (Hinkel \& Bisaro, 2014). The DAF is used by PROVIA to promote adaptation research and policies worldwide.

The emphasis of this research is on maintenance and restoration of the natural capital for adaptation using a diagnostic adaptation framework (DAF) rather than a more methodological framework as outlined by the IPCC technical guidelines. A major challenge with using a framework based upon methodological choices (e.g. the IPCC technical guidelines) is that it covers a wide range of disciplines making it difficult to follow, requires expertise in a broad range of different disciplines relevant to the adaptation question, and practitioners with that expertise employ a diversity of social and natural science research approaches. The DAF, in contrast, characterises typical adaptation challenges and discusses which adaptation approaches are applicable to meeting these challenges. In some instances more research may be needed to arrive at a solution. The DAF therefore is aimed at researchers and policy analysts who are seeking answers to challenges posed by climate change and seeking the best approaches to alleviate the anticipated or existing problems. The DAF has been used successfully in the Netherlands and used in the adaptation policy planning by the Dutch Delta Programme in the Wadden Region. It compared the research methods used in the Delta Programme with those suggested by the diagnostic framework (Werners et al, 2015). Like the Netherlands the Coast of Guyana lies below sea level and is very vulnerable to the effects of climate change such as sea 
level rise. Therefore, adaptation needs in the Netherlands related to sea level rise are expected to parallel those in Guyana, and the DAF would seem an appropriate tool to support decision makers who require more science based information to help them respond to climate change impacts and opportunities for adaptation.

The DAF calls for an iterative process and allows for more flexibility and adjustments when developing a strategy to address a particular adaptation challenge (Klien et al, 1999; Hinkel and Bisaro, 2014). The DAF asks a series of questions aimed at the development and evaluation of five steps in an adaptation cycle: (i) identifying adaptation needs, (ii) identifying adaptation options (iii) appraising adaptation options, (iv) planning and implementing adaptation and (v) monitoring and evaluation. The adaptation cycle (Figure 8) can be entered at any point. For the purposes of this research, the cycle was entered at the point of identifying adaptation needs. Analysis was restricted to identification of needs, identification of adaptation options, and finally appraising those adaptation options. Discussion touches upon planning and implementation of adaptations and monitoring and evaluation, but these were not central to the research.

\subsection{Overview of the Application of a Diagnostic Adaptation Framework for}

\section{Guyana}

The approach taken to identify adaptation needs, to identify adaptation measures, and to appraise adaptation options was based upon the framework developed by Hinkel and Bisaro (2014), and modified for the current research context (Figure 9). The framework indicates anticipated outcomes of the analysis (nature of outcomes) that will form the basis for the Results and Discussion section of this thesis.

The framework distinguishes between adaptation challenges researched, methods used and the criteria applied for choosing a particular method. In the operational use of the framework, adaptation challenges are studied by identifying and classifying the research questions that frame the research. Adaptation challenges are further classified according to whether private or public interests are involved and whether individual or collective action is sought for the respective action. 


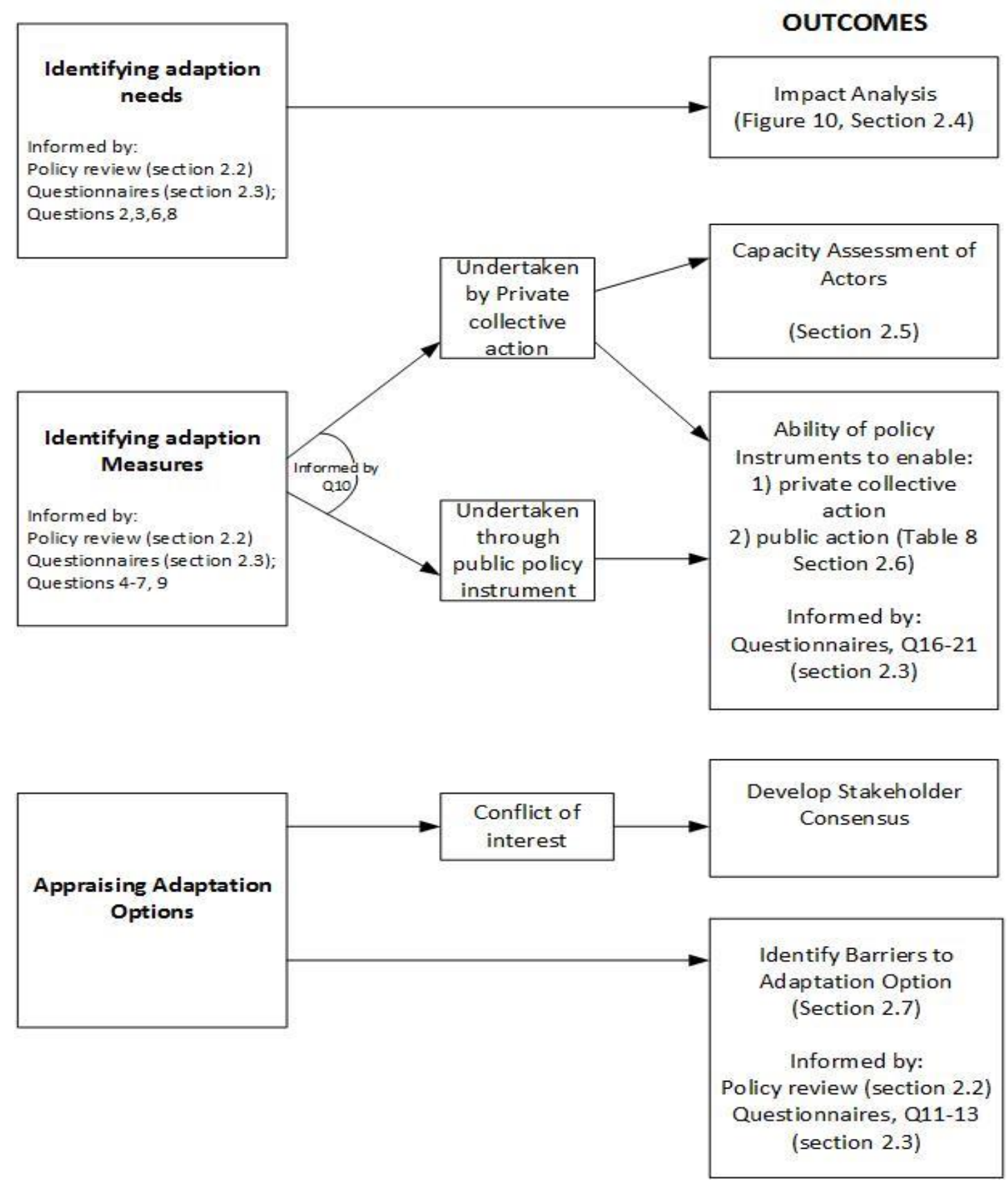

Figure 9: Identification of Adaptation Needs, Measures and Options and analysis of outcomes. Source: Modified from Hinkel and Bisaro, 2014 
To identify adaptation needs, an initial broad list of considered or perceived needs was constructed through review of policy documents (Section 2.2) and through responses to questionnaires completed by individuals working within Ministries of the Guyana government (Section 2.3). This list of adaptation needs was then assessed to determine whether a credible impact analysis has been completed (Figure 10, Section 2.4), and if not, to identify areas of consideration necessary to better understand the nature of a perceived adaptation need (i.e. the information that must be collected to clarify the need).

Next, adaptation measures were considered. These are the possible activities or solutions that might be employed to meet an adaptation need. Adaptation measures may be infrastructurebased, ecosystem-based, or blended. Potential adaptation measures were identified from review of policy documents and responses to questionnaires (as above). For a given adaptation need, possible ecosystem-based and infrastructure-based measures were considered. For each measure, a determination was made as to whether the measure would be implemented by private collective action (adaptations involving a single large private actor will not be considered), or through public policy instruments. In parallel, an assessment of public policy was completed with respect to how relevant policy would enable (or constrain) private collective or public action (Section 2.6).

The final component of the research was appraising adaptation options (measures) to identify barriers to implementation. Barriers might arise from conflicts of interest among stakeholders. Predicting these would require an extensive analysis to identify all affected stakeholders and understand their needs and concerns. Such an analysis was beyond the scope of this research. However, other potential barriers to implementing a given adaptation option (e.g. structural, funding, training) were analysed (Section 2.7).

\subsection{Identifying Guyana's adaptation priorities through review of key policy and strategy documents}

In 2010 the UNFCCC recommended the national adaptation plan (NAP) process for Least Developed Countries (LDCs) under the "Cancun Adaptation Framework" (CAP). The process enables the LDCs to formulate and implement national adaptation plans (NAPs) as a means of identifying medium and long-term adaptation needs and developing and implementing strategies and programmes to address those needs. Guyana is not categorized as a LDC but is 
currently developing a similar plan known as the "Climate Resilience Strategy and Action Plan (CRSAP)" to provide a comprehensive framework for addressing climate change adaptation and resilience in Guyana.

Several other policy documents, referred to below, were developed which address major areas that relate to the natural environment, climate policy and biodiversity conservation. These policy documents all focus on future national economic development but were created within a framework that attempts to define sustainability and provide some safeguards for conservation and better use of the country's natural resources. The selected documents were screened for adaptation projects and initiatives because they were structured and written based on the integration of natural resource management and national development policy. The documents were selected that are related to the natural resource sector and were reviewed to identify activities related to climate adaptation. These include projects, policy statements, and policy instruments, available or proposed. Even though ecosystem-based adaptation was not directly identified in these documents, some of the suggested projects encapsulated the essential principles of ecosystem-based adaptation in their core activities that is the use of natural capital with regards to climate change and disaster risk reduction. This information is presented in a piecemeal manner and disjointed from a coherent plan of action to address climate change. The key documents listed and described below, were selected for review and provided a better understanding of the capacity for ecosystem-based adaptation and how this can be integrated into an overall adaptation strategy for Guyana. More specifically, the research identified the extent to which ecosystem-based adaptation is being considered and addressed within a climate change framework and what gaps exist that will inhibit a successful adaptation strategy.

Ecosystem-based adaptation has its core principle the use of biodiversity and ecosystem services to reduce adverse impacts and enhance resiliency. It is usually described as the "soft" adaptation approach as compared to hard adaptation which requires the construction of heavy infrastructures such as dams, seawalls (dykes), empoldering or complicated drainage and irrigation structures (Mimura et al 2010; Sovacool, 2011; Clark et al, 2012). The analytic reviews were done with this in mind, that is enhanced management of natural resources can provide a tool for vulnerability reduction. From each document, the projects and deliberations that focused on natural resource management were extracted and synthesized into a framework for a strategy on ecosystem-based adaptation. Since ecosystem-based adaptation is considered a 
relatively new strategy, this concept was not mentioned directly, but activities and projects that relate to conservation of natural resources, improved crop varieties, water management and rehabilitation of degraded ecosystems were extracted and included in the framework for ecosystem-based adaptation to climate change. Within the context of suggesting cost-effective climate change adaptation strategies the conservation of natural buffers for ecosystem-based adaptation was also viewed from a co-benefits approach that will promote biodiversity conservation, poverty alleviation, and enhanced sink capacity.

The policy documents reviewed were:

(a) The Low Carbon Development Strategy (LCDS) (2010): Climate change comes directly under the Office of the President in Guyana and the LCDS originated from same Office with input from a wide range of institutions and stakeholders. The document outlines the country's strategy for protection of its pristine rainforests, for making investments in low deforestation and for building a low carbon, climate-resilient economy. The document was finalized after about one year of consultations with communities across Guyana in addition to inputs from the United Nations and consultation with professionals involved in other climate change initiatives. It sets out a strategy to forge Guyana's low carbon development and identifies priorities for an initial period of ten years within a framework that allows for further consultations for a more long term approach.

(b) National Adaptation Strategy: To address climate change in the agriculture sector of Guyana (2009): This document examines Guyana's agriculture sector within the current global and local context, and identifies institutions and stakeholders involved in the adaptation initiatives. It also looked at the barriers and opportunities to climate change adaptation and recommendations for improving adaptation responses. This document was prepared by independent consultants commissioned by the Caribbean Community Climate Change Centre (CCCCC) under the Mainstreaming Adaptation to Climate Change (MACC) Project. The Caribbean Community Climate Change Centre coordinates the Caribbean region's response to climate change and it is the key node for information on climate change issues and on the region's response to managing and adapting to climate change within the Caribbean Community. The study attempted to identify and understand the integration of agricultural development and national policy in 
Guyana and examined the challenges and opportunities faced by the agricultural sector as a result of climate variability. It also identified options and opportunities for improving the adaptation responses to climate change together with the stakeholders and respective institutions in the associated adaptation activities. There were no projects that dealt specifically with ecosystem based activities.

(c) National Mangrove Management Action Plan (2010 -2012): The major objective of this plan is to respond to climate change and mitigate its effects through restoration and protection of Guyana's mangrove ecosystems so that the ecological functions are maintained and there is a continuation of vital services such as protection against ocean surges. The Plan was funded by the European Commission's Global Climate Alliance linked to sustainable coastal zone management and prepared with the input of several key institutions involved with the management of mangrove forests. These included the Guyana Forestry Commission (GFC), National Agricultural Research and Extension Institute (NAREI) and the Ministry of Works and Hydraulics (Sea Defences). Due to the fragmented nature of the existing legislation mangrove conservation and management is the responsibility of several institutions. Apart from the national institutions already mentioned, the Guyana Environmental Protection Agency also shares responsibility for the management of mangroves.

(d) Integrated Coastal Zone Management Action Plan (2000): This plan outlines a coordinated effort for an integrated approach to coastal zone management and promotes and supports sustainable development of coastal resources. Effective management and protection of the coastal zone is crucial to guard against the effects of sea level rise and coastal flooding. The Action Plan originated from the Environmental Protection Agency and the preparation was coordinated by an Integrated Coastal Zone Management Committee (ICZMC). The document was approved by the country's Cabinet in 2001. The document outlines the specific roles of key institutions in the implementation of activities cited in the plan, with overarching goals being to promote sustainable development of coastal resources and to main the integrity of coastal ecosystems.

(e) National Biodiversity Action Plan II (2007-2011): The document originated from the Environmental Protection Agency which is the focal point for biodiversity conservation and the sustainable use of natural resources. The strategy was prepared in keeping with 
Guyana's commitment to the Convention on Biological Diversity (CBD) and it focuses on conservation and sustainable use of Guyana's biodiversity and sharing of benefits, with emphasis on critical resources such agricultural lands, forests, and coastal, marine and freshwater systems. Financial support for preparation of the strategy was provided by the World Wildlife Fund for Nature (WWF). The Environmental Protection Agency coordinated the activities for the preparation of the plan. This was done through a consultative process with stakeholders, including indigenous communities, from across Guyana.

Other subsidiary documents reviewed included: (i) An assessment of the economic impact of climate change on the coastal and human settlements sector in Guyana (ECLAC, 2011), (ii) Poverty Reduction Strategy Paper (IMF, 2006), (iii) Thematic Study of Mangroves in Guyana (FAO, 2005), (iv) Shell Beach Protected Area Management Plan (PAC, 2014) and (v) Guyana Second National Communication to the United Nations Framework Convention on Climate Change (Government of Guyana and UNDP, 2012). The review identified the projects and programmes that utilize natural systems and relate to ecosystem-based adaptation activities in areas of sustainable water management, mangrove restoration, agricultural systems and protected areas.

\subsection{Administration of Questionnaires}

A questionnaire was developed to complement and supplement the findings from the review of policy documents (2.3.1). Significant resources and programmes already exist within the various Ministries and Organizations which can contribute to driving the design and implementation of ecosystem-based approaches. Face to face interviews were not done because no visits were made to Guyana during the research. A variety of factors, however, influence the extent to which the interest in this activity has been embedded into existing programmes and the questionnaire was designed to gather additional information to support and fill the gaps observed from the analytic reviews of the policy documents. The aim was to survey existing and planned adaptation strategies to cope with climate change impacts in Guyana on key sectors, namely forest and forestry, agriculture, water, the environment and local government among others. It covered areas related to level of awareness with regards to climate change and adaptation, funding schemes, incentives, community and government partnerships and barriers to the 
adaptation process. The additional data gathered was linked to each ecosystem-based project identified in the policy documents to give a sense of readiness and likelihood of successful implementation of the projects. Responses gathered supported various aspects of the Diagnostic Adaptation Framework, including: identification of adaptation needs (Questions 2, 3, 6, 8), identification of adaptation measures (Questions 4-7, 9), need for private collective action versus public-policy based action (Question 10), the ability of relevant policies to enable or constrain necessary private collective or public policy-based action (Questions 16-21), and identification of barriers for adaptation measures (Questions 11-13).

All of the information gathered from the survey was kept confidential and kept among the respondent, the researcher and his thesis supervisors. Survey responses were presented in aggregate so no individual respondent could be directly identified. Since the study involved the participation of humans, a formal application was made to the Research and Ethics Board (REB), Ryerson University, prior to administration of the questionnaire. The application went through a rigorous screening process after which approval was granted by the REB to proceed with the research. The questionnaire was then uploaded to Survey Monkey, an online survey platform. An invitation and consent form were sent to selected individuals in organizations and Ministries whose work relates to climate change in Guyana. Each participant who returned a signed a "Consent Form" then received access to the survey.

The survey was administered by an online platform, SurveyMonkey, and the participants selected were government employees and people working with environmental non-governmental organizations (NGOs) who have at least five years of experience in natural resources or related sectors. Twenty participants were selected of which seventeen were government employees, and three were from NGOs. The inclusion criteria were based upon my experience working in Guyana and the participants were selected based on a wide range of experiences, which is, from five years to as much as twenty five years and covered participants' knowledge in disciplines related to climate policy, governance, biodiversity, meteorology and coastal zone management. The participants were selected from organizations that are closely related to the policy documents and in some cases the selected policy papers originated from those institutions. 


\subsubsection{A modified Version of the questionnaire}

reference.

A compressed reproduction of the questionnaire is provided here for convenient

Please indicate $(\mathrm{x})$ in the list below and elaborate (optional).

1. Are there any expected impacts of climate change that are directly related to your Ministry's mandate?

[ ] many

[] some

[] only few

[ ] not at all

If yes, can you identify the impacts (in space below) that are anticipated, maybe in decreasing level of severity?

2. From your Ministry's perspective, why is climate change important? Click all that apply and write a number, to the left of your selection, indicating the relative importance to your Ministry's mandate. (Use a ranking between 1 and 5 with $1=$ most important and $5=$ least important).

[ ] is not important at all

[ ] affects productivity

[ ] affects the conservation of soil

[ ] affects provision of drinkable water

[] affects wildlife habitat

[ ] affects suitability for non-timber forest products

[ ] affects suitability for environmental services

[ ] affecting pests, diseases and weeds

[ ] affecting abiotic damages (e.g. fire or storm risks)

[ ] reduce regeneration success

[ ] affects the planting season

[ ] changes in wood quality/seed quality/water quality

[ ] crop yields

[ ] flood control

[ ] human and domestic animal diseases

[ ] incidences of heat stroke

[ ] increases erosion

[ ] other effects which ones? Please specify:

3. What are the main vulnerabilities/problems perceived that affect your Ministry? Select all that apply

[ ] Increased precipitation

[ ] Decreased precipitation

[ ] Increased variability in precipitation

[ ] Decreased runoff

[ ] Increased runoff

[ ] Increased variability in runoff 
[ ] Declining surface water quality

[ ] Increased risk of floods

[ ] Sea level rise

[ ] Decreased groundwater recharge

[ ] Increased in temperature in the atmosphere

[ ] Extreme weather events (thunderstorms, lighting, freak storms)

[ ] Increased incidences of unknown diseases (e.g. chikungunya)

[ ] Changes in biodiversity

[ ] Others (please identify)

4. My research will focus on ecosystem-based adaptation priorities and strategies in Guyana. By "ecosystem-based adaptation", I mean managing the ecosystem to increase resilience and reduce the vulnerability of people and the environment to climate change. Within your own Ministry, how often is ecosystem-based adaptation distinguished from 'traditional adaptation' (e.g. upgrading infrastructure)?

[ ] Not at all

[] Always

[] Sometimes

5. Considering the adaptation priorities of your Ministry, how much focus is there on ecosystembased adaptation versus traditional adaptation?

[ ] Not at all

[] Less focus on ecosystem-based adaptation

[ ] Focus is evenly divided between ecosystem-based and traditional adaptation priorities

[ ] More focus on ecosystem-based adaptation

[ ] Focus is entirely (or almost entirely) on ecosystem-based adaptation

6. What are the main adaptation objectives within your Ministry? Please select all that apply and give a number ranking, to the left of your selection. (Use a ranking between 1 and 5 with $1=$ most important and $5=$ least important).

[ ] better flood control

[ ] better coastal zone management (reinforced sea walls)

[ ] better management of litter

[ ] modification of buildings to withstand flooding

[ ] Appropriate crop varieties for floods / drought

[ ] green buildings

[] conservation of mangroves

[ ] no defined adaptation objectives identified within the Ministry

[ ] other (please identify)

7a. Based on your response to Question 6, your Ministry may have defined adaptation objectives. Are adaptation measures in place that will help meet these objectives? Please select all that apply

[ ] adaptation measures already in place

[ ] potential for short term (1-2 years) adaptation strategy

[ ] potential adaptation strategy in the long term (3-5 years) 
7b. If adaptation measures are currently in place, please identify what those measures are:

7c. If adaptation strategies are anticipated within the next 5 years, please identify what measures will be implemented (anticipated) as part of those strategies.

8. If adaptation measures are in place, or anticipated within the next 5 years, what stimulated the adoption of these measures? Select all that apply.

[ ] extreme weather events and flooding

[ ] research results and meteorological data

[ ] policy and legislation

[ ] risk assessment and cost benefit analysis

[ ] other (please identify)

9. Would the types of adaptation measures in place or those anticipated to come on stream promote ecosystem resilience i.e. qualify as ecosystem-based adaptation?

[] Yes

[] Some would

[] No

10. Will the adaptation measures in place (or anticipated) require community engagement to be successful (i.e. will people have to change their behaviour in order for your objectives to be met)?

[] Yes

[] No

11a. If you answered "Yes" to Question 10, are there adequate incentives for communities to implement measures for adaptation to climate change?

[] Yes

[] No

11b. Please identify some of the incentives in place (or proposed) that encourage community participation in adaptation measures

12. Do you think there is a successful partnership between the government and communities for adaptation to climate change?

[] Yes

[] No

[ ] In some cases (briefly explain)

13. What barriers to community participation would you identify? What might prevent a positive response to incentives (listed in response to Question 11b) would you identify?

[] Lack of knowledge and awareness about climate change

[ ] Focus on personal economic well-being

[ ] sense of resignation, it is not my problem therefore lack of cooperation

[] lack of adequate funding from government and donors

[ ] lack of proper legislation / data validation 
[ ] Inadequate support to implement incentive program

[ ] Lack of good and convincing examples?

[ ] Skepticism of need

[ ] Other (please identify)

14. How do the respective strategies (Mangrove Action Plan, Biodiversity Strategy, and Poverty Reduction Strategy Paper) support the short-term and long-term adaptation initiatives of your Ministry?

[ ] very supportive

[] supportive

[ ] not supportive

15a. Have the above strategies been embedded in existing policies of your Ministry?

[] Yes

[] No

15b. Please provide any examples you have of how these strategies have been embedded in policies of your Ministry.

16. Do you think there is appropriate funding coming from internal and external sources for action on adaptation (select any that you believe apply)?

[ ] Internal funding level is appropriate

[ ] Internal funding level is inappropriately high

[ ] Internal funding level is inappropriately low

[ ] External funding level is appropriate

[ ] External funding level is inappropriately high

[ ] External funding level is inappropriately low

17. Do you think more regional projects with the Caribbean Community (CARICOM) partners will benefit adaptation in Guyana?

[] Yes

[] No

Why would you say yes or no? Can you please identify any CARICOM project that benefitted adaptation?

18. Do you believe financial incentives to communities, for attainment of targets linked to adaptation to climate change, will encourage successful adaptation to climate change?

[] Yes

[ ] No

If yes, what types of incentives do you believe would be most effective in engaging communities to achieve adaptation targets?

19. Do you engage in activities that directly or indirectly influence public policy on adaptation to climate change? Please select all that apply.

[ ] Direct engagement with policy makers

[ ] Direct engagement with donors (individuals or organizations) 
[ ] Letters in newspapers, opinions, editorials

[ ] Public lobbying

[ ] Engagement with your immediate supervisor

[] No

[ ] Other (please identify)

20. Do you think more funding needs to be drawn in for Guyana to successfully adapt to climate change? If yes, please identify the funding sources that you believe need to be expanded for successful adaptation.

[ ] Government funding from budgetary resources

[ ] Internal private funding (individual, corporate, government)

[ ] External private donor funding (International Non-Governmental Organizations, Foundations, International Financial Institutions)

[ ] External donors

[ ] Any other (please identify)

21. Earlier in the survey you identified the main priorities for adaptation within your Ministry. You were also asked to identify any barriers for community engagement in adaptation measures. This final question asks you to identify obstacles for successful implementation of your Ministry's adaptation strategies. There may be some overlap with your response to Question 13, but there may also be some institutional or funding barriers that you identify here. Please rank those that you would consider to be obstacles by putting a number to the left of your selection. (Use a ranking between 1 and 5 with $1=$ most important and $5=$ least important).

[ ] Political directives

[ ] Non-cooperation/support from organization's management

[ ] Inadequate resources (including financial resources)

[ ] Lack of adequately trained staff

[ ] Inappropriate incentives to communities

[ ] Lack of public awareness / interest

[ ] Inappropriate policy / legislation to achieve objectives

[ ] Regulatory hurdles

[ ] Shifting priorities, changing focus of government

[ ] Lack of adequate and timely planning

[ ] Too little or no consultation with the communities

\subsection{Impact Analysis}

An impact analysis was done for each of the selected adaptation challenge and a series of questions were asked to gather data on the adaptation challenge that is addressed by a given project (ongoing or proposed). What research questions are raised, if any, the approach applied and the results achieved and the criteria applied for selecting the questions and approaches. When choosing approaches a variety of criteria can be selected as outlined in Figure 10, to determine what was already done and what else is required in addressing a particular challenge. 
Impact studies and models were examined for credibility and the need to gather additional data on these studies if required. This was to ensure that the representative range of uncertainties for climate and socio-economic scenarios were addressed. Additionally, when one or more studies were available an analysis was done to look for ambiguity and conflicting results. In the absence of comprehensive studies projections were made on future impacts within the full uncertainty range to project potential impacts within what is considered reasonable limits.

Where impact models were absent, risks were characterised by data gathered from data trends from climate sensitive information such as rainfall drought and extreme weather with support from data gathered from the survey questionnaire. 


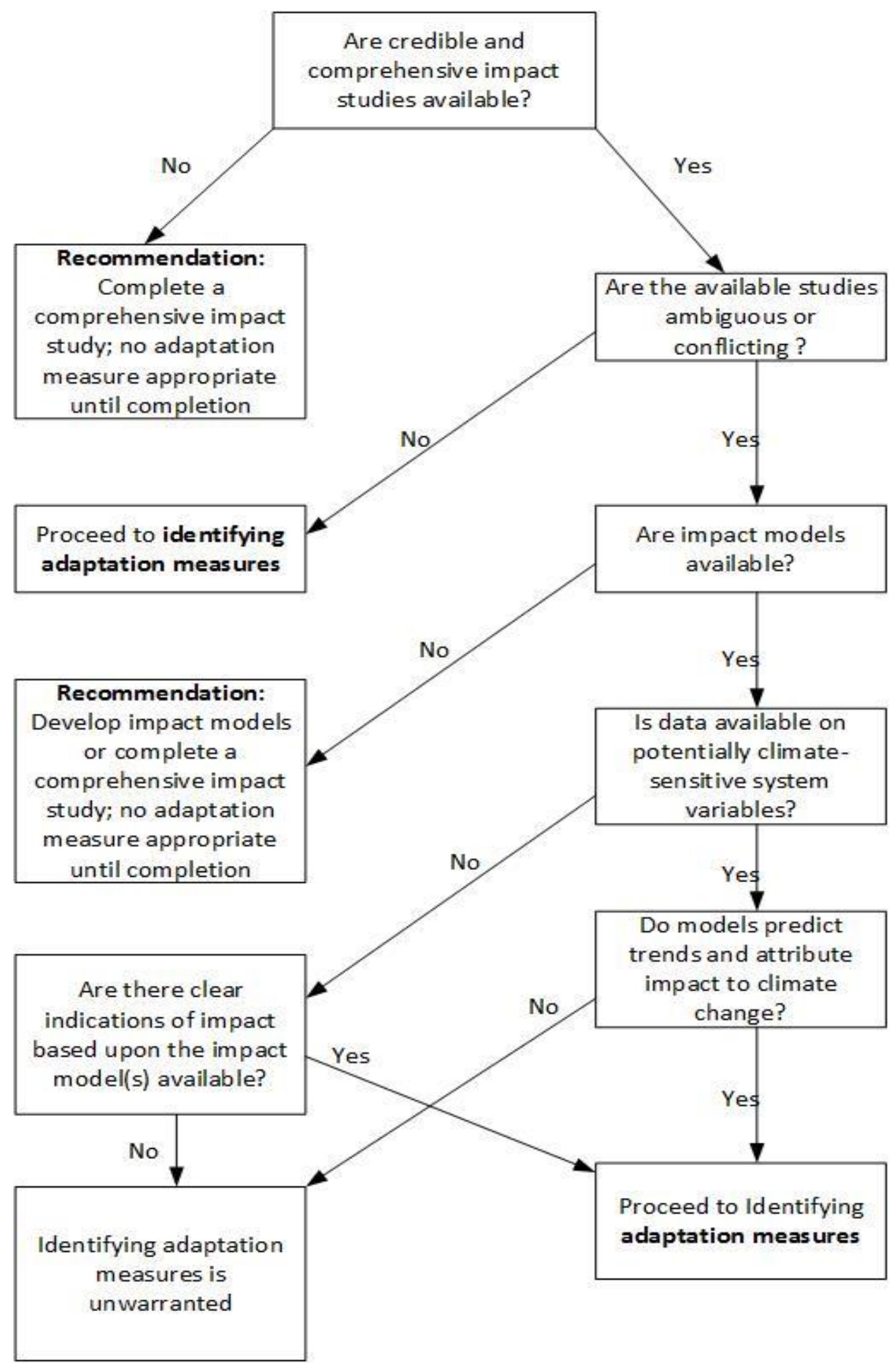

Figure 10: Criteria for choosing salient approaches to impact analysis and for identifying adaptation measures 


\subsection{Capacity Assessment of Actors}

Capacity to implement adaptation is critical for implementation and includes financial, human and technical resources, including availability of appropriate technology. Guyana does not always possess the requite capacity to successfully implement the needed projects. Analysis of capacity refers to the availability of resources of all kinds that are required if an intervention is to be made to change an adaptation need (AN). An analysis was made of the natural, financial, human resources and institutions based on the selected adaptation measures (AM) that were identified. One of the most important capacity requirements is the availability of adequate funds for the AN, therefore an evaluation was made of local budgetary funds, support from international financial institutions (IFIs), and financial inputs from private collectives such as local and international non-governmental organizations (NGOs), communities and companies. A complete analysis included both private individuals and public actors to ensure that the inputs from each are clear. Private individuals are usually aware of their own capacity and often come with their own funds. Despite this, some AN activities may require public inputs and public action, depending on the nature of the AN under consideration.

Some of the data gathered from the survey was used to better understand the level of financial needs, education, training needs, and other available skills. Information was also gathered from Guyana's National Capacity Self-Assessment (NCSA) Report for the UNFCCC (Stock-Taking and Thematic Assessments) and the NCSA cross-cutting Assessments. These strategy documents were prepared to meet the capacity needs of the three Rio Conventions and were supported with funds from the Global Environment Facility ${ }^{47}$. The NCSA revealed a lack of human, financial and technical capacity to successfully implement projects in support of the Rio Conventions. Additional indications of capacity related to existing or recent programs that undertake activities relevant to an identified AM (e.g. current large-scale programs in restoration of mangroves). Success or failure in these programs would indicate level of capacity to undertake similar activities for purposes of adaptation.

\footnotetext{
${ }^{47}$ National Capacity Self-Assessment in Guyana, Environmental Protection Agency, Guyana (2007) Available at: https://www.thegef.org/gef/guyana-ncsa (Accessed on June, 2015)
} 


\subsection{Assessing Ability of Policy Instruments to Enable Necessary Action}

The policy documents that were reviewed all outlined key strategies that address various aspects of environmental management and referred to climate change and adaptation with varying emphasis. It is obvious that the impacts of climate change have been recognized and the political support is inherently expressed to implement the strategies outlined in the documents. Political support is evidenced from the speeches made by politicians, both from the government and the opposition, to support projects on climate change adaptation. Additionally, the policy documents reviewed were all endorsed by the Cabinet of the Guyana government, effectively granting approval to these policy documents and clearing them for implementation. The ability of the policy instruments to enable or deliver on actions outlined in the respective strategies pivots around governance which is still largely driven from the central government. Budgetary allocations and expenditure are controlled by the Centre; the most senior regional public servant is employed by the central government and reports directly to the Minister responsible for regional and local government; and the laws which the regional and local authorities administer are initiated, enacted, and imposed by the Centre. It follows, therefore, that no matter what the political allegiance and complexion of the regional and local governments; the economic and social decisions which influence and control the lives of their citizens are made by the central government where the funding is provided.

The projects identified in the various sectoral policies however encouraged collaboration among Ministries and Agencies and emphasized training, especially in Information Technology (IT), to meet the needs of communities nation-wide. Reference is also made to the strengthening of key agencies such as the Environmental Protection Agency to meet the national and international social and environmental standards set by the GRIF investments. In the case of small enterprise development, there are incentives in the form of grants, a mutual grantee fund and skills development and capacity building in agencies responsible for small and medium enterprise development. Guyana's Small Business Act of 2004 establishes the Small Business Development Fund and a Small Business Council (LCDS, 2010). The bureau of this council supports the inclusion of vulnerable groups and works with rural women's groups and the Ministry of Agriculture.

Given the concern about climate change, the complexity of the science and the importance of adaptation, the contributions and participation of both the Government and private 
citizens are crucial to successfully address the problem. This needs a coordinated strategy that would encourage mainstreaming of climate change with the various Ministries, the local governance structures and the inclusion of civil society.

The policy documents were prepared with a focus on a Government driven initiative, and even though local participation is strongly encouraged adequate incentives to stimulate such participation are not adequate. Policy and planning with regards to project implementation is largely the responsibility of the central government especially for climate change which is considered a national issue. Regional and local initiatives are encouraged but due to lack of adequate financial and technical capabilities the support from the central government is always needed. There needs to be more autonomy at the local level especially with regards to the design, funding and execution of adaptation projects at the regional and local levels.

Local participation is most meaningful when this is done by a Non-Governmental Organization (NGO) with financial support from a local or foreign donor agency. This is evidenced by the success of some local conservation NGOs for sea turtles, wildlife and mangroves. There have been several successful NGO driven projects either alone or in partnership with the Government. The Mangrove Action Plan is a good example of a private collective and the Government. The project received finding from the European Union but it is managed by a private individual who donates her time and expertise to the project. She enjoys a lot of flexibility in her work and has been successful in gathering the support and participation of a large number of private citizens in the project. The Mangrove Rehabilitation Project was successful in training the local people in mangrove nursery management, planting and husbandry practices, therefore building the technical capacity required for implementation of the project and sharing the knowledge for similar activities at other locations.

\subsection{Identifying Barriers to Adaptation Options}

The identification of barriers focussed on the adaptation options selected for further appraisal and possibly planning and implementation. A careful analysis was made of the potentially challenging obstacles that can be overcome for possible implementation of the AN option. The barriers were examined from three perspectives (a) the people involved and the context within which they act such as governance (b) the system or area of concern such a better shoreline management and (c) the needs that are required such as funding and prioritization. 
Information gathered from the survey, particularly questions 11-13 were carefully analysed to identify potential barriers and where the focus has been on community involvement, use and availability of adequate incentives and the forging of partnerships to achieve the maximum output from the selected AS option. Barriers were also examined within the context of section 2.6 which refers to the use of policy instruments and legislation that may affect the implementation of certain actions.

\subsection{Results and Discussion}

Some of the policy documents reviewed are due for revision, such as the Integrated Coastal Zone Management Plan which is now fifteen years since it was prepared. Much has changed since then as with some other policy instruments with regards to the political vision, the legislation and more knowledge about climate change. When the documents were analysed for policy direction on climate change adaptation only the LCDS, The National Adaptation Strategy to Address Climate Change in the Agriculture Sector of Guyana and The National Mangrove Management Action Plan contained policy guidance directly aimed at adaptation to climate change. Most of the information was gathered from these three policy documents. It is expected that "Climate Resilience Strategy and Action Plan (CRSAP)", now under preparation, is likely to be a more coherent document with practicable guidance on climate adaptation policies.

At the conclusion of the survey twelve (12) responses were received from 20 respondents that were targeted and attached to the various Ministries, organizations and NGOs closely associated with climate change and the natural resource sector of Guyana. The online platform SurveyMonkey was used and the responses was analysed as an aggregate. Only one NGO submitted a response.

From the reviews, available data, and from the surveys, four climate vulnerabilities were identified (Figure 11) and considered important for adaptation actions since their impacts can cause significant damage to the economy and to livelihoods. The vulnerabilities include: sea level rise, flooding, drought and extreme weather events. Even though these were previously identified as important threats based on the frequency of occurrence, the survey indicated the respondents' views on these threats which were considered critical for action to be taken. Adaptation planning for climate change must therefore be engaged with these threats and the impacts caused on socio-economic sectors and the natural ecosystems. Information gathered 
from the policy reviews and the survey questionnaires also highlighted the need for more public awareness, interagency collaboration, research, human resource capacity, regional cooperation, incentives and more technical and financial support to combat the threat of climate change. Adaptation to climate change activities are largely driven by the government, therefore efforts should be encouraged for more private collective action.

The rationale for integrating adaptation into policies and development strategies is underlined by the fact that increased resilience to climate variability and change can generally further development objectives (Tompkins \& Adger, 2003). This is especially important for countries such as Guyana where the coastlands are below sea level and face frequent threats of flooding from increased precipitation and overtopping of sea defences due sea level rise. Adaptation calls for natural resource management, the development of social and human capital and strengthening of institutional systems (Adger et al, 2003). With such practices communities become more resilient to climate variability and change, hence the inclusion of climatic risks in the design and implementation of policies is vital to reduce vulnerability and enhance sustainability. Ecosystem degradation and vulnerability to climate change are development issues rather than strictly environmental problems (Vignola, et al, 2012). As the loss of natural capital and the associated vulnerabilities are a threat for sustainable development, national development policies should integrate ecosystem management and adaptation to climate change. Efforts should also be made for more participation and involvement of private collective actions since households and communities in Guyana were found to be active agents in the management of vulnerability (Pelling, 1997).

Adaptation initiatives have been described as "slow" by the respondents to the questionnaires, in Guyana and community participation is very low. One respondent stated that "successful adaptation initiatives are driven by some economic incentive or an experience of a disaster (e.g. flood / drought) and not necessarily of the need to adapt”. The respondent further stated that "this can be observed in the Mangrove Management project, whereby, communities have suffered economically as a result of the loss of mangrove forests and are more vulnerable to sea level rise and storm surge. This has led to successful community participation in the project". Lack of knowledge and inadequate or absence of incentives were mentioned as two of the main reasons for lack of private participation. 


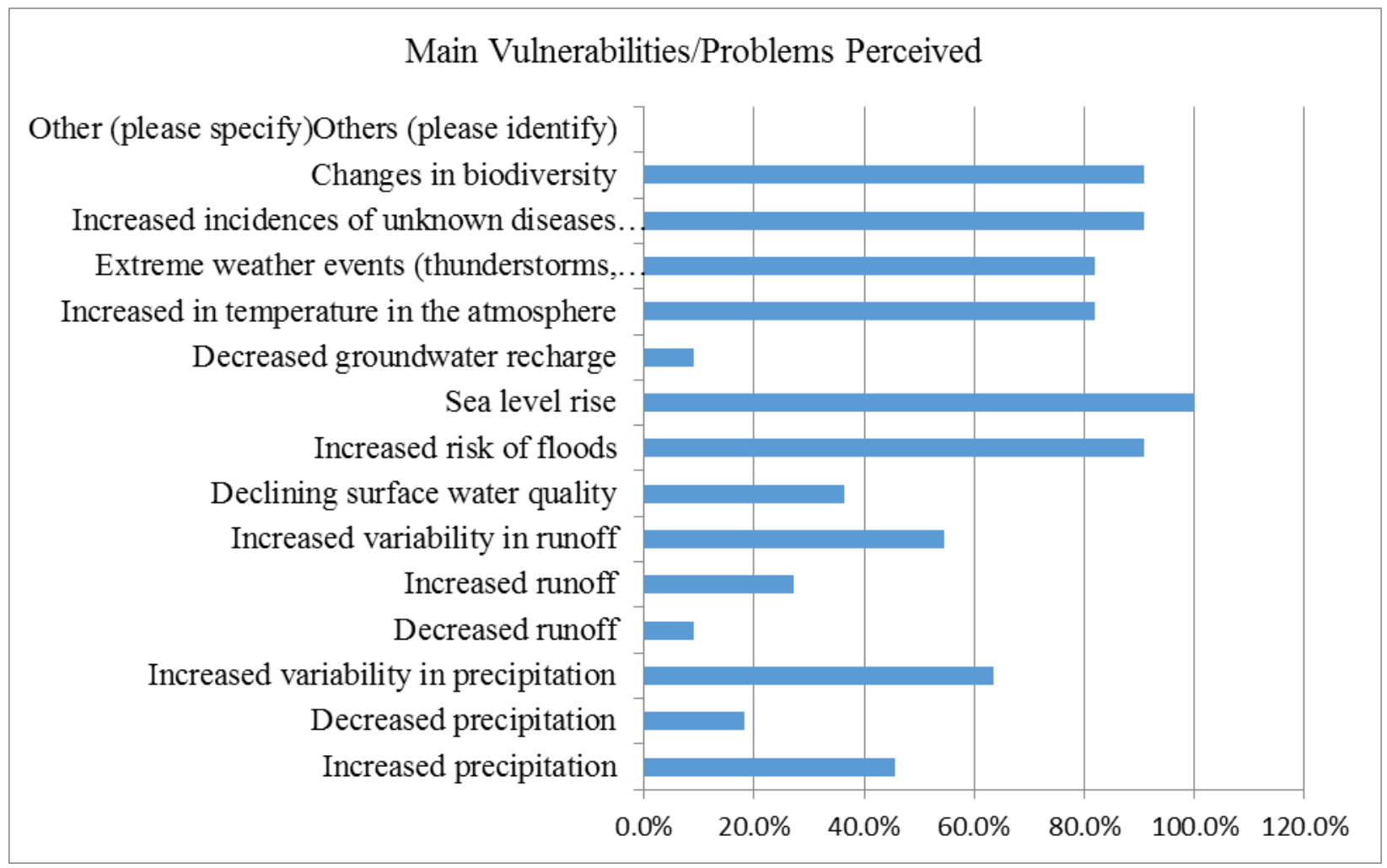

Figure 11: The main vulnerabilities identified in the survey questionnaire

\subsection{Identification of Adaptation Needs}

Adaptation needs were assessed keeping in mind the climate threats that were identified and the various sectors that are likely to be most severely impacted both in terms of vulnerability to climate variability and the effects on livelihoods. Guyana has made some advances in terms of defining its adaptation priorities, developing strategies and policies, and proposing actions. The coastal and agriculture sectors appear to be the highest priorities, considered in key documents such as those listed in Section 2.2. Moreover, some action is already taking place in coastal infrastructure, with a large conservancy project funded through the Special Climate Change Fund administered through the Global Environment Facility under the auspices of the UNFCCC. Further, Guyana has proposed a number of specific projects to be financed by Fast Track financing and other funding included in the Copenhagen Accord (Keller et al, 2011).

Since accepting the Doha Amendment in 2014, this has paved the way for development of more adaptation projects and further access by Guyana of funds under the Clean Development 
Mechanism, the Adaptation Fund and the Green Climate Fund under the Kyoto Protocol. ${ }^{48}$ Keeping in mind the major challenges from climate change are flooding and sea level rise, drought and extreme weather events, a set of adaptation projects were extracted from key policy documents on development within the natural resources and related sectors.

\subsubsection{Identification of Needs based upon review of policy documents}

The priority areas identified in the policy documents, especially the Low Carbon Development Strategy, focused on sectors that are most vulnerable to the impacts of sea level rise, floods, droughts and extreme weather events and are listed below:

(a) Coastal Zone: Emphasis on shore protection (shoreline erosion), mangrove replanting; initiate an integrated coastal zone management program; and studies on the impacts of sea level rise for various sectors and for cities.

(b) Agriculture and fisheries: Change crops, varieties and possibly practices; improve farm-level management and productivity; identify inland areas for new large-scale agricultural areas; move crops away from the coastal zone; promote aquaculture; change export market policies; transfer of appropriate technologies; introduce new species and crops; pest control for crops; mainstream climate change into poverty alleviation program; and impact surveys and studies.

(c) Water: Water conservation, monitoring and inventory of water availability; more efficient use in agriculture and energy production; increase availability through rainwater collection, building wells inland, expanding water storage capacity, implementing stricter controls and improving management of the supply network; drainage re-use, artificial recharge of reservoirs from rivers, and removing sediments and weeds; encourage growth of low water use crops, high value per water use crops, and salt-tolerant crops; adjust energy production to balance with other uses; and closing plants during low flow times.

(d) Energy: Promote conservation techniques; fuel efficient equipment and buildings; efficient transportation; alternative power sources such as hydropower; co-generation; and wind, solar, ocean thermal and wave energy.

(e) Forestry and land-use: Introduce sustainable logging practices; forest fire protection; agroforestry/reforestation/afforestation of commercially important species in areas likely to favour

\footnotetext{
${ }^{48}$ Ministry of Foreign Affairs, (2014)Republic of Guyana, Available at: http://minfor.gov.gy/index.php/component/content/article?id=161 (Accessed on June, 2015)
} 
growth as a result of a shift in vegetation zones due to climate change; establish more protected areas; use previously cleared forests for human settlements; promote settlements, industry and agriculture in selected regions of the interior; and detailed studies on climate and environment.

(e) Waste: Improved water disposal management plans, managed waste sites, waste reduction measures and improved sewage treatment.

In addition to the above, the LCDS identified a number of priority adaptation measures for implementation. These include the following:

(i) Upgrading infrastructure and assets to protect against flooding through urgent, near-term measures (such as upgrading and maintaining drainage systems, building ocean seawalls, improving sanitation and water and flood-proofing health clinics).

(ii) Addressing systematic and behavioural concerns; these initiatives include strengthening building codes and expanding the early warning system and an emergency response system.

(iii) Developing financial and risk insurance measures to boost resiliency post-flooding. The availability of contingent funds to provide immediate financial help after flooding.

(iv) Switching to flood resistant crops.

(v) Establishing the climate change adaptation needs of Guyana's hinterland regions, including forest communities. Initial scoping work identified the need for empoldering communities, strengthening river defences and introducing improved crop varieties.

\subsubsection{Identification of needs based upon questionnaires}

The questionnaire highlighted the recognition and acceptance of climate change and the need to urgently act to address the threats especially those posed to the majority of the population that live on the coast. Even though the sample of respondents was relatively small it complemented the information gathered from the policy documents and confirmed the four major vulnerabilities identified from the policy documents; sea level rise, flooding, drought and extreme weather events. One respondent wrote "based on the projections in Guyana's Second National Communication to the UNFCCC: - changes in principal climate variables are already evident in the data. During the 1960 - 2006 period, including the 2005 and 2006 extremes, monthly precipitation increased on average by $4.88 \mathrm{~mm}$ and surface temperatures rose by $0.3^{\circ} \mathrm{C}$. For the period 1951 - 1979 sea levels rose by $10.2 \mathrm{~mm} / \mathrm{yr}$, significantly higher than the global 
average. - Precipitation is predicted to decrease by about $10 \%$ by the 2090 s, although intense events are expected to become more frequent".

Drought did not feature in the surveys as the other vulnerabilities mentioned and was not clearly identified by the respondents, because it was not emphasized as an option in the questionnaire. A decrease in precipitation was included but this was not easily identified by the respondents as a top priority and the association with low rainfall and drought was not made.

Some of the impacts identified were: overtopping of sea defences, rising temperatures, deforestation, diminishing natural resources, loss of employment, floods affecting schools and damage to properties and agriculture commodities. Another important outcome of the survey is the need for more awareness on ecosystem based adaptation and the value of using natural capital in the fight against climate change.

\subsection{Impact Analysis}

The impact analysis centres on the adaptation challenges of sea level rise, flood protection, adaptation to drought, and adaptation to extreme weather events based on the modified DAF framework outlined in Figure 10. The framework illustrates the stepwise interpretation and reframing of the adaptation challenges as this evolves to selecting an adaptation measure.

\subsubsection{Impact Analysis for Adaptation Need: Coastal Flood Control}

The framework as outlined in Fig 10, distinguishes between adaptation challenges researched, methods used and the criteria applied for choosing a particular method. With regards to coastal flooding the first question "Are credible and comprehensive impact studies available?", the answer is "yes". Relevant impact studies and models were done locally (Guyana), regionally (the Caribbean and Latin America) and globally, especially in the Netherlands, Australia and several other countries (Pelling, 1999; Charveriat, 2000; Middelmann-Fernandes, 2009; Arkema et al, 2013; Lenderink, et al, 2014). These studies emphasize the need to protect vulnerable coastlines and natural defences because of the damage incurred on habitats and the high risks posed to poor families and property exposed to hazards of floods. In Guyana, the proper functioning of the drainage and irrigation system was seen as critical in alleviating flood disasters. 
It must, however, be noted that with regards to ecosystem based adaptation and coastal flooding, more research is needed that are applicable to Guyana or the region. If this answer was "no" then the recommendation would be to "complete a comprehensive impact study and no adaptation measure appropriate until completion". With a "yes" to the first question the next question is "are the available studies ambiguous or conflicting?". This needs an in depth analysis, but based on the literature reviewed it is suggested that the answer to this question is "no". With several studies on storm surges and coastal planning, it is suggested that a subset should be selected that are more relevant and similar to the conditions and needs of Guyana. With "no" as the answer the next step is to "proceed to identifying adaptation measures" which completes this stage of the adaptation cycle. The general trend with the models is the need for an early warning system and the participation of the local communities in the decision making process. "Are impact models available"? Several models are available on storm surges, coastal flooding and inundation and these can help to support a decision that can progress towards an adaptation measure. With "yes" as the answer the next step is to proceed to ask the question "is data available on potentially climate sensitive system variables? The answer to this is yes, a fair amount of data is available from the local Hydrometeoreological Department of the Ministry of Agriculture, Guyana and from regional databases held by intuitions such as the Caribbean Climate Change Centre (CCCC). Data can be accessed from data bases in South America and also from National Oceanic and Atmospheric Administration (NOAA). If this answer was "no" then proceed to ask the question is "are there clear indications of impact based upon the impact model(s) available? If the answer to this is "no" the identifying adaptation measures at this time is unwarranted. This question reflects the essence of a similar question "do models predict trends and attribute impact to climate change? If the answer to both of these is yes, then proceed to identify the adaptation measure. Based on the answers provided to the questions it is suggested that that an adaptation measure can be identified for coastal flooding.

\subsubsection{Impact Analysis for Adaptation Need: Drought}

The impact analysis for drought follows the same questions asked for costal floods. The first question to ask is "are there credible and comprehensive impact studies available"? Within the Guyana context the answer to this question in "no" because, even though drought is a wellknown climate hazard, severe drought in itself is a relatively recent phenomena for Guyana and 
specific studies are not available. Some data and information on temperature increases and extended dry spells can be gathered from newspaper reports and statistics collected by the Civil Defense Commission (CDC). Additionally the droughts in Guyana are largely provoked by the ENSO phenomenon and are therefore not directly linked to anthropogenic climate change. However, studies in other jurisdictions have shown that global warming intensifies both drought and heat, making drought events even dryer and heat waves even warmer than they otherwise would have been (Bradbury \& DeConcini, 2012; Trenberth, et al, 2014). These studies were conducted in North America and evaluated the changes in precipitation over the region. Observations show that changes are occurring in the amount, intensity, frequency and type of precipitation. These aspects of precipitation generally exhibit large natural variability, and El Niño and changes in atmospheric circulation patterns such as the North Atlantic Oscillation have a substantial influence. Projections from the IPCC indicate a decrease in precipitation for Guyana and the Latin American Region which is likely to result in more severe droughts in the future.

As a complex natural hazard, drought is best characterized by multiple climatological and hydrological parameters. Improving our understanding of the relationships between these parameters is necessary to develop measures to reduce the impacts of droughts. Unlike other climate-related hazards, droughts are usually long in duration; damages are usually nonstructural and may cover a large region with unclear physical boundaries, so the impacts are usually difficult to identify (Bergman, 2007). Mishra \& Singh (2010) refer to the difficulty in determining the onset and end of drought and in measuring the impacts since the effects increase slowly and accumulate after a long period of time. More information is required on the effects of drought on crop yields and more research should be geared towards climate change and drought to establish probabilities and trends for droughts. One of the projects identified in the LCDS is: "Hinterland Adaptation Measures". This project intends to develop, reproduce and distribute crop varieties suitable for hinterland communities. Drought is more prevalent in the hinterland regions, especially in southern Guyana neighbouring to Brazil. The communities living there are the most vulnerable to drought and the major crops grown are upland rice, Oryza sativa L., cassava, Manihot esculenta Crantz, sweet potato, Ipomoea batatas (L.) Lam, peanuts, Arachis hypogea L., beans, fruits and vegetables. Screening and selection for heat and drought tolerant varieties of these crops should be a significant component for agricultural research in the 
region. Efforts should also be focused on establishment of field and seed genebanks to maintain and keep selected germplasm of the commonly used crop types. Additionally, more attention and priority should be given to research on the impacts of drought by local entities, such as the University of Guyana, and by regional institutions such as the University of the West Indies and the Caribbean Climate Change Centre (CCCC). Efforts along these suggestions will support a more comprehensive assessment of drought and will allow for a more informed selection of drought adaptation measures. However, given the current status on impact analysis relevant to drought, no further consideration is given with respect to "Identifying Adaptation Measures" or "Appraising Adaptation Options".

\subsubsection{Impact Analysis for Adaptation Need: Extreme Storm Events}

Impact analysis for adaptation need for extreme weather events will ask the same questions as those asked in 3.2.1 and 3.2.2. The first question is "are credible and comprehensive impact studies available? The answer to this question is no, therefore the recommendation is to "complete a comprehensive impact study; no adaptation measure appropriate until completion”.

Scientists are still trying to understand the true nature of extreme weather events and the linkage to climate change and while some studies have been published on the socio-economic implications of extreme weather events (Rosenzweig et al, 2001; Uleberg et al, 2014; Vasileiadou, et al, 2014) not many scientific papers are available on the science and impacts of extreme weather events. More comprehensive studies are required on impacts and forecasting of extreme weather events. Again, given the current status on impact analysis relevant to extreme weather events, no further consideration is given with respect to "Identifying Adaptation Measures" or "Appraising Adaptation Options", although adaptation measures directed to coastal flood control may serve as pre-adaptations for extreme weather events, and perhaps for drought.

\subsubsection{Impact Analysis for Adaptation Need: Sea Level Rise}

With the majority of Guyanese living along a Coast that is below sea level, the rise in future sea levels is one that is great concern to the people. This threat was noticeably expressed from the aggregate response received from the survey questionnaires. In examining the impact analysis for sea level rise the first question is "are credible and comprehensive impact studies 
available? The answer to this is "yes", and some of these studies and models were done locally (Guyana), regionally (the Caribbean and Latin America) and globally especially in the United States, the Netherlands, and several other countries. (Koningsveld, 2008; Olsthoorn, 2008; Anthoff, et al, 2010; Burton, 2012). With a "yes" to the first question the next question is "are the available studies ambiguous or conflicting” The analysis for this is continuing but based on the literature reviewed it is suggested that the answer to this question is "no". The studies all point to the fact that the ocean has been rising slowly and relentlessly since the late 19th century, one of the hallmark indicators that the climate of the earth is changing. The average global rise has been about eight inches since 1880, but the local rise has been higher in some places where the land is also sinking, as in some coastal locations in the southern United States. Additionally a rise in the sea level could have catastrophic effects for the Caribbean and would affect the poorest and most vulnerable in the region.

With several studies on storm surges and with sea level rise models, it is suggested that a subset should be selected that are more relevant and similar to the conditions and needs of Guyana. With "no" as the answer the next step is to "proceed to identifying adaptation measures" which completes this stage of the adaptation cycle. If the answer was "yes" then the next question to ask is "are impact models available"? Several models are available on estimation of sea level rise and flooding, and these can help to support a decision to progress towards an adaptation measure. If the answer is no then the recommendation is to "develop impact models or complete a comprehensive impact study; no adaptation measure appropriate until completion". With "yes" as the answer the next step is to proceed to ask the question "is data available on potentially climate sensitive system variables? The answer to this is yes, a fair amount of data is available from the local Hydrometeoreological Department of the Ministry of Agriculture, Guyana and from regional databases held by intuitions such as the Caribbean Climate Change Centre (CCCC). Data can accessed from data bases in South America and also from National Oceanic and Atmospheric Administration (NOAA). Based on the answers provided to the questions it is suggested that an adaptation measure can be identified for sea level rise. 


\subsection{Identifying Adaptation Measures for Coastal Flooding and Sea level Rise}

There are several possible adaptation measures contributing to reducing climate change impacts. However, each case must be studied individually to implement the most appropriate adaptation measures to solve or improve problems in affected communities. This is the basis upon which the DAF was created and offers a method to support adaptation planning which relies strongly on previous research but is also iterative. Guyana's climate change adaptation process is largely policy-driven. The DAF offers an opportunity to evaluate the framework and its value in supporting method selection in the adaptation policy process. A number of adaptation measures, initiatives and ideas were identified and proposed in the various policy documents and the survey questionnaire.

\subsubsection{Identification of potential measures (hard and ecosystem-based) based upon policy review}

The policy documents reviewed identified both hard and ecosystem-based adaptation projects. Keeping in mind that coastal flooding is linked to both sea level rise and high rainfall, hard and ecosystem based adaptation should concentrate on reinforcing and maintaining the integrity of two important infrastructures; the sea defenses and the dam surrounding the Conservancies such as the EDWC. The EDWC was the beneficiary of a GEF project between 2008 and 2013 that looked at rehabilitation of the EDWC. The project was completed and the main objectives were:

- To strengthen understanding of the EDWC and the coastal drainage systems through the development of a hydraulic engineering foundation critical for flood control management

- To identify strategic interventions for follow-on investments to reduce flood risk

- To implement selected infrastructure investments aimed at increasing the drainage relief capacity of the EDWC and to strengthen institutional capacity to manage water levels in the EDWC

This project is a good example of blended hard (stability of conservancy dam) and soft adaptation (building institutional capacity to manage water level and reduce flood risks), however it is still early to assess the success of this project. The project faced its first test in July, 2015. With high levels of rainfall, the new relief canal constructed in this project was very useful in preventing floods to the rice farmers within Region 5. 
Projects that can improve urban drainage and strengthen sea defenses should be given close attention with regard to coastal flooding and sea level rise. For hard adaptation the LCDS listed two projects:

(i) The upgrading of infrastructure and assets to protect against flooding through urgent, nearterm measures (such as upgrading and maintaining drainage systems, building ocean seawalls, improving sanitation and water and flood-proofing health clinics)

(ii) Further upgrading of flood protection, seawalls and expansion of drainage and irrigation is proposed

Adequate research and engineering information is available to implement the above adaptation measures but must be supported with inputs and consultations from the local communities.

For ecosystem based adaptation one project is listed: (i) Switching to flood resistant crops. There has been some success in developing flood tolerant varieties of rice, Oryza. sativa L. (Fukao, et al, 2011; Niroula, et al, 2012), one of the main crops grown on the coast in Guyana. Work should commence with screening accessions of rice for suitability based on the ecological condition of low coastlands.

The other major ecosystem based project is the mangrove rehabilitation project along the coast of Guyana. The costs for reinforcement of earthen dams and the construction of sea walls (mentioned in 1.4.1) are almost prohibitive. The mangrove rehabilitation project is a more affordable adaptation measure and should be continued because it also has the potential to generate co-benefits such carbon sequestration and small community enterprises such as bee keeping. According to the National Mangrove Action Plan (2010 -2012) the major objectives of the plan is to "respond to climate change and to mitigate its effects through the protection, rehabilitation and wise use of Guyana's mangrove ecosystems through processes that maintain their protective function, values and biodiversity while meeting the socio-economic development and environmental protection needs in estuarine and coastal areas". The project has developed a fair amount of capacity that can be used to promote the project at other location (apart from the East Coast) along the coastline. 


\subsubsection{Identification of potential measures (hard and ecosystem-based) based upon questionnaires}

The adaptation measures identified as priorities from the questionnaire includes both hard and soft adaptation. For hard adaptation the following were selected as top priorities:

(i) Reinforced sea walls

(ii) Modification of buildings to withstand flooding

For ecosystem based adaptation gain the two top choices were:

(i) Appropriate crop varieties for flood

(ii) Planting of mangroves

Ecosystem based adaptation has been practiced by the mangrove restoration project and to a lesser extent by the Conservation Adaptation Project (CAP) with respect to water management. Important ways to promote investments in ecosystem based adaptation are to raise awareness on the value of nature-based solutions and to identify their costs and benefits in the adaptation strategy. It is a collaborative effort across scales that made the project successful, and increased capacity of the local communities to undertake other similar ecosystem based projects. It anticipated that other ecosystem based projects can be undertaken at other locations across the country.

The mangrove rehabilitation / restoration project received strong support from the communities. Through this project, considerable capacity has been developed for mangrove husbandry in planting and propagation, nursery management, and monitoring the growth of the newly established stands of mangrove. The communities are representatives on the various mangrove regional committees, work as mangrove rangers and also work as tour guides in the mangrove plantations. The communities are also engaged in bee keeping and honey production.

\subsection{Capacity assessment of actors}

The implementation of an adaptation measure is dependent on a number of factors, essential to achieve the goal of the AM. Two of the most important requirements identified from the survey questionnaires and that are most necessary for the implementation of an AM are, adequate numbers of technically capable personnel and the availability of funds. From the surveys and information gathered from the policy documents it is evident that participation from private individuals is very low. The few local NGOs working in the environmental field are 
limited by the paucity of trained and experienced individuals and funds. This deficiency is somewhat alleviated by the presence of several international NGOs such as World Wildlife Fund for Nature (WWF), Conservation International (CI) and Flora and Fauna International (FFI). The international NGOs are adequately staffed and well resourced.

In the 2014 National Budget of Guyana of the previous Government allocated US\$90.6 million for projects identified under GRIF, including projects on climate adaptation ${ }^{49}$. To successfully continue with climate change adaptation measures, Guyana would need more funds from the national budgetary allocations and continued support to strengthen its financial capacity from facilities such as the GEF, the Adaptation Fund under the UNFCCC and the Green Climate Fund.

\subsection{Ability of public policy instruments to enable (or constrain) actors}

In Guyana the policy process is initiated, researched, refined, and driven largely by Government but with interactions between state and non-state actors. The process that can be described as planned adaptation is explicitly actor oriented and assumes that the adaptation process typically involves multiple actors, and broad stakeholder participation is encouraged. One challenge observed is the overlapping functions of some organizations involved in climate change activities or on the sectors impacted by climate change.

There can be collisions among government agencies in the natural resource sector especially with land use planning and this can sometimes affect the successful execution of projects related to land management and climate change. At the level of policy, planning and management, several agencies in Guyana have been mandated to play a role in land use planning, natural resources management and implementation. These include the Guyana Forestry Commission (GFC), Guyana Lands and Surveys Commission (GLSC), Guyana Geology and Mines Commission (GGMC), Ministry of Amerindian Affairs (MOAA), the Ministry of Agriculture (MOA), Ministry of Local Government (MLG), and the Guyana Environmental Protection Agency (EPA), among others. While the Commissioner of Lands and Surveys is the custodian of all public lands, the GFC, GGMC and GLSC administer State land that is utilised for forestry, mining, agriculture, recreational, religious, residential, grazing, industrial,

\footnotetext{
${ }^{49}$ Budget Speech (2014) by Hon. Dr. Ashni Singh, Minister of Finance; Tenth Parliament of Guyana. Sessional Paper No.1 of 2014
} 
commercial, business, tourism and other uses. Each of these three Government agencies may issue licenses and permits for different purposes for the same plot of land. In recognition of the complexity of the land use issues the government established the National Land Use Committee (NLUC) and the Natural Resources and Environment Advisory Committee (NREAC). These Committees function in concert with the Cabinet Sub Committee on Natural Resources to harmonise tenure to a particular area with multiple potential uses. A National Land Use Policy is still to be finalized. The implementation of a comprehensive land use policy and an associated adequate land development plan will facilitate a more structured approach to the diverse land uses in and around Guyana.

- A similar situation exists for water with two agencies administering the legislation relevant to the water sector. The Guyana Water Incorporated is responsible for the distribution of water for the country, while the Hydrometeorology Service of the Ministry of Agriculture is responsible for the monitoring and assessment of surface and groundwater resources. Policy instruments emanating from these organizations can duplicate or collide with each other; therefore a more harmonized approach is required for smooth implementation. Harmonization will create consistency of the laws, regulations, standards and practices, so that the same rules will apply to each organization. The revised legislation will ensure that conflicts are minimized and clear boundaries are established.

\subsection{Appraising adaptation options - identification of barriers}

Barriers can delay the implementation of adaptation measures or totally exclude the issue from the policy process. Hence, barriers can influence the extent to which climate adaptation is mainstreamed (Uittenbroek, et al 2013). The adaptation option in this study considered coastal flooding and sea level rise, especially with regards to ecosystem based adaptation. The barriers were determined based on information gathered from the policy documents and from the survey questionnaire (Figure 12) and were based on:

(a) The people involved and the context within which they act, such as governance

(b) The system or area of concerned

(c) The needs that are required, such as funding and prioritization

The first barrier observed was the lack of awareness, especially for ecosystem based adaptation. The community may have a sense of conservation of natural resources but may not 
be able to make the connection been the value of ecosystem services and climate change. There is need for more outreach on use of coastal vegetation such as mangroves, for sea defences and the promotion of a "win- win" situation between the conservation and maintenance of ecological functions and the protection of the coast from sea level rise and flooding using natural capital. Even though most of the activities are still directed from the central government, the goal is to get communities to participate more fully in decisions that affect their communities with regards to projects related to adaptation to climate change.

The survey also pointed out lack of incentives, inadequate funding, a sense of resignation, lack of good examples and personal well-being as barriers to community participation (Figure 12). This confirms the need for a strong information campaign on climate change adaptation and ecosystem based adaptation, driven by the government and community leaders together with adequate budgetary allocations to financially support such programmes. Personal well-being is usually thought of as a dynamic process that gives people a sense of how their lives are going, through the interaction between their circumstances. A high level of well-being means that a person is more able to respond to difficult circumstances, to innovate and constructively engage with other people and the world around them. When someone expressed a "sense of resignation" this means the problem belongs to someone else, or since it is inevitable that the problem is going to happen, there is no point in doing anything about it. This needs to be corrected by providing regular and timely information to the communities about climate adaptation and the need to safeguard, restore and protect natural ecosystems to combat coastal flooding and sea level rise.

Berrang-Ford, et al (2014) stated that institutional capacities, as measures of good governance, are the strongest predictors of a good adaptation policy. An analysis of the various policy documents revealed that there is insufficient harmonization of the policies and this can lead to overlapping mandates among institutions, and limited understanding of roles, responsibilities and stakeholder involvement as it relates to achieving overall objectives of the adaptation option. Additionally, there is overlap with the legislation with regards to sectors such as water and land management.

The shortage of technical skills was also identified in the policy documents. When much needed funding is secured, there is a struggle to find trained personnel to do the work. There is need for more people to be trained in the fields of engineering, ecology, meteorology, and 
climate policy to support the team in combatting climate change and coastal flooding. The education curriculum at secondary and university levels should include more courses on the environment and climate science and attractive scholarships and incentives should be granted to students who choose careers in environment and climatology. Inadequate funding has been clearly identified in the survey questionnaire and mentioned in all the policy documents that were reviewed. There should be a more aggressive campaign to seek funds outside of the current GRIF arrangement due to conclude in 2015. The GCF is crucial for countries like Guyana for support in research, training and community outreach and engagements. A more informed people are likely to enhance and promote good governance and strong climate policies.

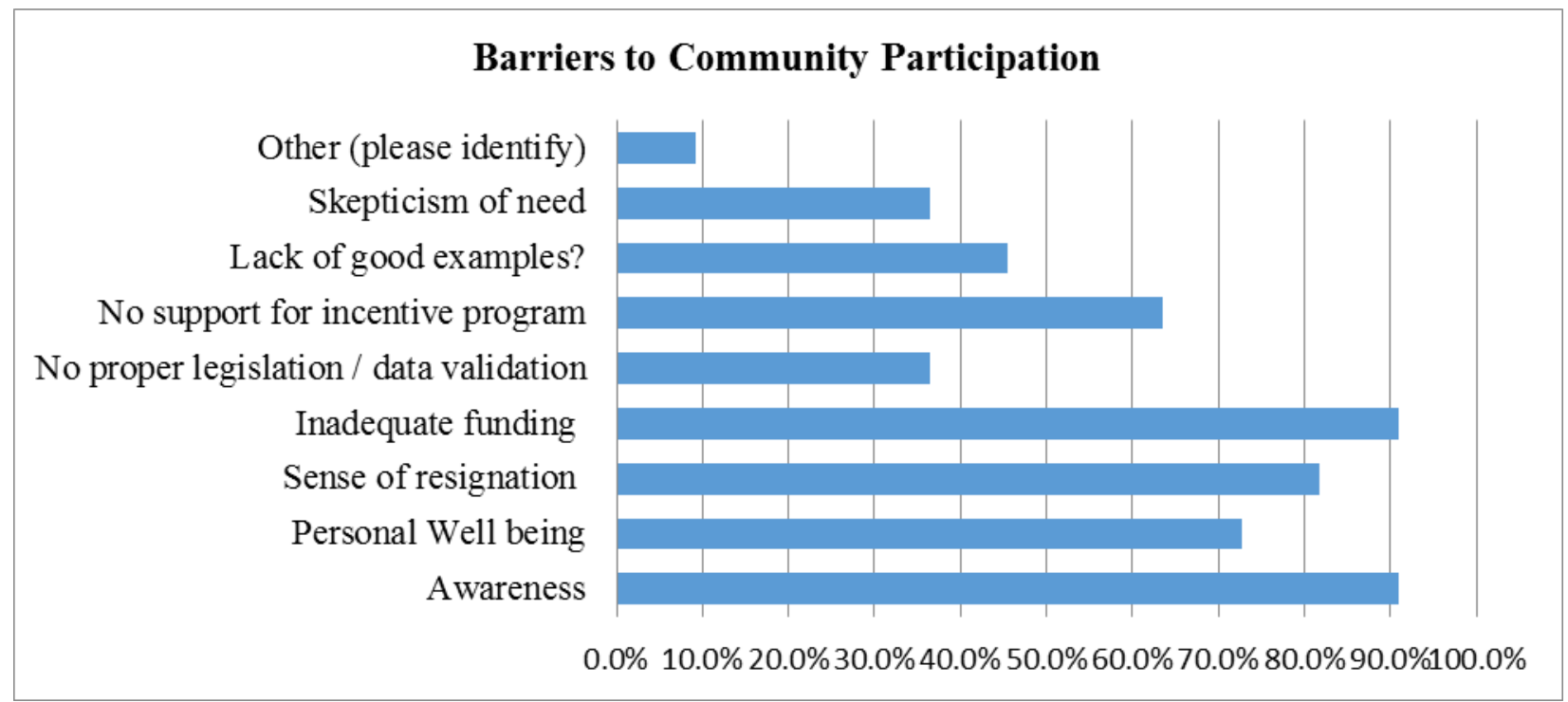

Figure 12: Barriers identified for community participation 


\subsection{Summary of recommendations regarding adaptation strategies.}

Guyana, a developing country, is highly susceptible to sea-level rise and flooding, because much of the population lives at or below sea level and depends upon the coastal infrastructure of aging sea walls and shoreline vegetation to protect them from rising sea levels. The Government clearly recognizes the country's acute vulnerability to climate change, which has been made more noticeable by regular coastal floods, but with limited financial resources, it has focussed more on mitigation, which earns financial benefits for the country, and less on adaptation, especially ecosystem based adaptation. This needs to be corrected, keeping in mind the increased intensities and frequencies of the identified vulnerabilities of coastal flooding, sea level rise, drought and extreme weather events worldwide (Peduzzi, 2005; Hannam, 2013; Cai, et al, 2014).

Ecosystem based adaptation certainly has the potential to be integrated into the adaptation strategy in Guyana but there must be more public awareness and research. Even though there were projects that were ecosystem based identified in the policy documents, ecosystem based adaptation as a specific strategy was not considered as a specific item in any of the policy documents reviewed and it is suggested that this be included in any future adaptation strategy. More scientific information is also required for drought and extreme weather events to guide the selection of an appropriate adaptation measure. Some lessons learnt from regional jurisdictions suggest that there should be adaptation and ecosystem services should be mainstreamed into national policies. As the loss of natural capital and the associated vulnerabilities are a threat for sustainable development, national development policies should integrate ecosystem management and adaptation to climate change. It was also clear that there is a need to develop innovative funding and to strengthen the linkage between adaptation and mitigation.

The success of Guyana developing an effective adaptation strategy will depend to a large extent on how plans to provide finance from the Green Climate Fund work out. While industrialised OECD countries have made "pledges" this is not the same as hard cash. The world waits to see what will transpire in Paris later in 2015. The Unite States is key and whatever commitments are made could very well be "rolled back" should the Republicans come to power in 2016. The prospect for our planet effectively meeting the challenge of mitigating the worst effects of global warming is very much in the balance. 
Local communities are important decision-makers in adaptation and ecosystem management. National policymakers should empower local and indigenous communities facilitate adaptation processes that include local knowledge. Policies should also promote environmental education and relevant career training in the sectors necessary for developing a workforce with the necessary capacity to implement adaptation measures and for promoting adaptation and ecosystem based activities in local communities. Understanding climate change impacts and vulnerability can be complex, so technical expertise is required to understand and interpret the results of scientific studies. Policy makers should interact with scientists to take into account uncertainties inherent in climate change studies. Policy-makers should create institutional arrangements and funding sources to facilitate the development and use of relevant social and natural science knowledge into policy processes.

\subsection{Results and main findings}

Data and information gathered from the policy reviews and supported by the survey questionnaire clearly identified four climate vulnerabilities (Figure 11) which are considered as priorities and important for adaptation actions since their impacts can cause significant damage to the economy and to livelihoods. Long term planning for adaptation in Guyana should therefore be done with the following threats in mind:

(a) sea level rise

(b) coastal flooding

(c) drought

(d) extreme weather events

The DAF also identified the two threats for which adaptation measures can be prioritized and tested; sea level rise and coastal floods and the need for more research data for drought and extreme weather events. Additionally the research also identified the need for

- More public awareness for ecosystem based adaptation

- A heightened and more structured interagency collaboration for adaptation activities

- Appropriate research to support adaptation such as ecosystem based adaptation

- More human resource capacity to drive the adaptation process

- The need for more regional cooperation and information sharing

- Need for incentives to encourage more private participation 
- More efforts to encourage private participation in adaptation and to strengthen governance at the local level

- Additional technical and financial support to combat the threat of climate change.

- Ecosystem based adaptation is based on the best available science and local knowledge, and should foster knowledge generation and diffusion

- $\quad \mathrm{EbA}$ is about promoting resilient ecosystems and using nature-based solutions to provide benefits to people as exemplified by the mangrove rehabilitation project.

\subsection{Benefits and information of value to Government of Guyana}

Guyana is currently preparing its Climate Resiliency and Adaptation Strategy (CRSAP). The results from this research can provide additional information to this document especially with regards to the importance of integrating ecosystem based adaptation into the overall adaptation strategy. A recent review of current and planned adaptation actions in the Caribbean emphasised the need for an ecosystem-based approach to adaptation and states that "there is clear national and regional recognition that ecosystem services can greatly reduce adaptation costs while providing numerous co-benefits (i.e., mangroves and reefs protect shorelines from erosion and supply fisheries; forests mitigate landslides, flooding and drought) ${ }^{, 50}$

The use of the DAF process is recommended in the selection of adaptation options, measures and appraising the selected measures as outlined and discussed in this research. This research also emphasized the need for more information sharing and regional collaboration to ensure local and external knowledge is available in usable formats for all stakeholders. The cataloguing of knowledge and an assessment of knowledge efficacy in addressing climate change impacts would significantly enhance the development and subsequent implementation of EbA strategies.

With a change in Government in 2015, it is recommended that the new government put together a well-informed team to attend the COP 21 Meeting in Paris, France in December 2015, where the new climate agreement will be negotiated. The new climate agreement will impact domestic policies and Guyana should participate fully, especially with regards to gathering funds for adaptation to climate change. It is also suggested that the OCC remains at the Office of the

${ }^{50}$ Medeiros et al, 2011. Review of Current and Planned Adaptation Action: The Caribbean. Available at: http://www.adaptationpartnership.org/resource/caribbean-current-and-plannedadaptation-action (Accessed on: August, 2015) 
President, at least until after the COP 21 Meeting in Paris after which a re-assessment can be made with regards to climate policy and management.

\subsection{Directions for future research}

First and foremost, there is a need to design more encompassing, more locally-based processes to integrate EbA with existing mechanisms and approaches for climate change adaptation in Guyana. Research would involve further field testing and refinement of EbA approaches which explicitly integrate local and external knowledge in selected communities and for a diverse range of ecosystems are required in order to scale up successful EbA initiatives. Since Guyana is a diverse country with respect to its biodiversity and ecosystems, an exciting opportunity exists to compare and contrast across locations which would help to indicate how contexts and local distinctiveness lead to different outcomes. That would provide scientific backing and identify good-practice case studies which would indicate where problems resulted so that those problems could be solved. Finally, there need to be more studies and analyses on the economics and financial advantages of ecosystem based adaptation and engineering options for climate change adaptation in Guyana. 


\section{Appendices}

\section{Appendix I}

RYERSON

UNIVERSITY

\section{Ryerson University}

\section{Consent Agreement}

Title of Study: Policy options for addressing Climate Change, with a focus on Ecosystem based Adaptation (EbA): A case study of Guyana

You are invited to participate in a research study. Before you give your consent to be a volunteer, it is important that you read the following information and ask as many questions as you wish to make sure you understand what you will be asked.

Investigator: Ramesh Lilwah, MASc Candidate

Purpose of the Study: This study is designed to evaluate and synthesize the information related to ecosystem based activities and climate change, suggest improvements based on a tested strategy elsewhere and recommend integration into the overall national adaptation strategy. About twenty (20) participants will be selected based on their expertise and involvement in the fields of environment, climate policy and natural resource management and asked to complete a questionnaire.

What Participation Means? The study includes a review and analysis of key policy and strategy documents and data collection from a survey questionnaire. The questions relate existing and planned adaptation strategies to climate change in key organizations such within the natural resource sector. The questionnaire should take about 20 minutes to complete and is to be done at a place or location that is convenient to you.

Potential Benefits: Your participation in this research project will increase your awareness about climate change and the relatively new and innovative technique of ecosystem based adaptation. It will also contribute to enhancing the climate adaptation strategy in Guyana for the benefit of the people especially those living on the vulnerable coastlands. One of my key expectations is that the results of the study will contribute to a policy for inclusion of ecosystem based adaptation in building climate resiliency in Guyana. 
What are the Potential Risks to you as a Participant: There may be risks to participating in this study. If people in government learn that you have talked to me about your experience, or if confidential information is shared, then you might feel threatened or concerned that you will be ostracized and penalized due to your participation. To safeguard you, I will therefore not disclose your information to other participants or government officials.

Confidentiality: In all cases, responses from the questionnaire will be kept confidential. The data collected for this study will be used for academic purposes only. Records will be kept strictly confidential and only the investigator, his faculty supervisors and Yeates School of Graduate Studies, Ryerson University, Toronto will have access to the data from the questionnaire. The storage of the data will kept for not more than 6 months, from the time the questionnaire is administered to the final phase of data analysis. All the completed/partially completed questionnaires will be destroyed thereafter.

Incentives for Participation: You will not be paid or given any other incentives to participate in this study.

Costs to participation: The costs for participation will be your time. Please note you will not be reimbursed for time spent to complete the questionnaire.

Compensation for Injury: By agreeing to participate in this research, you are not giving up or waiving any legal right in the event that you are harmed during the research.

Voluntary Participation and Withdrawal: Participation in this study is completely voluntary. If any question makes you uncomfortable, you can skip that question, refuse to answer any particular question or stop participation altogether. Withdrawal will not affect your future relations with Ryerson University. In cases of withdrawal, any data you have provided will not be used or recorded.

Questions about the Study: If you have any questions about the research now, please feel free to ask. If you have questions later about the research, please contact:

Ramesh Lilwah,

Telephone Number: + 6472917122 or + 6473407270 ,

ramesh.lilwah@ryerson.ca

Dr. Bernard Fleet,

Ryerson University, Toronto

Telephone Number: + 416530 0934, fleetec@gmail.com

Dr Andrew Laursen,

Ryerson University, Toronto

Telephone Number: + 4169795000 ext. 3389, alaursen@ryerson.ca 
This study has been reviewed by the Ryerson University Research Ethics Board. If you have questions regarding your rights as a participant in this study please contact:

Research Ethics Board

c/o Office of the Vice President, Research and Innovation

Ryerson University, 350 Victoria Street,

Toronto, ON M5B 2K3

416-979-5042, rebchair@ryerson.ca

\section{Policy options for addressing Climate Change, with a focus on Ecosystem based Adaptation (EbA): A case study of Guyana}

\section{Confirmation of Agreement}

Your signature below indicates that you have read the information in this agreement and have had a chance to ask any questions you have about the study. Your signature also indicates that you agree to be in the study and have been told that you can change your mind and withdraw your consent to participate at any time. You have been given a copy of this agreement.

You have been told that by signing this consent agreement you are not giving up any of your legal rights.

Name of Participant (please print)

Signature of Participant

Date

Signature of Investigator 


\section{Appendix 2}

\section{Joint Concept Note}

\section{Background}

On November $9^{\text {th }}, 2009$, Guyana and Norway signed a Memorandum of Understanding (MoU) regarding cooperation on issues related to the fight against climate change, in particular those concerning reducing emissions from deforestation and forest degradation in developing countries (REDD-plus ${ }^{1}$ ), the protection of biodiversity, and enhancement of sustainable, low carbon development.

An accompanying Joint Concept Note (JCN) set out the framework for taking the Guyana-Norway co-operation forward. It set out how Norway would provide Guyana with financial support for REDD-plus results, and formed the basis for the first payment from Norway to Guyana. An update of the Joint Concept Note was finalized in March 2011 and has guided the partnership until December 2012.

Since the first Joint Concept Note was published, considerable progress has been made in the Guyana-Norway cooperation.

This current version of the Joint Concept Note replaces the concept note of March 312011.

${ }^{1}$ As defined in the Bali Action Plan (2/CP.13). 


\section{Section 1: Introduction}

This Joint Concept Note constitutes the overarching framework for taking the Guyana-Norway cooperation forward. Specifically, it addresses Paragraphs 2 (c), 3 and 4 of the MoU signed between Guyana and Norway on November $9^{\text {th }}, 2009$. The Joint Concept Note sets out how Norway is providing, and will continue to provide, financial support to Guyana, based on Guyana's delivery of results as measured, and independently verified or assessed, against two sets of indicators:

- REDD-plus Performance Indicators: A set of forest-based greenhouse gas emissionsrelated indicators, as described in more detail in section 3 below. Results against these indicators will be independently verified according to the established practice of the partnership. These indicators will gradually be substituted as a system for monitoring, reporting and verifying (MRV) emissions from deforestation and forest degradation in Guyana is established. The development of the MRV system is guided by the MRV roadmap. ${ }^{2}$

- Indicators of Enabling Activities: Indicators are identified that can be independently assessed ${ }^{3}$ through publicly available information on progress regarding a set of policies and safeguards to ensure that REDD-plus contributes to the achievement of the goals set out in Paragraph2(c) of the MoU signed between Guyana and Norway on November $9^{\text {th }}$, 2009, namely "that Guyana's LCDS Multi-Stakeholder Steering Committee and other arrangements to ensure systematic and transparent multi-stakeholder consultations will continue and evolve, and enable the participation of all affected and interested stakeholders at all stages of the REDD-plus/LCDS process; protect the rights of indigenous peoples; ensure environmental integrity and protect biodiversity; ensure continual improvements in forest governance; and provide transparent, accountable oversight and governance of the financial support received." The enablers are described in more detail in Section 2 and table 1 below.

Norwegian financial support is being channeled through a multi-contributor financial mechanism the Guyana REDD-plus Investment Fund (GRIF). The support is financing two sets of activities:

- The implementation of Guyana's Low Carbon Development Strategy (LCDS)

- Guyana's efforts in building capacity to improve overall REDD+ and LCDS efforts.

Section 4 sets out how the financial mechanism operates.

The first payment to the GRIF was made in October, 2010 and the second payment in March 2011 for results achieved between October 1, 2009 and September 30, 2010. The third contribution was announced in December 2012 for forestry results from January $1^{\text {st }}$ to December $31^{\text {st }} 2011$ and for results on indicators of Enabling Activities from October $1^{\text {th }} 2010$ to December $21^{\text {st }} 2012$.

The contents of this concept note have been updated to include the longer term goals of the partnership towards its end in 2015. The annual progress in developing the MRV system and in

2 http://wwww.forestry.gov.gy/Downloads/Terms_of \%20Reference for Guyana's MRVS Draft.pdf

${ }^{3}$ Up until now the enabling activities have been 'verified', this have been a challenging exercise since qualitative and subjective views highly influence the understanding and verification of the indicators. The Governments of Guyana and Norway have therefore chosen to change the language from'verified' to 'independently assessed' in order to accommodate for the qualitative nature of these indicators. 
strengthening the quality of REDD-plus-related forest governance will be defined as steps towards reaching these goals. The Government of Guyana is responsible for making publicly available the necessary data for assessing performance against the given indicators.

\section{Section 2: Enabling Activities}

The continuation of result-based financial support from Norway to Guyana will depend on publicly observable progress on forest governance, as outlined below.

\section{Section 2.1 Indicators of Enabling Activities}

Performance in enabling activities will be measured against progress on six key categories of activities:

\section{Strategic framework:}

All aspects of Guyana's planned efforts to reduce deforestation and forest degradation, including forest conservation, sustainable management of forests and enhancement of forest carbon stocks ("REDD-plus"), are being developed in a consistent manner, through an internationally recognized framework for developing a REDD-plus programme, and will continue to evolve over time. Guyana is developing its REDD-plus efforts under the Forest Carbon Partnership Facility (FCPF), managed by the World Bank. Furthermore, all REDD-plus efforts will, at all stages, be fully integrated with Guyana's Low Carbon Development Strategy (LCDS). The contributions to Guyana's LCDS from Norway and other contributors, including the FCPF, will be administered in a transparent manner. Information concerning all expenditures, both planned and implemented, will be publicly available on the relevant website of the Government of Guyana, and through national systems of public disclosure, including to the National Assembly.

Guyana has chosen the Forest Carbon Partnership Facility (FCPF) as the strategic framework for its REDD+ efforts. The Readiness Preparation Proposal (RPP) will be finalized during 2012 with IDB as the delivery partner.

Goal of the partnership

Guyana and Norway support the relevant decisions of the UNFCCC COPs in Cancun, Durban and Doha, and in particular the decision to agree a new, global climate agreement by 2015, for implementation from 2020 at the latest. The Governments believe that the partnership between the two countries can provide many useful lessons for the crafting of the new agreement, as well as influencing the effective functioning of other multilateral processes, e.g. the FCPF. This could include lessons on creating effective climate finance mechanisms, setting REDD+ reference levels, and providing practical lessons on the implementation of safeguards. By the end of 2014, the Governments will make one or more joint submissions to the UNFCCC, covering each area where there the Governments believe that there are shared lessons that will help the global multilateral process. As well, the Government of Guyana's Readiness Package ("R-package") will be prepared and assessed by the FCPF's Participants Committee (PC) in the fall meeting 2014, contingent on financial resources from FCPF, or other resources, being available in time to do so. 
Improved Financial Intermediation

Subject to IDB decision-making processes, the IDB Financial and Safeguards Intermediary role will be operational in the first half of 2013 .

By the end of 2013, an outline strategy will be prepared setting out how the interim financial mechanisms could in the future be transitioned into national systems once mutually agreed benchmarks for independent assessment of financial, social and environmental safeguards are met. This could form part of a submission into the UNFCCC process, as a contribution to global efforts to design effective REDD+ finance mechanisms.

\section{Continuous multi-stakeholder consultation process:}

The LCDS, including the REDD-plus strategy and prioritized LCDS funding needs, is subject to an institutionalized, systematic and transparent process of multi-stakeholder consultation, enabling the participation of all potentially affected and interested stakeholders at all stages of the REDD-plus/LCDS process. This process will continue to evolve over time. Particular attention will be given to the full and effective participation of indigenous peoples and other forest-dependent communities.

\section{Goals of the partnership}

Monthly meetings of the Multi Stakeholder Steering Committee (MSSC), with comprehensive minutes of every meeting made publicly available immediately upon approval from the following MSSC meeting.

Information and consultation program in place by June 2013, leading to a sustainable intensification of outreach activities both in the hinterland and elsewhere, including: :

- From January 2013 keeping the GRIF and LCDS web pages updated with relevant information about the progress of ongoing processes.

- Initiating in January 2013 a responsible body for communication, information and consultations - located either in the Office of Climate Change (OCC), the Project Management Office (PMO) or REDD Secretariat. The body will be established in January 2013 and, subject to timely availability of GRIF resources, will be fully operational by the end of 2013 , with the ability to lead the development and sustain the implementation of the elements identified below.

- The establishment of information and consultation routines tailored specifically to the needs of Amerindian communities, including non-internet based channels of communication like in-person meetings, information folders, and traditional media.

- Coordinated information flows related to the different parts of LCDS implementation, including but not limited to LCDS progress, IFM, EITI, FLEGT, FCPF and GRIF projects.

- Collaboration with the National Toshaos Council (NTC) and MSSC members to strengthen their capabilities to function as agents of information sharing

- Develop annual stakeholder engagement and awareness plans consistent with the conceptual process framework developed, to be implemented starting in early 2014. 


\section{Governance:}

A transparent, rules-based, inclusive forest governance, accountability and enforcement system for forest governance in Guyana is being progressively strengthened, in accordance with Guyana's outline REDD-plus Governance Development Plan (RGDP) and the enabling activities for 2012 , as outlined in table 1 .

\section{Goals of the partnership}

- Application for EITI Candidacy presented to the EITI board by May 2013, application for EITI compliance at the last EITI board meeting in 2015.

Commencement of formal negotiations with the EU by the end of 2012, with the aim of agreeing to a Voluntary Partnership Agreement (VPA) under the EU FLEGT Action Plan by March 2015. Ratification of the VPA by Guyana by September 2015. Development of a plan for the implementation of the VPA to be completed by the end of 2015 .

- Continued implementation of Independent Forest Monitoring (IFM), with the first IFM assessment due by the end of 2013; In keeping with Section 4 of the agreed Terms of Reference for IFM, the next IFM assessments will be conducted at 2 years intervals thereafter, the next one taking place in December 2015

Enforcement and implementation of activities outlined by the Special Land Use Committee (SLUC) - and communicated publicly - will continue in 2013.

- The fifth national report submitted by 31 March 2014 to the CBD, including to the extent possible a description of the synergies between the protection of biodiversity, REDD+ and the LCDS.

- Implementation of a GoG (MNRE) programme, with actions focused on specific efforts to manage degradation from extractive activities where this needs to be done, including, for example: the start up of an enhanced miners' environmental knowledge programme through a mining extension service initiative and enhanced dialogue with the sectors and relevant stakeholders towards ensuring that sectoral best practices are applied and sustained thereafter.

The rights of indigenous peoples and other local forest communities as regards REDDplus:

The Constitution of Guyana guarantees the rights of indigenous peoples and other Guyanese to participation, engagement and decision making in all matters affecting their well-being. These rights will be respected and protected throughout Guyana's REDD-plus and LCDS efforts. There shall be a mechanism to enable the effective participation of indigenous peoples and other local forest communities in planning and implementation of REDD-Plus strategy and activities.

Guyana's policy is to enable indigenous communities to choose whether and how to opt in to the REDD-plus/LCDS process. This will take place only when communities wish to do so with their titled lands, in accordance with Guyana's policy of respecting the free, prior and informed consent of these communities.

\section{Goals of the partnership}

- GRIF funding made available to enable the achievement of the Government of Guyana's policy objective of completion of land titling for all eligible Amerindian communities by 2015 , with progress measured relative to a publicly available timeline

- GRIF funding made available for all CDPs through the Amerindian Development Fund

Opt In mechanism designed based among other things on evaluation of the piloting experience of the mechanism, and implemented starting in July 2015. 
Implementation starting by June 2013 of the part of the outreach program under the multi-stakeholder indicator which is tailored and targeted towards the needs of Amerindian communities.

Integrated land-use planning and management:

Several aspects of REDD + relates to the development of a system for environmentally sustainable and climate smart area planning and management. Several of the current interim performance indicators and enabling activities are directly relevant in this context. To ensure sustained positive impact from our combined efforts, the long term goal should be for these indicators and activities to result in a formalized system for area planning and management:

Goals of the partnership

- By September 2015, Guyana has a formal system in place for holistic area planning and management.

- A key element of this system should be a publicly available map of area use (including, but not limited to, full transparency regarding existing and planned concession and reconnaissance areas for forestry and mining, titled lands for Amerindian communities, areas planned and concessioned for industrial agriculture etc.)

- In the process of developing the system for area planning and management and the area use map, formal status of varying degrees of protection should be awarded to a significant part of the areas identified as Intact Forest Landscapes and priority areas for biodiversity, This will gradually replace the Intact Forest Landscapes interim performance indicator. The measures taken will as a whole be in line with Guyana's stated goal of maintaining 99,5 per cent of its forest for the duration of the partnership and stay on a similar trend after 2015 , though the degree of forest protection will depend on various factors, including the availability of international climate finance.

\section{Monitoring, reporting and verification:}

Guyana has progressed far in developing a national MRV system. Guyana has established a deforestation baseline and performed two forest area assessments for the years 2009-10 and 2010-11.

\section{Goals of the partnership}

- Guyana has implemented the MRV-roadmap and reached a reporting level incorporating several Tier 3 elements by the end of 2015. These Tier 3 elements include, but are not necessarily limited to, the use of high resolution data at national level that allows for disaggregation, the use of methods that provide estimates of greater certainty than lower tiers for key carbon pools, the use of comprehensive field sampling that is linked to GIS based systems which integrates land use and management activity data, and is subject to quality checks, and validations. Further, other areas relevant to Tier 3 reporting, will be further explored as stated in the MRV Roadmap.

Guyana will conclude technical analyses that inform a reference level that is to be submitted to the UNFCCC. The reference level will reflect the core elements of the reference level agreed by the GoG and the GoN, and also make provisions that the reference level be reassessed at regular intervals as/if global rates decrease. The aim is to submit the reference level to the UNFCCC by mid 2014, if this is technically feasible. If 
this goal proves impossible to meet due to technical challenges, the deadline can be extended after written agreement by both parties

Section 2.2 Assessing Progress Against Enabling Indicators

Table 1 below sets out how progress will be measured regarding enabling indicators going forward. These indicators are informed by the long term goals of the partnership as agreed in section 2.1 above, and thereafter updated in accordance with the long term goals.

Guyana and Norway have agreed that the necessary information to assess Guyana's delivery on these indicators will be easily accessible in the public space. Independent assessment of the information thus accessible determines to what degree, the REDD-plus enablers have been met

\section{Section3: REDD-plus performance indicators}

Guyana is being paid for its performance through an incentive structure which rewards keeping deforestation below an agreed reference level, as well as avoiding increased forest degradation.

The Governments of Guyana and Norway strongly endorse the establishment of such an incentive structure under the United Nations Framework Convention on Climate Change (UNFCCC). To help facilitate such an agreement, the Governments have decided to pilot such an incentive structure on a national scale and in a pragmatic, gradually evolving, workable and hopefully replicable manner. Once an international regime is in place, the Guyana-Norway partnership will be adjusted accordingly. Section 3.1 sets out the incentive structure, while Section 3.2 outlines how performance is to be assessed.

\section{Section 3.1 REDD+ incentive structure}

The payments due to Guyana for a given year are paid post facto. They are calculated as follows:

1. Measure avoided deforestation by subtracting Guyana's observed deforestation rate against the agreed reference level. See Section 3.1.1

2. Determine avoided greenhouse gas emissions by applying a set of carbon-density proxies to:

(i) convert the observed avoided deforestation rate into avoided greenhouse gas emissions:

(ii) subtract increased emissions from forest degradation based on agreed indicators and their reference levels as set out in table 2 . See Section 3.1.2

3. Apply an interim carbon price of US\$5 per tonne of avoided emissions, providing Guyana does not exceed an agreed level of deforestation within the context of the GuyanaNorway partnership - see Section 3.1.3. If the deforestation rate is above the levels stipulated in section 3.1 .3 , payments will be reduced and ultimately cease.

\section{Section 3.1.1 - Measuring Avoided Deforestation and Forest Degradation}

Setting a Deforestation Reference Level

For a global REDD+ mechanism to be effective it must incentivize both (i) reductions in deforestation in countries with high levels of deforestation and (ii) maintenance of low deforestation rates in countries that have maintained their forest cover. If only countries with high 
deforestation rates are compensated for improving their forest protection under an international climate regime, deforestation pressures will move to countries with currently low deforestation, like Guyana, and the overall emissions reduction effect will be diluted or lost.

On the other hand, if a global incentive structure does not ensure global additionality, the international community will be paying for "hot air" and there will be no mitigation impact.

This point is broadly accepted within the UNFCCC negotiations, and there is general agreement that a REDD-mechanism must provide genuine incentives for forest conservation in low deforestation countries, as well as ensure global additionality.

Therefore, Norway and Guyana have - pending the finalization of a UNFCCC reference level methodology - decided to use the "combined reference level" methodology to set a provisional reference level, based on an equal weighting of Guyana's mean 2000 - 2009 deforestation rate and the mean 2005 - 2009 rate in developing countries with deforestation. The "combined reference level ${ }^{\prime}$ methodology provides incentives for all categories of forest countries, and ensures that emissions from deforestation and forest degradation are reduced cumulatively at a global level.

In setting a historical deforestation baseline for Guyana under the Guyana-Norway REDD+ partnership, the mean value for the 2000-2009 period is used; $0.03 \%$ (see box 1 for background). This adheres to the principles used for setting the historical deforestation baseline in the Brazilian Amazon Fund

The "global average deforestation rate" is calculated 4 across 85 developing forested countries by dividing the sum of reported forest area loss in only those countries which lost forest by the starting area of forest across all countries, Data on forest loss is taken from FAOs Forest Resources Assessment 2010 (FRA 2010). For the period 2005-2010 the "global average deforestation rate" was $0.52 \%$. This figure will be subject to revision given new data from future FAO FRA's or from the IPCC.

The reference level for Guyana is the mean value of these two measures, that is, $0.275 \%$.

Setting Reference Leve/s for forest degradation indicators.

In the first two years of the partnership, Guyana's MRVS was not sufficiently developed to enable an analysis of forest degradation in Guyana that would enable a facts- based reference level to be established for all degradation indicators. Guyana has made substantial progress in improving the knowledge base for degradation indicators, and the current set of indicators and their associated reference levels are described in table 2

Section 3.1.2 Converting to Avoided Greenhouse Gas Emissions

Guyana is working to implement an IPCC-compliant MRV-system for emissions or removals of carbon from Guyana's forest sector. Until such a system is in place, a set of basic interim (proxy) indicators will be used to assess Guyana's performance. As a more sophisticated forest carbon accounting-system is implemented, these basic indicators will be gradually phased out. The set of interim performance indicators is based on the following assumptions:

${ }^{4}$ The open source Osiris database was used for these calculations (wwrw.conservation.org/osiris). Note that this is an underestimate because it does not include deforestation that occurred within countries that had a net gain in forest, nor does it account for all deforestation in countries that lost forest as some countries' reported forest area loss are net values. 
- They provide justification and prioritization for near-term implementation of REDD-plus efforts.

- They are based on conservative estimates while encouraging the development of a more accurate MRV system over time through building national capacities.

- They will contribute towards the development of a national MRV-system, based on internationally accepted methodologies and following the IPCC reporting principles of completeness, consistency, transparency, uncertainty, comparability, and encourage independent international review of results.

When calculating reduced emissions from avoided deforestation, an interim default value of 100 tons of Carbon is applied. This interim carbon figure corresponds to 367 tons of $\mathrm{CO} 2$. When calculating emissions caused by forest degradation, a default value of 400 tons per hectare is applied, this corresponds to 1468 tons of $\mathrm{CO} 2$. These conservative carbon values help to ensure that emission reductions from deforestation are not over-estimated and emissions from forest degradation are not under-estimated.

The interim indicators are described in table 2 below.

\section{Section 3.1.3 Calculating Payment}

Payments due to Guyana will be calculated by applying an interim carbon price of US\$5/ton $\mathrm{CO} 2$, as established in Brazil's Amazon Fund.

However, this price will only be applied if Guyana's observed deforestation rate is below the agreed level. This is explained in the following section.

Agreed maximum level of Deforestation

If designed for maximum effectiveness and efficiency, a future global incentive system could allow for significant variations in individual countries' deforestation rates while still ensuring global additionality.

However, in the absence of a global system, such an approach alone would imply that Guyana would be eligible for significant payments even if it were to increase its deforestation along a business-as-usual trajectory towards the agreed reference level of $0.275 \%$

However, neither Norway nor Guyana wishes to see such an increase in deforestation, and in November 2009 the Joint Concept Note clearly stated that

"(...) the Participants agree that Norwegian financial support from 2011 onwards is also dependent on no national-level increase in deforestation over an agreed level that shouid be as close to historical levels as is reasonable in light of expanded knowledge of these historical rates and the quality of that knowledge. Such a level can only be set when more robust data is available concerning current and historic deforestation."

At the same time, Guyana's national development requires limited but strategic use of forest assets to enable (i) a limited amount of economic activity to take place within the forest, where the economic value to the nation of such activity is very valuable; (ii) a limited amount of essential national infrastructure to be constructed where this is in line with critical development goals; (iii) support for the sustainable development of forest villages. Guyana is reaching a stage of economic development where experience from other countries suggests that enabling these objectives brings further deforestation pressures. 
Therefore, pending the introduction of a global incentive system, it would defeat the purpose of making REDD + an attractive development option for forest countries if this REDD + agreement meant that no increases at all be allowed in Guyana's historically low deforestation rates. First, the rates are so small that the margin of error of measurements in itself could yield significant annual variations (as measured in per cent). Second, insisting on such strict limitations would probably yield an insufficient incentive structure for the people of Guyana to stick to a lowdeforestation development path, as the economic downsides would be disproportionate to the incentive offered.Third, the relevance of historical trends when deforestation rates are extremely low is not as useful a predictor of future pressures on the forest as it is in countries with higher historic rates of deforestation.

There is no given mathematically correct answer to how these concerns should best be balanced. Guyana and Norway have chosen a model that on the one hand enables Guyana to exercise careful, strategic use of limited forest areas for high value economic activity, the construction of essential national infrastructure and sustainable development of forest villages. On the other hand, the model puts in place incentives that would quickly penalize an upward trend in deforestation, see box 2 .

The essence of this approach has two implications:

(i) One-off predictable and controllable deforestation events will be allowed for critical national infrastructure that is part of Guyana's transition to a low carbon development path. ${ }^{5}$ During the duration of the current Guyana-Norway partnership, the only such event will be the construction of the Amaila Falls hydro-electricity plant. This plant is the flagship of Guyana's Low Carbon Development Strategy, and is expected to eliminate over $92 \%$ of the country's energy-related emissions, after the emissions associated with its construction are accounted for ${ }^{6}$. It will only go ahead after Guyana and Norway have agreed that the necessary Environmental and Social safeguards have been met, and an independent verification agreed by Guyana and Norway confirms the overall beneficial effects of the project from a climate change perspective.

(ii) Economic activities will be permitted within the forest, within a ceiling on deforestation of 0.056 per annum, without any financial penalty apart from the reduction in compensation caused by a smaller margin between the reference level and the verified deforestation level. For any deforestation rate up to this level, Guyana will be eligible for payments equaling the full margin between the reference level and the verified deforestation level. For deforestation rates between 0,056 per cent and 0,1 per cent (unless they relate to the Amaila Falls project as described above), eligibility for payments would be calculated as a gradually decreasing percentage of the payments that would be due if only the margin between the reference level and the verified deforestation level were taken into account, as set out below. At deforestation rates at or above 0,1 per cent, no payments would be due to Guyana for that given year.

5 The exception is only from the 'agreed maximum level of deforestation' provision. The emissions resulting from such activities would still be part of the total deducted from the reference level to determine total payments due to Guyana. I.e., emissions from Amaila would still count as deduction in total amount due to Guyana in the years when Amaila was established.

6 The January 2011 ESIA for the Amaila Falls project can be found at http://amailahydropower.com/latestnews/key-project-documents. Section 5 details how a $92 \%$ reduction in net greenhouse gas emissions is calculated. 
Box 2:

Mechanism for reducing results based payments if deforestation rate exceeds the agreed maximum level $(0,056 \%)$

\begin{tabular}{|l|c|c|c|c|c|}
\hline $\begin{array}{l}\text { Deforestation } \\
\text { rates (\%) }\end{array}$ & $\begin{array}{c}\text { Up to } \\
0.056\end{array}$ & $\begin{array}{c}0.057- \\
0.062\end{array}$ & $\begin{array}{c}0.063- \\
0.080\end{array}$ & $\begin{array}{c}0.081- \\
0.090\end{array}$ & $0.091-0.1$ \\
\hline $\begin{array}{l}\text { Reduced } \\
\text { compensation } \\
\text { (\% per }\end{array}$ & 0 & 1,5 & 2,0 & 2,5 & 3,0 \\
$\begin{array}{l}0.0015 \\
\text { increased } \\
\text { deforestation) }\end{array}$ & & 0 & & & \\
\hline
\end{tabular}

Examples of reductions in compensation at levels above agreed maximum level:

\begin{tabular}{|l|c|c|c|c|c|}
\hline $\begin{array}{l}\text { Deforestation } \\
\text { rate (\%) }\end{array}$ & $\begin{array}{l}\text { Up to } \\
0.056\end{array}$ & 0.07 & 0.08 & 0.09 & 0.1 \\
\hline $\begin{array}{l}\text { Reduced } \\
\text { compensation } \\
(\%)\end{array}$ & 25 & 45 & 70 & 100 \\
\hline
\end{tabular}

This approach is compatible with the Government of Guyana's declared long-term strategy to maintain the maximum amount of forest cover in Guyana, if an appropriate incentive structure is in place to make this strategy viable. This is being done through a balanced mix of maintaining forests under full protection (areas where only small-scale subsistence farming by forest dependent communities is allowed) and sustainable commercial forest management (where existing forestry concessions can operate within the terms of their licenses and the GFC's sustainable forest management guidelines).

In sum, this means:

a) that a ceiling on the level of deforestation that can take place before 2015 with any incentives still flowing, has been set at only around 35 per cent of the level of deforestation that the reference level would imply;

b) the accommodation of limited annual upward variations to ensure that the incentive structure still makes REDD+ a positive development choice for Guyana; and

c) that Guyana is incentivized to maintain more than 99.5 per cent of its forest cover for the duration of the partnership.

See box 3 for a summary description of how performance based payments will be calculated.

Norwegian support to GRIF - alone or in combination with other contributors - will not exceed the sum calculated on the basis of the above described methodology.

It is also likely that while support from Norway will be sufficient to provide majority funding for results delivered by Guyana, in a given year, it is unlikely to equal the total sum owed to Guyana. Therefore, to ensure that the incentives which underpin the partnership are fully in place, Guyana and Norway will work together to seek to get other Participants to join the partnership.

Once other Participants are in place with sufficient commitments to the Partnership, this will enable Norwegian (and other Participants') contributions to vary directly with performance, i.e. a reduction in estimated emissions will lead to relatively higher contributions, increases to relatively lower contributions. 


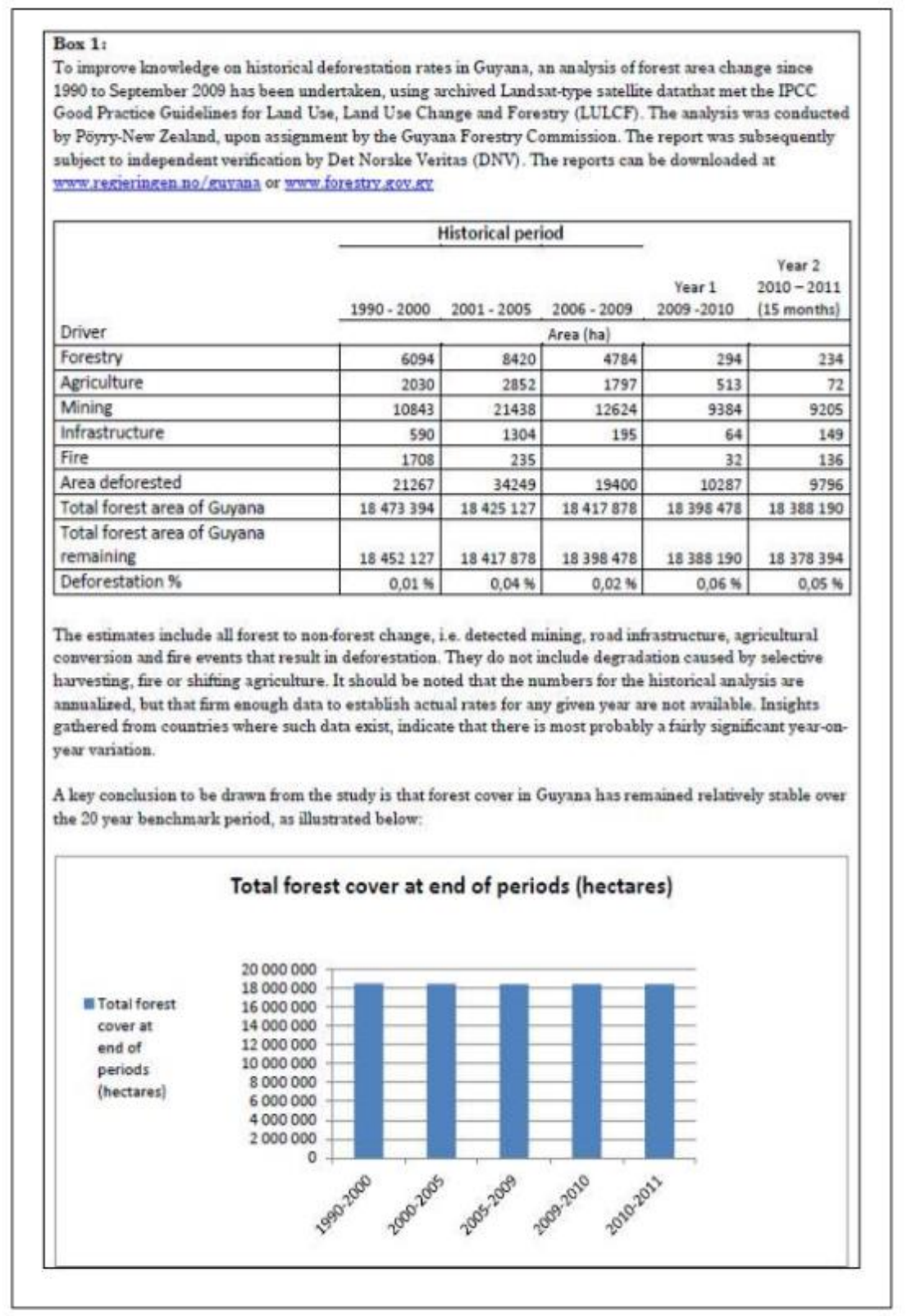


Box 3:

How will results based payments be calculated?

To calculate the results based payments due to Guyana based on the results in any given year, the following steps will be followed:

1. Subtracting Guyana's reported and verified deforestation rate from the agreed interim reference level of $0.275 \%$;

2. Calculating the carbon emission reductions achieved through avoided deforestation (as compared to the agreed reference level) by applying an interim and conservatively set estimate of carbon loss of $100 \mathrm{tC} / \mathrm{ha}$. This value will be replaced once a functional MRV system is in place. The interim carbon loss figure corresponds to $367 \mathrm{tCO}_{2} / \mathrm{ha}$.

3. Subtracting from that number changes in emissions - on a ton-by-ton basis - from forest degradation as measured against agreed indicators and their reference levels, as specified in Table 2 .

4. In calculating the carbon effects of forest degradation, an interim and conservatively set carbon density of $400 \mathrm{tC} / \mathrm{ha}$ will be applied. Upon agreement under the UNFCCC on how to estimate and account for emissions from degradation, this approach will be adjusted accordingly;

5. The tons of "avoided emissions" is then multiplied with an interim carbon price of US\$ $5 /$ ton $\mathrm{CO} 2$, as established in Brazil's Amazon Fund.

6. If the deforestation rate in a given rate exceeds 0,056 , the payments will be gradually reduced as a proportion of the sum derived through step 1-4 above, or cease (if at or exceeding 0,1 per cent), as stipulated in section 3.1.3, box 2 .

Section 3.2 Monitoring Progress Against reducing emissions and enhancing removals of carbon in Guyana's forests

Progress against reducing emissions and enhancing removals of carbon in Guyana's Forests will in time be measured through the MRV system that is being put in place as set out in the MRVsystem Road-map ${ }^{7}$.

Pending the implementation of the MRV-system, Table 2 sets out the interim REDD+ performance indicators described above. Guyana and Norway agree that these indicators will evolve as more scientific and methodological certainty is gathered concerning the means of verification for each indicator, in particular the capability of the MRV system at different stages of development.

A roadmap for the establishment of a national MRV system and accompanying Terms of Reference for the system have been developed to provide a framework for verifiable, performance monitoring, set against international best practice and nationally appropriate

${ }^{7}$ http://vwww.forestry.gov.gy/Downloads/Terms_of \%20Reference for_Guyana's_MRVS_Draft.pdf . 
circumstances. In years 1, 2 and 3 (2009-2011), implementation has also commenced in a number of administrative and technical areas. Broad based MRV-system Steering and Technical Committees have been established and initial technical work has commenced and advanced in forest area and forest carbon stock assessment and monitoring. The framework has been created for annual reporting on deforestation and forest degradation in accordance with interim REDD+ Performance Indicator that will evolve into a full MRV system. The first product has been the completion of historic reporting on forest/non forest cover and deforestation by driver, over the period 1990 to 2009, accompanied by annual reporting of forest/non forest cover and deforestation and forest degradation results in accordance with REDD+ Interim indicators set out in the JCN. Concurrently, work is also proceeding for field based assessments of forest carbon stock assessment and monitoring, the establishment of demonstration activities, and detailed technical studies on reference level setting and forest degradation, as well as other areas.

During 2009-2011, significant improvements to Guyana's ability to measure deforestation indicators were made. In particular, it was determined (and independently verified) that deforestation rates were extremely low.

Progress has also been made to gain a greater understanding of how degradation is to be measured, and this leading to further work in 2013 and onwards, when new scientifically-based knowledge will enable progress on refining the reporting on indicators to assess degradation, including that from mining and infrastructure (currently the dominant drivers of degradation).

Guyana and Norway have agreed that annual independent verification of REDD+ performance indicators will be conducted by one or more neutral expert organizations, to be appointed jointly by the Participants. The assessment determines what results Guyana has delivered according to the established indicators for REDD-plus performance. For the first and second reporting periods, the measurement of progress was carried out by Poyry, Indufor and WinRock in collaboration with the Guyana Forestry Commission, and independent verification was carried out by DNV. DNV was selected on the basis of an international tender process in accordance with Norwegian procurement regulations.

\section{Section 4: Financial mechanism:}

The Guyana REDD + Investment Fund (GRIF) is channeling REDD-plus financial support from Norway and other potential contributors to the implementation of Guyana's LCDS.

Pending the creation of an international REDD + mechanism, the Guyana REDD+ Investment Fund (GRIF) represents an effort to create an innovative climate finance mechanism which balances national sovereignty over investment priorities with ensuring that REDD+ funds adhere to globally accepted financial, environmental and social safeguards.

The GRIF is an interim solution for channelling climate finance to Guyana - designed for the Guyana-Norway Partnership up to 2015 - pending the transfer of payment intermediation, and associated processes, to Guyana's national systems. This will be done when it is possible to specify how independent verification of Guyana's adherence globally accepted financial, environmental and social safeguards can be implemented. This will draw on UNFCCC and other relevant guidance.

Until such time as national systems can be used, the World Bank's International Development Association (IDA) was invited byGuyana and Norway to act as Trustee and is responsible for providing financial intermediary services to the GRIF. 
The Trustee (i) receives payments for forest climate services provided by Guyana; and (ii) transfers these payments and any investment income earned on these payments, net of any administrative costs, to Partner Entities, for projects and activities that support the implementation of Guyana's LCDS. Transfer of funds takes place on approval by the GRIF Steering Committee, which consists of Guyana and Norway, with observers from Partner Entities, as well as Guyanese and Norwegian civil society.

Partner Entities provide operational services for the approved LCDS investments, and apply their own globally accepted operational procedures and safeguards. As of December 2012, Guyana and Norway have approved as Partner Entities the Inter-American Development Bank (IDB), the World Bank and the United Nations Development Group.

More information on the operation of the GRIF is set out in the Administration Agreement between the Government of Norway and the World Bank. ${ }^{8}$

\section{Improved Financial Intermediation}

The Guyana REDD + Investment Fund (GRIF) has experienced significantly slower than anticipated progress, although important lessons have been learned. The two Governments recognize the need for disbursements from the GRIF into Guyana's economy and relevant LCDS and REDD + investments to strengthen the effectiveness of REDD+ as an intrinsic part of Guyana's sustainable development. As such, work is being undertaken to allow for a more flexible, fit-for-purpose financial mechanism that would ensure the application of internationally recognized safeguards while allowing for stronger Guyanese ownership. As part of this, a pilot for an IDB role as Financial and Safeguards Intermediary is being developed, with the goal of it being operational in the first half of 2013

Goal of the partnership

The proposed role for the IDB as Fiduciary Safeguards Intermediary will ensure compliance with IDB's fiduciary, environmental and social safeguards for simpler projects. If proven suitable for the implementation of a range of GoG-activities it can also be useful to the further development of Guyana's domestic institutional capability.

It is hoped that by 2015 , the financial mechanisms of the partnership can be used as examples of interim flexible climate financing instruments, which allow for rapid approval of projects and stronger national ownership, while at the same time applying internationally recognized (in this case IDB) standards for fiduciary, environmental and social safeguards.

$8_{\text {http://lcds.gov.gy/guyana-redd-investment-fund-grif.htm] }}$ 
Table 1- Key REDD+ Efforts in 2012/13 (from 21 December 2012 to 15 June 2013):

\author{
Improved REDD+ Governance
}

Through 2012, the Government of Guyana continued to improve governance standards within the REDD+-related forest dependent sectors. These efforts to improve REDD+-related governance, will continue in 2013 and onwards. The information necessary to assess Guyana's completion of the actions below will be easily accessible in the public space. ${ }^{9} \mathrm{Based}$ on the goals of the partnership presented in section 2 the following actions will take place between December $21^{\text {st }}$ 2012 and June $15^{\text {th }} 2013$ :

\title{
Strategic framework
}

- Continued engagement between the IDB and the GFC with the aim of advancing an agreement on the FCPF, contingent on the completion of IDB's internal processes of approval of Guyana's FCPF programme.

- Guyana will publish its LCDS Addendum which will highlight its updated REDD+ strategy, including learnings to date from the Guyana-Norway partnership and an outline plan for advancement on the FCPF programme.

\section{Continuous multi-stakeholder consultation process}

- Monthly meetings of the MSSC, with comprehensive minutes of every meeting made publicly available immediately upon approval from the following MSSC meeting.

- Establishment of a Communications and Outreach team within the OCC, PMO or REDD+ secretariat, in anticipation of GRIF resources for its operations (see next point).

- With reference to the long term goals: Information and consultation project concept note presented to GRIF SC. The project will be addressing general information concerning Climate change and REDD+, LCDS and the Norway Guyana partnership, specific information on Amerindian land titling, the opt-in mechanism, FLEGT, EITI, IFM, GRIF projects and other relevant information. The project will recognize the need of tailored and non-internet based information to indigenous groups and others without stable internet access.

- Regular updates of the GRIF and LCDS webpages.

\section{Governance}

- Application for EITI Candidacy at EITI board meeting in May 2013

- Develop an interim definition of legality for the EU FLEGT VPA for Guyana by end of June 2013

- Outline in 2013 a GoG (MNRE) programme, with a particular focus on specific efforts to manage degradation from extractive activities where this needs to be done, including, for example: an enhanced miners' environmental knowledge programme through a mining extension service initiative and enhanced dialogue with the sectors and relevant stake holders towards ensuring sectoral best practices are applied and sustained thereafter, where necessary

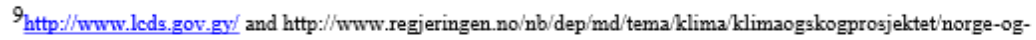
guyana-avtale-om-a-bevare-guyan html?id= 592318

1 
The rights of indigenous peoples and other local forest communities as regards REDD+

- Present the Amerindian Land Titling project to the GRIF steering committee, after the normal GRIF public hearing period for new project notes is concluded

- Opt-in concept note ready and pilot community for opt-in mechanism selected

- Strategy and development of tailored information and consultations for hinterland communities addressed in the outreach program.

- Initiating implementation of Community Development Plans through the Amerindian Development Fund.

$\underline{\text { Integrated land-use planning and management }}$

- Strategic Approach to land use planning publicly communicated by March 2013.

Establish a plan, timeline and responsible agency for the development of a map of area use (including, but not limited to: existing and planned concession and reconnaissance areas for forestry and mining, titled lands for Amerindian communities, areas planned and concessioned for industrial agriculture etc.)

- Based on the evolving area use map, determine a roadmap by June 2013 to codify the formal status of varying degrees of protection for the areas identified as Intact Forest Landscapes and priority areas for biodiversity. This will gradually replace the Intact Forest Landscapes interim performance indicator. 
Table 2: Interim Indicators for REDD+ performance in Guyana ${ }^{10}$

\begin{tabular}{|c|c|c|c|c|}
\hline $\begin{array}{l}\text { Source of } \\
\text { emissions or } \\
\text { removals }\end{array}$ & Justification & $\begin{array}{l}\text { Interim } \\
\text { performance } \\
\text { indicator }\end{array}$ & $\begin{array}{l}\text { Monitoring and } \\
\text { estimation }\end{array}$ & $\begin{array}{l}\text { IPCC } \\
\text { LULUCF } \\
\text { reporting }\end{array}$ \\
\hline \multicolumn{5}{|c|}{ Deforestation indicator: } \\
\hline Gross deforestation & $\begin{array}{l}\text { Emissions from } \\
\text { the loss of } \\
\text { forests are } \\
\text { among the } \\
\text { largest per unit } \\
\text { emissions from } \\
\text { terrestrial } \\
\text { carbon loss. }\end{array}$ & $\begin{array}{l}\text { Rate of } \\
\text { conversion of } \\
\text { forest area as } \\
\text { compared to } \\
\text { agreed reference } \\
\text { level. } \\
\text { Forest area as } \\
\text { defined by } \\
\text { Guyana in } \\
\text { accordance with } \\
\text { the Marrakech } \\
\text { accords: } \\
\text { - Minimum } 30 \% \\
\text { tree cover } \\
\text { - At a minimum } \\
\text { height of } 5 \\
\text { meter } \\
\text { - Over a } \\
\text { minimum area } \\
\text { of } 1 \text { ha. } \\
\text { Conversion of } \\
\text { natural forests to } \\
\text { tree plantations } \\
\text { shall count as } \\
\text { deforestation with } \\
\text { full carbon loss. } \\
\text { Forest area } \\
\text { converted to new } \\
\text { infrastructure } \\
\text { including logging } \\
\text { roads, shall count } \\
\text { as full carbon loss, } \\
\text { unless otherwise }\end{array}$ & $\begin{array}{l}\text { Forest cover as of } \\
\text { September } 2009 \text { will } \\
\text { be used as baseline } \\
\text { for monitoring gross } \\
\text { deforestation. } \\
\text { Reporting to be } \\
\text { based on medium } \\
\text { and high resolution } \\
\text { satellite imagery } \\
\text { and in-situ } \\
\text { observations where } \\
\text { necessary. } \\
\text { Monitoring shall } \\
\text { detect and report on } \\
\text { expansion of human } \\
\text { infrastructure (eg. } \\
\text { new roads, } \\
\text { settlements, } \\
\text { pipelines, } \\
\text { mining/agriculture } \\
\text { activities etc.) }\end{array}$ & $\begin{array}{l}\text { Activity } \\
\text { data on } \\
\text { change in } \\
\text { forest land }\end{array}$ \\
\hline
\end{tabular}

${ }^{10}$ The Participants agree that these indicators will evolve as more scientific and methodological certainty is gathered concerning the means of verification for each indicator, in particular the capability of the MRV system at different stages of development. Based on experiences from the first and second reporting and verification exercise, some adjustments have been made in this table. However, the process has identified a need to develop further detail on the operationalisation of the indicators. Significant improved ability to operationalise the indicators has already been achieved, and this process vill continue over the duration of the partnership. 


\begin{tabular}{|c|c|c|c|c|}
\hline & & $\begin{array}{l}\text { informed by field } \\
\text { study that } \\
\text { identifies an } \\
\text { alternative carbon } \\
\text { loss level. }\end{array}$ & & \\
\hline \multicolumn{5}{|c|}{ Degradation indicators: } \\
\hline $\begin{array}{l}\text { Loss of intact } \\
\text { forest landscapes }\end{array}$ & $\begin{array}{l}\text { Degradation of } \\
\text { intact forest } \\
\text { through human } \\
\text { activities will } \\
\text { produce a net } \\
\text { loss of carbon } \\
\text { and is often the } \\
\text { pre-cursor to } \\
\text { further } \\
\text { processes } \\
\text { causing long- } \\
\text { term decreases } \\
\text { in carbon } \\
\text { stocks. } \\
\text { Furthermore, } \\
\text { preserving } \\
\text { intact forests } \\
\text { will contribute } \\
\text { to the } \\
\text { protection of } \\
\text { biodiversity. }\end{array}$ & $\begin{array}{l}\text { The total area of } \\
\text { intact forest } \\
\text { landscapes within } \\
\text { the country should } \\
\text { remain constant. } \\
\text { Any loss of intact } \\
\text { forest landscapes } \\
\text { area } 12 \text { shall be } \\
\text { accounted as } \\
\text { deforestation with } \\
\text { full carbon loss. } \\
\text { The IFL Baseline } \\
\text { map developed in } \\
\text { the first reporting } \\
\text { period will be used } \\
\text { to assess } \\
\text { changes. Note that } \\
\text { this indicator will } \\
\text { be subject to } \\
\text { review as } \\
\text { stipulated in } \\
\text { section } 2.1 .13\end{array}$ & $\begin{array}{l}\text { Using similar } \\
\text { methods as for } \\
\text { forest area change } \\
\text { estimation. }\end{array}$ & $\begin{array}{l}\text { Changes in } \\
\text { carbon } \\
\text { stocks in } \\
\text { forests } \\
\text { remaining } \\
\text { as forests }\end{array}$ \\
\hline $\begin{array}{l}\text { Forest } \\
\text { management (i.e. } \\
\text { selective logging) } \\
\text { activities in natural } \\
\text { or semi-natural } \\
\text { forests }\end{array}$ & $\begin{array}{l}\text { Forest } \\
\text { management } \\
\text { should work } \\
\text { towards } \\
\text { sustainable } \\
\text { management of }\end{array}$ & $\begin{array}{l}\text { All areas under } \\
\text { forest } \\
\text { management } \\
\text { should be } \\
\text { rigorously } \\
\text { monitored and }\end{array}$ & $\begin{array}{l}\text { Data on extracted } \\
\text { volumes is collected } \\
\text { by the Forestry } \\
\text { Commission. } \\
\text { Independent forest }\end{array}$ & $\begin{array}{l}\text { Changes in } \\
\text { carbon } \\
\text { stocks in } \\
\text { forests } \\
\text { remaining } \\
\text { as forests }\end{array}$ \\
\hline
\end{tabular}

${ }^{11}$ Intact Forest Landscape (IFL) is defined as a territory within today's global extent of forest cover which contains forest and non-forest ecosystems minimally influenced by human economic activity, with an area of at least $500 \mathrm{~km}^{2}(50,000 \mathrm{ha})$ and a minimal width of $10 \mathrm{~km}$ (measured as the diameter of a circle that is entirely inscribed within the boundaries of the territory)." (See www.intactforests.org)

12 When assessing loss of IFL, the established elimination criteria will be applied:

- Settlements (including a buffer of $1 \mathrm{~km}$ );

- Infrastructure used for transportation between settlements or for industrial development of natural resources, including roads (except unpaved trails), railways, navigable waterways (including seashore), pipelines and power transmission lines (including a buffer of $1 \mathrm{~km}$ on each side);

- Areas used for agriculture and timber production;

- Areas affected by industrial activities during the last 30-70 years, such as logging, mining, oil and gas exploration and extraction, peat extraction, etc.

The threshold values for IFL-patches ( $500 \mathrm{~km} 2$, min. width $10 \mathrm{kms}$ ) will not be applied in assessing IFL loss.

13 The analysis of loss of IFL area during the second reporting period was conducted after the verification process had ended. The result reported under this indicator for the second reporting period will therefore be verified in relation to the year 3 verification.

in 


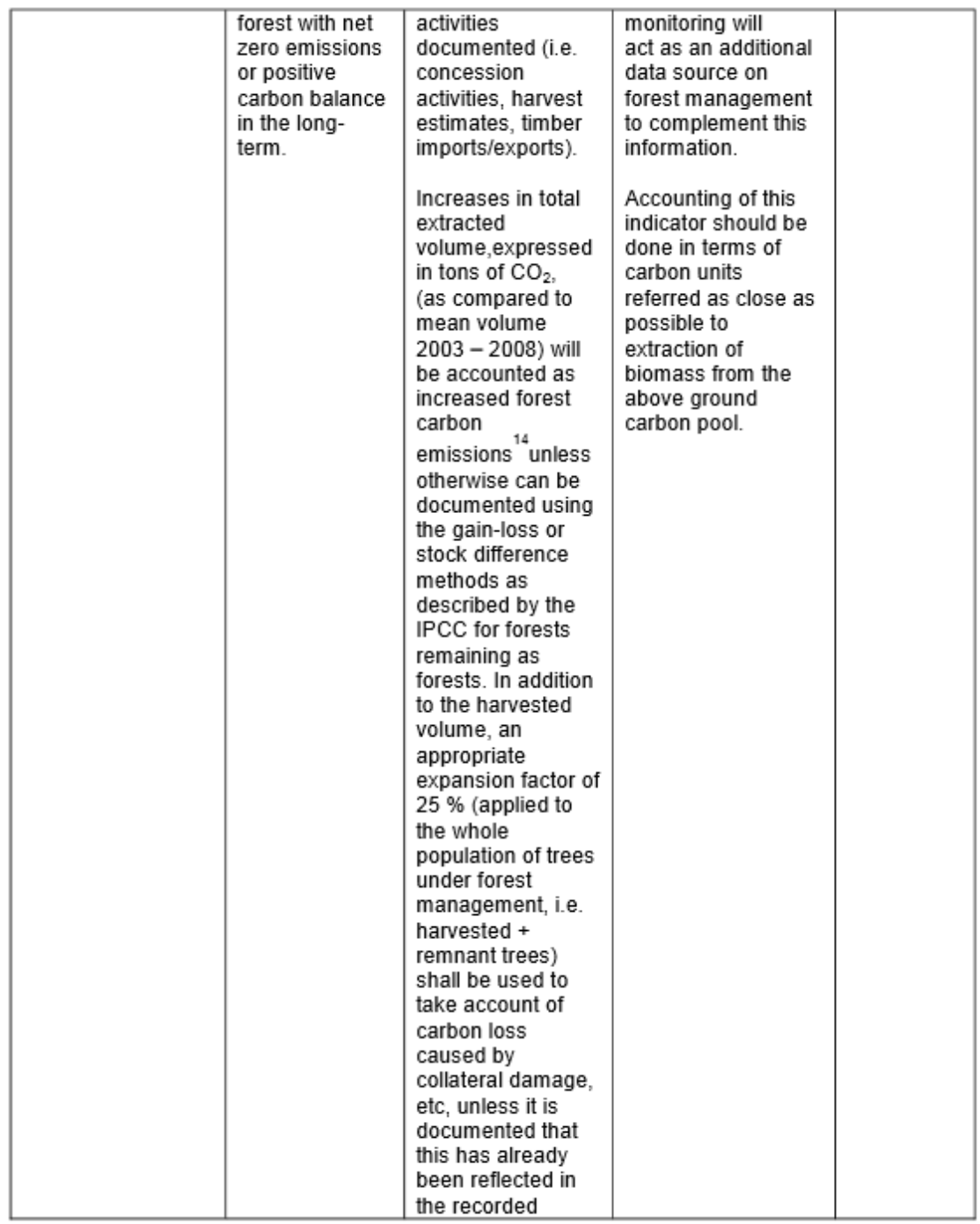

14 The participants agree on the need to create incentives for net-zero or carbon positive forest management practices in Guyana. This will require a sophisticated MRV system to assess the carbon effects of forestry activities. This will be an objective of the MRV system under development. In the interim period, focus will be on incentives for avoiding increased emissions from forest management activities.

on 


\begin{tabular}{|c|c|c|c|c|}
\hline & & extracted volume. & & \\
\hline $\begin{array}{l}\text { Carbon loss as } \\
\text { indirect effect of } \\
\text { new infrastructure. }\end{array}$ & $\begin{array}{l}\text { The } \\
\text { establishment } \\
\text { of new } \\
\text { infrastructure in } \\
\text { forest areas } \\
\text { often } \\
\text { contributes to } \\
\text { forest carbon } \\
\text { loss outside the } \\
\text { areas directly } \\
\text { affected by } \\
\text { constructions. }\end{array}$ & $\begin{array}{l}\text { High resolution } \\
\text { satellite imagery } \\
\text { and/or field } \\
\text { observations shall } \\
\text { be used to detect } \\
\text { degradation in a } \\
100 \text { m buffer } \\
\text { surrounding new } \\
\text { infrastructure (incl. } \\
\text { mining sites, } \\
\text { roads, pipelines, } \\
\text { reservoirs etc.). } \\
\text { As the benchmark } \\
\text { for this indicator, } \\
\text { the annualized } \\
\text { number of the } \\
\text { mapped degraded } \\
\text { area from the } \\
\text { second reporting } \\
\text { period will be used } \\
\text { (4368 ha) } 15 \text {. Any } \\
\text { degradation above } \\
\text { this benchmark in } \\
\text { subsequent } \\
\text { reporting years will } \\
\text { result in reduced } \\
\text { compensation. } \\
\text { Unless other } \\
\text { emission factors } \\
\text { can be } \\
\text { documented } \\
\text { through the } \\
\text { MRVS, these } \\
\text { areas shall be } \\
\text { accounted with a } \\
50 \% \text { annual }\end{array}$ & $\begin{array}{l}\text { Mediumand high } \\
\text { resolution } \\
\text { satellite to be used } \\
\text { for detecting human } \\
\text { infrastructure (i.e. } \\
\text { small scale mining) } \\
\text { and related } \\
\text { degradation. }\end{array}$ & $\begin{array}{l}\text { Changes in } \\
\text { carbon } \\
\text { stocks in } \\
\text { forests } \\
\text { remaining } \\
\text { as forests }\end{array}$ \\
\hline
\end{tabular}

${ }^{15}$ For the second reporting period, Guyana made use of a new and significantly improved method for mapping infrastructure related degradation. A historical proxy analysis of areas affected by degradation from infrastructure was conducted for the period 2000-2010. The total area of a 100m buffer surrounding all new infrastructure was calculated for the historical period, as well as for the for the year 2 reporting period. This analysis indicated that the area affected by new infrastructure in the year 2 reporting period was comparable to the historical period. This exercise will be verified in the next verification of the interim performance indicators.

As a benchmark for infrastructure related degradation in future reporting periods, the area mapped as degraded in the second reporting period will be used. This area equaled 5460 ha, but as the second reporting period had a length of 15 months, and subsequent reporting periods will be 12 months, this number was annualized. The new benchmark is therefore 4368 ha. 


\begin{tabular}{|c|c|c|c|c|}
\hline & & $\begin{array}{l}\text { carbon loss, i.e. } \\
\text { areas mapped in } \\
\text { one year will be } \\
\text { accounted with a } \\
\text { further } 50 \% \\
\text { carbon loss in } \\
\text { subsequent } \\
\text { reporting periods. }\end{array}$ & & \\
\hline $\begin{array}{l}\text { Emissions resulting } \\
\text { from subsistence } \\
\text { forestry, land use } \\
\text { and shifting } \\
\text { cultivation lands } \\
\text { (i.e. slash and burn } \\
\text { agriculture). }\end{array}$ & $\begin{array}{l}\text { Emissions } \\
\text { resulting from } \\
\text { communities to } \\
\text { meet their local } \\
\text { needs may } \\
\text { increase as } \\
\text { result of inter } \\
\text { alia shorter } \\
\text { fallow cycle or } \\
\text { area expansion. }\end{array}$ & $\begin{array}{l}\text { Not considered } \\
\text { relevant in the } \\
\text { interim period } \\
\text { before a proper } \\
\text { MRV-system is in } \\
\text { place. }\end{array}$ & & $\begin{array}{l}\text { Changes in } \\
\text { carbon } \\
\text { stocks in } \\
\text { forests } \\
\text { remaining } \\
\text { as forests }\end{array}$ \\
\hline $\begin{array}{l}\text { Emissions resulting } \\
\text { from illegal logging } \\
\text { activities }\end{array}$ & $\begin{array}{l}\text { Illegal logging } \\
\text { results in } \\
\text { unsustainable } \\
\text { use of forest } \\
\text { resources while } \\
\text { undermining } \\
\text { national and } \\
\text { international } \\
\text { climate change } \\
\text { mitigation } \\
\text { policies }\end{array}$ & $\begin{array}{l}\text { Areas and } \\
\text { processes of } \\
\text { illegal logging } \\
\text { should be } \\
\text { monitored and } \\
\text { documented as far } \\
\text { as practicable. }\end{array}$ & $\begin{array}{l}\text { The monitoring of } \\
\text { illegal logging is } \\
\text { within the main } \\
\text { objectives of the } \\
\text { GFC's forest } \\
\text { monitoring system, } \\
\text { and is informed by } \\
\text { an illegal logging } \\
\text { database. In } \\
\text { addition to reporting } \\
\text { on illegal logging via } \\
\text { the database, } \\
\text { Independent Forest } \\
\text { Monitoring will } \\
\text { support } \\
\text { performance } \\
\text { monitoring of forest } \\
\text { legality through the } \\
\text { IFM framework. } \\
\text { Should IFM detect } \\
\text { potentially } \\
\text { significant } \\
\text { challenges with the } \\
\text { established forest } \\
\text { monitoring system, } \\
\text { this indicator will be } \\
\text { reassessed. } \\
\text { In the absence of } \\
\text { hard data on } \\
\text { volumes of illegally } \\
\text { harvested wood, a } \\
\text { default factor of } \\
\text { 15\% } \\
\text { (as compared to the } \\
\text { legally harvested }\end{array}$ & $\begin{array}{l}\text { Changes in } \\
\text { carbon } \\
\text { stocks in } \\
\text { forests } \\
\text { remaining } \\
\text { as forests }\end{array}$ \\
\hline
\end{tabular}

- - 


\begin{tabular}{|c|c|c|c|c|}
\hline & & & $\begin{array}{l}\text { volume) will be } \\
\text { used. This factor } \\
\text { can be adjusted up } \\
\text { and downwards } \\
\text { pending } \\
\text { documentation on } \\
\text { illegally harvested } \\
\text { volumes, inter alia } \\
\text { from Independent } \\
\text { Forest Monitoring. } \\
\text { Medium resolution } \\
\text { satellite to be used } \\
\text { for detecting human } \\
\text { infrastructure and } \\
\text { targeted sampling of } \\
\text { high-resolution } \\
\text { satellite for selected } \\
\text { sites. } \\
\text { Accounting of this } \\
\text { indicator should be } \\
\text { done in terms of } \\
\text { carbon units } \\
\text { referred as close as } \\
\text { possible to } \\
\text { extraction of } \\
\text { biomass from the } \\
\text { above ground } \\
\text { carbon pool. }\end{array}$ & \\
\hline $\begin{array}{l}\text { Emissions resulting } \\
\text { from } \\
\text { anthropogenically } \\
\text { caused forest fires }\end{array}$ & $\begin{array}{l}\text { Forest fires } \\
\text { result in direct } \\
\text { emissions of } \\
\text { several } \\
\text { greenhouse } \\
\text { gases }\end{array}$ & $\begin{array}{l}\text { Area of forest } \\
\text { burnt each year } \\
\text { should decrease } \\
\text { compared to } \\
\text { current amount }\end{array}$ & $\begin{array}{l}\text { Coarse-resolution } \\
\text { satellite active fire } \\
\text { and burnt area data } \\
\text { products in } \\
\text { combination with } \\
\text { medium resolution } \\
\text { satellite data used } \\
\text { for forest area } \\
\text { changes }\end{array}$ & $\begin{array}{l}\text { Emissions } \\
\text { from } \\
\text { biomass } \\
\text { burning }\end{array}$ \\
\hline \multicolumn{5}{|c|}{ Indicator on increased carbon removals: } \\
\hline $\begin{array}{l}\text { Encouragement of } \\
\text { increasing carbon } \\
\text { sink capacity of } \\
\text { non-forest and } \\
\text { forest land }\end{array}$ & $\begin{array}{l}\text { Changes from } \\
\text { non-forest land } \\
\text { to forest (i.e. } \\
\text { through } \\
\text { plantations, } \\
\text { land use } \\
\text { change) or } \\
\text { within forest } \\
\text { land } \\
\text { (sustainable } \\
\text { forest } \\
\text { management, } \\
\text { enrichment } \\
\text { planting) can } \\
\text { increase the }\end{array}$ & $\begin{array}{l}\text { Not considered } \\
\text { relevant in the } \\
\text { interim period } \\
\text { before a proper } \\
\text { MRV-system is in } \\
\text { place but any } \\
\text { dedicated activities } \\
\text { should be } \\
\text { documented as far } \\
\text { as practicable. } \\
\text { In accordance with } \\
\text { Guyanese policy, } \\
\text { an environmental } \\
\text { impact }\end{array}$ & & $\begin{array}{l}\text { Activity } \\
\text { data on } \\
\text { change to } \\
\text { forest land } \\
\text { and } \\
\text { changes in } \\
\text { carbon } \\
\text { stocks in } \\
\text { forests } \\
\text { remaining } \\
\text { as forests }\end{array}$ \\
\hline
\end{tabular}

- 


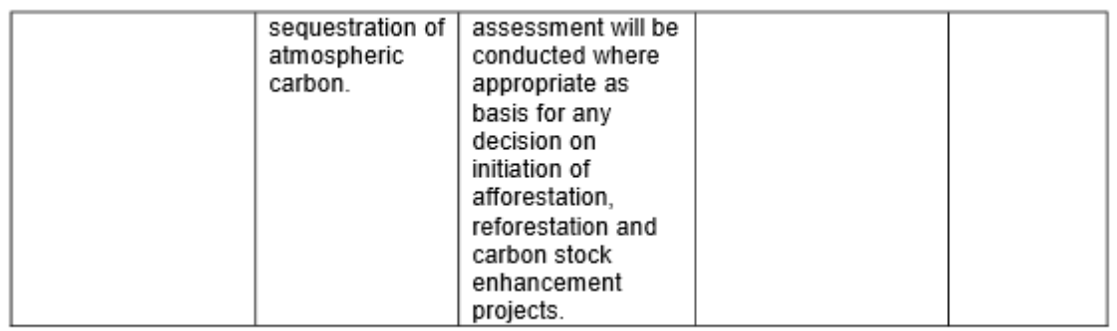




\section{Appendix 3}

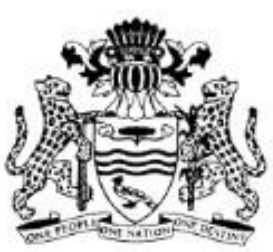

\section{Memorandum of Understanding between the Government of the Cooperative Republic of Guyana and the Government of the Kingdom of Norway regarding Cooperation on Issues related to the Fight against Climate Change, the Protection of Biodiversity and the Enhancement of Sustainable Development}

The Government of the Cooperative Republic of Guyana (Guyana) and the Government of the Kingdom of Norway (Norway), (hereinafter referred to as the "Participants"):

bearing in mind that climate change is among the greatest challenges facing the world today;

recognizing that cooperation on climate change issues can be instrumental in reducing greenhouse gas emissions globally and has a positive impact on the socio-economic development of developing countries and their communities;

recalling that Guyana and Norway are Parties to the United Nations Framework Convention on Climate Change (UNFCCC), the Kyoto Protocol, and the Convention on Biological Diversity; and are signatories to the United Nations Declaration on the Rights of Indigenous Peoples (UNDRIP);

considering that the Preamble to the UNFCCC acknowledges that the global nature of climate change calls for the widest possible cooperation between all countries, and their participation in an effective and appropriate international response in accordance with their common but differentiated responsibilities and respective capabilities and their social and economic conditions, and that commitments in this regard are specified in Article 4 of the UNFCCC;

recognizing the relevance of Guyana's National Development Strategy (NDS) and National Competitiveness Strategy (NCS) as the overall policy framework for Guyana's development plans, and Guyana's Low Carbon Development Strategy (LCDS) as an integral part of this overall policy framework;

noting that the LCDS includes a strong commitment to reducing emissions from deforestation and forest degradation, including conservation, sustainable management of forests and 
enhancement of forest carbon stocks (REDD-plus') and the significant contribution that this can make to the global effort to mitigate climate change;

expressing a willingness to work together to provide the world with a relevant, replicable model for how REDD-plus can align the development objectives of forest countries with the world's need to combat climate change;

declaring that financial support from Norway for results achieved by Guyana in reducing emissions from deforestation and forest degradation will be used in full to support activities and investments within the framework of Guyana's LCDS;

declaring that nothing in this Memorandum of Understanding (MoU) will be considered to prejudge the Participants' views on the mechanism through which developing countries should be paid for REDD-plus under a future UNFCCC REDD-plus arrangement. When such an arrangement is defined under the UNFCCC, it will define reference levels - or the methodology to set these - and the amount of results-based financial support for which developing forest countries will be eligible will be derived from the reference levels. Norwegian financial support and Guyana's obligations will be reassessed accordingly;

expressing the political will to develop a lasting process of cooperation on matters relating to global climate change, including REDD-plus, the protection of biodiversity and the rights and livelihoods of indigenous peoples and local forest communities;

have reached the following understanding:

\section{OBJECTIVE}

1. The objective of this MoU is to foster partnership between Guyana and Norway on issues of climate change, biodiversity and sustainable, low carbon development. Of particular importance is the establishment of a comprehensive political and policy dialogue on these issues, and close cooperation regarding Guyana's REDD-plus efforts, including the establishment of a framework for result-based Norwegian financial support to Guyana's REDD-plus efforts.

\section{PILLARS OF COOPERATION}

2. To further the objective laid out in paragraph 1 of this MoU, the Participants decide to enter into broad cooperation based on three main pillars:

a) A regular, systematic policy and political dialogue to facilitate a constructive exchange of views on global climate change and relevant environmental issues such as biodiversity. The overarching goal of this cooperation will be to contribute to the establishment of a new, global climate change regime and the further improvement of this

'As defined in the Bali Action Plan (2/CP,13). 
regime over time. In particular, the Participants intend to contribute to the creation of a robust mechanism for the inclusion of REDD-plus in a global climate regime. The Participants agree that Norway's submission to the UNFCCC on REDD-plus and the work of the Informal Working Group on Interim Financing for REDD+ provide an appropriate starting point for such efforts.

b) Collaboration, knowledge building, and sharing of lessons learned within the field of sustainable, low-carbon development, with REDD-plus as the key component of this. Sustainable, low-carbon development is essential if global warming is to not increase by more than $2^{\circ} \mathrm{C}$ above pre-industrial levels. Given the significant contribution of emissions from deforestation and forest degradation to climate change, and the real risk of increased pressure on forests in currently low-deforesting countries as rates in currently highdeforesting countries are decreased, the Participants consider it crucial that all tropical forest countries, both high- and low-deforesting countries, are given incentives to reduce and avoid emissions from deforestation and forest degradation.

c) Collaboration on REDD-plus, including establishing a framework for financial support from Norway into a Guyana REDD-plus Investment Fund. Financial support will be linked to Guyana's success in limiting greenhouse gas emissions from deforestation and forest degradation and establishing institutions and practices to strengthen Guyana's ability to reduce deforestation and forest degradation through the adoption and implementation of a REDD-plus governance development plan (RGDP). As a UNFCCC compliance grade capability for monitoring, reporting and verifying (MRV) emissions is established in Guyana, these results will be measured objectively in accordance with the rules and policies of the UNFCCC. Until these rules and policies are in place, attainment of initial REDD standards will enable financial support. The level of financial support will be based on interim arrangements to estimate and verify results in limiting greenhouse gas emissions from deforestation and degradation. Guyana's LCDS MultiStakeholder Stecring Committee and other arrangements to ensure systematic and transparent multi-stakeholder consultations will continue and evolve, and enable the participation of all affected and interested stakcholders at all stages of the REDDplus/LCDS process; protect the rights of indigenous peoples; ensure environmental integrity and protect biodiversity; ensure continual improvements in forest governance; and provide transparent, accountable oversight and governance of the financial support received. 


\section{FINANCLAL MECHANISM}

3. It is the Participants' intention to establish a Guyana REDD-plus Investment Fund (GRIF). The GRIF will be a multi-contributor financial mechanism run by a reputable international organization. It will be designed to channel results-based REDD-plus funds from Norway and other potential contributors to the implementation of Guyana's LCDS. Safeguards as well as fiduciary and operational policies of the organization selected will apply as appropriate to all activities to be financed by GRIF. The mechanism will also ensure full national and international oversight of financial flows. The Participants will encourage other developed countries to contribute to the Fund as part of their efforts to combat climate change. The GRIF could over time evolve to cover all types of climate change mitigation and adaptation funding, including if appropriate funding received under the UNFCCC.

\section{AN EVOLVING PARTNERSHIP}

4. The details of this partnership are further described in a Joint Concept Note on REDDplus cooperation between Guyana and Norway developed by the Participants. This note constitutes the basis for the work of the Participants. While Guyana and Norway consider that this Joint Concept Note clearly lays out their agreed positions as of November 2009. they are also aware that REDD-plus is a new concept, and that this partnership is in the forefront of developments, and are prepared to revise and further develop its content to reflect increased insights as the Partnership, and other related international efforts, move forward and lessons are learned.

\section{FOCAL POINTS}

5. To contribute to efficient cooperation, each of the Participants will designate a Focal Point to facilitate the implementation of paragraph 2 of this $\mathrm{MoU}$ in their respective countries through means to be decided.

6. The Focal Points may prepare and facilitate the policy and political dialogue described under paragraph 2a) of this Memorandum of Understanding, whenever necessary exchanging information relevant to its implementation. In particular, they may also hold and/or facilitate meetings in preparation for sessions of the UNFCCC as well as in the margins of meetings in that body or of the sessions of its subsidiary bodies. 
Done in Fairview Village, Guyana, on 9 November 2009, in duplicate and in English, both texts being equally authentic.

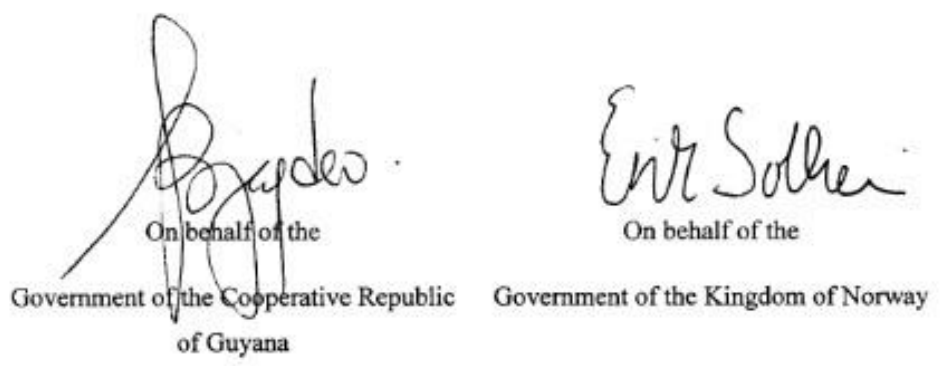




\section{References}

Adger, W.N., et al., 2001. Adaptation to climate change in the developing world. Progress in Development Studies, 3 (3): 179-195, doi: 10.1191/1464993403ps060oa

Adger, W.N., et al., 2003. Adaptation to climate change in the developing world. Progress in Development Studies, 3(3): 179-195, doi: 10.1191/1464993403ps060oa

Adger, W.N., et al., 2005. Successful adaptation to climate change across scales. Global Environmental Change, 15: 77-86 doi: 10.1016/j.gloenvcha.2004.12.005

Adger, W.N., 2006. Vulnerability. Global Environmental Change. 16: 268-281, doi:10.1016/j.gloenvcha.2006.02.006

Adriaenssens, V., et al., 2004. Fuzzy rule-based models for decision support in ecosystem management. The Science of the Total Environment, 319: 1-12, doi: 10.1016/S00489697(03)00433-9

Ahmad, K., Wei, L., 2012. Adaptation as a response to climate change: A literature review. Fifth International Annual Conference on Industrial Economics and Economic Theory, Shandong University, Jinan, P.R., China.

Allen, M.R., et al, 2009., Warming caused by cumulative carbon emissions towards the trillionth tonne. Nature, 458: 1163-1166.

Amos, J., 2006. Deep ice tells long climate story. BBC News (Science Reporter) Retrieved in May 2015.

Anthoff, D., et al, 2010. The economic impact of substantial sea level rise. Mitigation and Adaptation Strategies for Global Change. 15(4): 321-335, doi:10.1007/s11027-010-9220-7

Archer, D., et al, 2009. Atmospheric lifetime of fossil fuel carbon dioxide. Annual Review of Earth and Planetary Sciences, 37:117-134, doi: 10.1146/annurev.earth.031208.100206

Arkema, K.K., et al., 2013., Coastal habitats shield people and property from sea-level rise and storms. Nature Climate Change, 3: 913-918, doi: 10.1038/nclimate1944 
Arnell, N.W., et al., 2013. A global assessment of the effects of climate policy on the impacts of climate change. Nature Climate Change, 3:512-519, doi: 10.1038/nclimate1793

Babiker, M., et al., 1999. The Kyoto Protocol and developing countries. MIT Joint Program on the Science and Policy of Global Change. Report No. 56. Cambridge, MA, USA.

Bailey, R., et al., 2014. Livestock-climate change forgotten sector (Global Public Opinion on Meat and Dairy Consumption), Chatham House, The Royal Institute of International Affairs.

Banerjee, N., 2010. Carbon dioxide in the atmosphere crosses historic threshold. The Los Angeles Times, CA, USA.

Barnett, J., 2001. Adapting to climate change in Pacific Island countries: the problem of uncertainty. World Development, 29(6): 977-993. PII: S0305-750X (01) 000 22-5

Basher, R.E., 1999. Data requirements for developing adaptations to climate variability and change. Mitigation and Adaptation Strategies for Global Change, 4: 227-237.

Battle, M., et al., 1996. Atmospheric gas concentrations over the past century measured in air from firn at the South Pole. Nature, 383: 231-235.

Berang-Ford, L., et al., 2014. What drives national adaptation? A global assessment. Climatic Change, 124: 441-450. doi: 10.1007/s10584-014-1078-3

Bergman, C.J., 2009. A survey of drought impacts and mitigation in Kentucky. Masters Thesis \& Specialist Projects, Paper 95. http://digitalcommons.wku.edu/theses/95

Biello, D., 2013. Dangerous global warning closer, than you think, climate scientists say. Scientific American (online): Retrieved on June 2015.

Bierbaum, R. et al., 2007. Confronting climate change: Avoiding the unmanageable and managing the unavoidable. United Nations Foundation. Scientific Expert Group Report on 
Climate Change and Sustainable Development, prepared for the $15^{\text {th }}$ Session of the Commission on Sustainable Development.

Bierbaum, R. et al., 2013. A comprehensive review of climate adaptation in the United States: more than before, but less than needed. Mitigation and Adaptation Strategies for Global Change. 18: 361- 406, doi: 10.1007/s11027-012-9423-1

Biesbroek, G.R., et al., 2010. Europe adapts to climate change - comparing national adaptation strategies. Global Environmental Change, 20:440-450, doi.org/10.1016/j.gloenvcha.2010.03.005

Birdsall, N., Busch, J., 2009. Assessing performance-based payments for forest conservation: six successes, four worries, and six possibilities to explore of the Guyana-Norway Agreement. Centre for Global Development, Climate and Forest Paper \# 1. Washington, D.C., USA.

Bisaro, A., et al., 2010. Framing climate vulnerability and adaptation at multiple levels: addressing climate risks or institutional barriers in Lesotho. Climate and Development, 2: 161175, doi:10.3763/cdev.2010.0037

Blaikie, P., et al., 1996. At risk: natural hazards, people's vulnerability and disasters. Review by Liebow, E.B., in Human Ecology, 24(1): 141-145.

Bohringer, C., 2002. Climate Politics from Kyoto to Bonn: from little to nothing. The Energy Journal, 23(2): 51-71.

Boggan, J., et al., 1997. Checklist of the plants of the Guianas (Guyana, Suriname, French Guiana). 2nd Edition. Biological Diversity of the Guianas Program, Department of Botany, NMNH, Smithsonian Institution, Washington, DC.

Bovolo, I., 2013. Managing Flood Risks in Guyana, The Conservancy Adaptation Project. Latin America and the Caribbean Unit of the World Bank. Conservancy Adaptation Project (TF 916 92).

Bradbury, J., DeConcini, C., 2012. The connection between climate change and recent extreme weather events. World Resources Institute (Factsheet). 
Brooks, N., et al., 2005. The determinants of vulnerability and adaptive capacity at the national level and implications for adaptation. Global Environmental Change - Human and Policy Dimensions, 15: 151-163, doi.org/10.1016/j.gloenvcha.2004.12.006.

Buhaug, H., 2014. One effect to rule them all? A comment on climate and conflict. Climatic Change, 127: 391-397, doi: 10.1007/s10584-014-1266-1

Burck, J., et al., 2014. The climate change performance index, Results 2015. German Watch. Climate Action Network, Europe.

Burton, D., 2012. Comments on "Assessing future risks the: quantifying the effects of sea level rise on storm surge risk for the southern shores of Long Island, New York. Natural Hazards, 63(2): 1219-1221.

Butler, J.H., Montzka, H.A., 2015. The NOAA Annual Greenhouse Gas Index (AGGI). NOAA Earth System Research Laboratory, Boulder, CO, USA.

Cai, W., et al., 2014. Increasing frequency of extreme El Nino events due to greenhouse warming. Nature Climate Change, 4: 111-116, doi: 10.1038/nclimate2100

Carey, J., 2011. Calculating the true cost of global climate change. Yale Environment 360: In Biodiversity Climate Forests Policy and Politics in North America.

Charveriat, C., 2000., Natural disasters in Latin America and the Caribbean: an overview of risks. Inter-American Development Bank.

Civil Defence Commission, 1999. El Nino Crisis in Guyana, 1997 - 1998. CDC Secretariat: Georgetown, Guyana

Clark, S., et al., 2012. A cost-benefit analysis of adaptation to climate change: comparing ecosystem based adaptation versus engineered approaches to tropical storm variability. A project at the Bren School of Environmental Science and Management, UCSB, USA.

Climate Action, 2013, Ottawa, Canada 
Dalrymple, O.K., 2006. Sea-level rise implications for the coast of Guyana. Fourth LACCEI International Latin American and Caribbean Conference for Engineering and Technology. Mayaguez, Puerto Rico.

Dalrymple, O.K., Pulwarty, R.S., 2006. Sea-level rise implications for the coast of Guyana: sea walls and muddy coasts. Fourth LACCEI International Latin American and Caribbean Conference for Engineering and Technology. Mayaguez, Puerto Rico.

Dasgupta, S., et al, 2009. Climate change and the future impacts of storm-surge disasters in developing countries. CDG Working Paper 182. Washington, DC: Center for Global Development

de Bruin, K., et al., 2009. Adapting to climate change in The Netherlands: an inventory of climate adaptation options and ranking of alternatives. Climatic Change, 95: 23-45, doi.org/10.1007/s10584-009-9576-4

Dessai, S., et al, 2004. Defining and experiencing dangerous climate change. Climatic Change, 64(1): 11-25

Doswald, N., Osti, M., 2011. Ecosystem-based approaches to adaptation and mitigation - good practice examples and lessons learned in Europe. BfN-Skripten 306 (Federal Agency for Nature Conservation), Bonn, Germany.

Douglas, E.M., et al., 2012. Coastal flooding, climate change and environmental justice: identifying obstacles and incentives for adaptation in two metropolitan Boston Massachusetts communities. Mitigation and Adaptation Strategies for Global Climate Change, 17: 537-562, doi: $10.1007 / \mathrm{s} 11027-011-9340-8$

Dittrick, P., 2014. Small subset of wells account for most methane emissions, researchers say. Oil and Gas Journal, (Online): Retrieved on June, 2015.

Dupuis, J., Knoepfel, P., 2011. Barriers to the implementation of climate change adaptation policies: the case of Switzerland. Swiss Political Science Review, 17(1): 1-32, doi:10.1111/j.1662-6370.2011.02011.x 
Eakin, H., et al., 2015. Information and communication technologies and climate change adaptation in Latin America and the Caribbean: a framework for action. Climate and Development, 7(3): 208-222, doi.org/10.1080/17565529.2014.951021

ECLAC, 2011.

Ekstrom, J.A., et al., 2011. Barriers to climate change adaptation: a diagnostic framework. Lawrence Berkeley National Laboratory, Berkeley, California, USA. Contract Number: 500-07043.

El-Raey, et al, 1999, Adaptation to sea level rise in Egypt. Mitigation and Adaptation Strategies for Global Change. 4: 343-361

Environmental Protection Agency, 2000. Integrated Coastal Zone Management Plan. EPA, Georgetown, Guyana.

Environmental Protection Agency, 2001. National Biodiversity Action Plan 2001 - 2005. EPA, Georgetown, Guyana

Environmental Protection Agency Guyana (EPA Guyana), 2002. Guyana's national vulnerability assessment to sea level rise. Georgetown: EPA Guyana

EurActiv. 2010. EU set to overshoot its Kyoto emission targets. EU News and Policy Debates (online): Retrieved on June 2015).

Falke, A., 2011. Business lobbying and the prospects for American climate change legislation. GAIA- Ecological Perspectives for Science and Society20/1: 20-25

Falkner, R., et al., 2010. International climate policy after Copenhagen: towards a 'building blocks' approach. Global Policy, 1(3): 253-262.

FAO, 2005. Global Forest Resources Assessment: Country Report (173), Guyana. Forestry Department, Food and Agriculture Organization of the UN.

Fletcher, C.S., 2015. Economic equitable and affordable adaptations to protect coastal settlements against storm surge inundation (Open Access, online), doi: 10.1007/s10113-0150814-1 
Fleming, J.R., 1999. Joseph Fourier, the greenhouse effect, and the quest for a universal theory of terrestrial temperatures. Endeavor, 23(2): 72-75.

Folke, C., 2006. Resilience: the emergence of a perspective for social ecological systems analyses. Global Environmental Change, 16: 253-267, doi: 10.1016/j.gloenvcha.2006.04.02

Fussler, J., 2012. Emissions pathways to reach $2^{0} \mathrm{C}$ target. Model results and analysis (Final Report), Swiss Federal Institute of Technology, Zurich, Switzerland

Fukao, T., et al., 2011. The submergence tolerance regulator SUB1A mediates crosstalk between submergence and drought tolerance in rice. The Plant Cell, 23: 412-427, doi/10.1105/tpc. 110.080325

Gallopin, G.C., 2006. Linkages between vulnerability, resilience and adaptive capacity. Global Environmental Change, 16(3): 293-303, doi:10.1016/j.gloenvcha.2006.02.004

Gang, C., 2007. The Kyoto Protocol and the logic of collective action. Chinese Journal of International Politics, 1: 525-557, doi:10.1093/cjip/pom008.

Gari, J.A., 2011. The REDD+ mechanism and the REDD+ readiness. UNDP, Environment and Energy Group, Dakar.

Geden, O., 2013. Warming the World: It's time to give up the two degree target. Spiegel online International, Germany.

Gerken, J., 2013. $400 \mathrm{ppm}$ atmospheric CO2 levels soon to be surpassed scientists report. The Huffington Post, Mother Nature Network.

Gilman, E.L., et al., 2008. Threats to mangroves from climate change and adaptation options: a review. Aquatic Botany, 89: 237-250, doi:10.1016/j.aquabot.2007.12.009.

Goodstein, L., 2015. In the footsteps of other popes, Francis seeks worldly change. The New York Times, Online Edition: Retrieved on June, 2015. 
Graham, S., 2000. Savante Arrhenius (1859-1927). NASA, Earth Observatory, Retrieved on June 2015.

Green Climate Fund, 2015. Governments requested to accelerate signing of contributions to Green Climate Fund. Press Release, Green Climate Fund.

Grothmann, T., Patt, A., 2003. Adaptive capacity and human cognition. Postdam Institute for Climate Impact Research, Department of Global Change and Social Systems, Germany.

Gruning, C., Shuford., L.S., 2012. Case study: Guyana REDD+ Investment Fund (GRIF). Frankfurt School of Finance and Management - UNEP Collaborating Centre for Climate and Sustainable Energy Finance.

Gu, G., Adler, R.F., 2009. Interannual variability of boreal summer rainfall in the equatorial Atlantic. International Journal of Climatology, 29: 175-184, doi: 10.1002/joc.1724

Gutierrez, A.P.A., et al., 2014. Drought preparedness in Brazil. Weather and Climate Extremes, (Open Access, online), doi.org/10.1016/j.wace.2013.12.001

Guyana Graphic. 2012. Regions of Guyana. Retrieved on June 2015.

Guyana Poverty Reduction Strategy, 2006., IMF Country Report No. 06/364

Haddad, B.M., 2005. Ranking the adaptive capacity of nations to climate change when sociopolitical goals are explicit. Global Environmental Change, 15: 165-176, doi:10.1016/j.gloenvcha.2004.10.002

Haita, C., 2012. The state of compliance in the Kyoto Protocol. International Centre for Climate Governance, (ICCG Reflection No.12), Venice, Italy.

Hallegate, S., et al., 2011. Designing climate change adaptation policies. The World Bank Sustainable Development Network. Policy Research Working Paper 5568.

Hannam, P., 2013. Extreme weather likely to increase and intensify, report finds. The Sydney Morning Herald (Environment). Online edition, retrieved on June 2015. 
Hansen, J., et al., 2008. Target atmospheric CO2: where should humanity aim? Open Atmosphere Science, 2: 217-231, doi: 10.2174/1874282300802010217

Hansen, J., et al., 2013. Assessing "dangerous climate change": Required reduction of carbon dioxide to protect young people, future generation and nature, PLOS one (Open Access online) 8 (12): 1-26.

Haszeldine, R.S., 2009. Carbon capture and storage: how green can black be? Science, 325(5948): 1647-1652, doi: 10.1126/science.1172246.

Heltberg, R., et al., 2009. Addressing human vulnerability to climate change: towards a "no regrets" approach. Global Environmental Change, 19: 89-99. doi:10.1016/j.gloenvcha.2008.11.003

Hickey, C., Weis, T., 2012. The challenge of climate change adaptation in Guyana. Climate and Development, 4:1, 66-74, doi: 1080/17565529.2012.661036

Hinkel, J., Bisaro, A., 2014. Methodological choices in solution-oriented adaptation research: A diagnostic framework. Regional Environmental Change (Special issue on problem oriented approaches to adaptation research), open access on line, doi: 10.1007/s10113-014-0682-0

Hoffman, M.E., et al., 2011. Classifying knowledge on climate change impacts, adaptation, and vulnerability in Europe for informing adaptation research and decision-making: A conceptual meta-analysis. Global Environmental Change, 21: $1106 \quad$ - 1116, doi:10.1016/j.gloenvcha.2011.03.011

Hope, M., Pearce, R., 2014. Two degrees: the history of climate change's "speed limit". The Carbon Brief, (Analysis): 1-5.

Howden, S.M. et al., 2007. Adapting agriculture to climate change. PANS, 104 (50): 19691 19696 doi: 10.1073pnas.0701890104

Hultman, N., Langley, C., 2012. The Doha Climate Gateway: Limited progress toward a global agreement. UpFront (online) Brookings Institution Press 
Hydrometeoreological Protection Agency, 2001. National Climate Change Action Plan. Georgetown, Guyana.

Ibrahim, S.G., Uke, I.I., 2013. From Kyoto Protocol to Copenhagen: A theoretical approach to international politics of climate change. African Journal of Political Science and International Relations, 7(3): 142-153, doi: 10.5897/AJPSIR11.089

Inman, M., 2008. Nature Reports, Climate (online) d.o.i 1038/climate.2008.122

IPPC, 1990, 2001, 2006, 2007, 2011, 2012, 2013, Geneva, Switzerland

Jansen, M.A., Ostrom, E., 2006. Resilience, vulnerability and adaptation: a cross cutting theme of the International Humans Dimensions Programme on Global Environmental change. Global Environmental Change, 16: 239-239, doi: 10.1016/j.gloenvcha. 2006.04.003

Jones, L., Boyd, E., 2011. Exploring social barriers to adaptation: Insights from Western Nepal. Global Environmental Change, 21: 1262-1274 doi:10.1016/j.gloenvcha.2011.06.002

Jull, O.K., 2012. Canada withdraws from the Kyoto Protocol to avoid non-compliance penalties. Canada Bar Association, Canada.

Karl, T.R., et al., 2009. Global climate change impacts in the United States. A State of Knowledge Report from the U.S. Global Change Research Report, Cambridge University Press, NY, USA.

Kates, R.W., 2000. Cautionary tales: adaptation and the global poor. Climatic Change, 45: 5-17.

Kelly, P.M., Adger, W.N., 2000. Theory and practice in assessing vulnerability to climate change and facilitating adaptation. Climate Change, 47(4): 325-352.

Khan, M. and Sturm, M. 1995. Assessment of the vulnerability of coastal areas to sea-level rise: case study Guyana. The Hague, the Netherlands, Ministry of Transport, Public Works and Water Management. 
Klien, R.J.T., 2010. Linking adaptation and development finance: A policy decision not addressed in Copenhagen. Climate and Development. 2:303-206. d.o.i: 10.3763/cdev.2010.0049

Klein, R., 1015. Adaptation to climate change: Policy challenges and private initiatives ahead of the Paris Climate Summit. IVAs Konferenscenter, Stockholm and Stockholm Environment Institute (SEI).

Koningsveld, M.V., et al., Living with sea level rise and climate change: A case study of the Netherlands. Journal of Coastal Research, 24(2): 367-379.

Kunzig, R., 2013. Climate milestone: earth's $\mathrm{CO}_{2}$ level passes 400 ppm. National Geographic News.

Lashof, D.A., Ahuja, D.R., 1990, Relative contributions of greenhouse gas emissions to global warming. Nature. 344: 529-531

Laybourn, L., et al., 2012, Policy Analysis Reports, Climatico

Lazare, S., 2015. Global carbon levels surpass $400 \mathrm{ppm}$ for the first ever for entire month. Common Dreams, Eco Watch.

Leal-Arcas, R., 2013. The BRICS and climate change. International Affairs Forum (Open Access, online), doi: 10.1080/23258020.2013.824246

Lenderink, G., et al., 2014. Preparing local climate change scenarios for the Netherlands using resampling of climate model output. Environmental Research Letters, 9: 1-13, doi: 10.1088/1748-9326/9/11/115008

Levi, M.A., 2009. Copenhagen’s inconvenient truth. Foreign Policy, Vol. 88 (5) 92-104

Linham, M.M., Nicholls, R.J., 2010. Technologies for climate change adaptation. TNA Guidebook Series (UNEP), University of Southampton.

Lim, B., et al., 2004. Adaptation policy frameworks for climate change: developing strategies policies and measures. Cambridge University Press, Cambridge, UK. 
Liu, Y., et al., 2014. Climate and crop yields impacted by ENSO episodes on the North China Plain. Regional Environmental Change, 14: 49-59, doi: 10.1007/s10113-013-0455-1

Low Carbon Development Strategy (LCDS): Guyana, 2010. Transforming Guyana's economy while combating climate change. Office of the President, Guyana

Lugnot, M., Martin. G., 2013. Biodiversity provides ecosystem services: scientific results versus stakeholders' knowledge. Regional Environmental Change, 13:1145-1155, doi: 10.1007/s10113013-0426-6.

MacDonald, M., 20 MacDonald, M., 2006. Guyana drainage and irrigation systems rehabilitation project. Institutional and Financial Sustainability Report. Ministry of Agriculture, Georgetown, Guyana.

McCarthy, P.D., 2012. Climate change adaptation for people and nature: A case study from the U.S. Southwest. Advances in Climate Change Research. 3(1): 22-37, doi: 10.3724/SP.J.1248.2012.00022

McKibbin, W.J., Wilcoxen, P.J., 2002. The role of economics in climate change policy. Journal of Economic Perspectives. 16(2): 107-129.

McClendon, R., 2013. Earth's carbon dioxide levels to hit 400 ppm. Mother Nature Network.

McSweeney, C., et al., 2010. Guyana. UNDP Climate Change Country Profiles. Available at: http://country-profiles.geog.ox.ac.uk

Merger, E., et al., 2011. Options for REDD+ voluntary certification to ensure net GHG benefits, poverty alleviation, sustainable management of forests and biodiversity conservation. Forests 2(2): 550-577, doi: 10.3390/f2020550

Mertz, O., et al., 2009. Adaptation to climate change in developing countries. Environmental Management. 43:743-752, doi: 10.1007/s00267-008-9259-3

Middelmann-Fernandes, M.H., 2009. Review of the Australian studies database. Geoscience, Record 2009/034: 1-13

Miles, L., Kapos, V., 2008. Reducing greenhouse gas emissions from deforestation and forest degradation: global land-use implications. Science, 320: 1454-1455. 
Millner, A., Dietz, S., 2011. Adaptation to climate change and economic growth in developing countries. Grantham Research Institute, E.S.R.C, University of Leeds and London School of Economics and Political Science

Mimura et al, 2010. Approaches to climate change adaptation. The Committee on Approaches to Climate Change Adaptation. Japan.

Mirza, M.N.Q., 2011. Climate Change and extreme weather events: can developing countries adapt. Climate Policy, 3(3): 233-248, doi: 10.3763/cpol.2003.0330

Mishra, A.K., Singh, V.P., 2010. A review of drought concepts. Journal of Hydrology, 391(1-2): 206-216, doi:10.1016/j.jhydrol.2010.07.012

Moser, S.C., Ekstrom, J.A., 2010. A framework to diagnose barriers to climate change adaptation. PNAS, doi: 10.1073/pnas.1007887107

Mufson, S., 2014. China's pledge to cut greenhouse gases eliminates excuses from other nations. The Washington Post (online edition): Retrieved on June, 2015.

Munang, R., et al., 2013. Climate change and ecosystem based adaptation: a new pragmatic approach to buffering climate change impacts. Current Opinion in Environmental Sustainability, 5: 67-71, doi: 10.1016/j.consust.2012.12.001

Murray, L., 2011. China, world's biggest greenhouse gas emitter introduces more pollution control. Earth Times, Retrieved on June 2015.

Naumann, S., et al, 2011. Assessment of the potential of ecosystem based approaches to climate change adaptation and mitigation in Europe. Final report to the European Commission, Ecologic institute and Environmental Change Institute, Oxford University Centre for the Environment

Niroula, R.K., et al., 2012. SUB1A-dependent and -independent mechanisms are involved in the flooding tolerance of wild rice species. The Plant Journal, 72(2): 282-293, doi: 10.1111/j.1365313X.2012.05078.X 
Oh, I., 2015. The world's carbon dioxide levels just hit a staggering new milestone. Mother Jones, CA, USA.

Olawuyi, D.S., 2010. From Kyoto to Copenhagen: rethinking the place of flexible mechanisms in the Kyoto Protocol's post 2012 commitment period. Law, Environment and Development Journal, 6(1): 23-35.

Olhoff, A., 2014. Adaptation in the context of technology development and transfer. Climate Policy. 15(1): 163 - 169. doi: 10.1080/14693062.2014.873665.

Olivier, J.G.J., et al., 2013. Trends in global CO2 emissions: 2013 Report. PBL Netherlands Environmental Assessment Agency.

Olsthoorn, X., et al, 2008. Neo-Atlantis: The Netherlands under a 5-m sea level rise. Climatic Change. 91(1-2): 103-122, doi: 10.1007/s10584-008-9423-z

Orlove, B., 2005. Human adaptation to climate change: a review of three historical cases and some general perspectives. Environmental Science \& Policy, 8: 589-600, doi:10.1016/j.envsci.2005.06.009

Paavola, J., Adger, W.N., 2006. Fair adaptation to climate change. Ecological Economics, 56: 594-609, d.o.i:10.1016/j.ecolecon.2005.03.015

Panday, R., Jha, S.K., 2012. Climate vulnerability index-measure of climate vulnerability to communities: a case of rural lower Himalaya, India. Mitigation and Adaptation Strategies for Global Change, 17: 487-506, doi: 10.1007/s11027-011-9338-2

Parker, L., Blodgett, J., 2008. Greenhouse gas emissions: perspectives on the top 20 emitters and developed versus developing nations. CRS Report for Congress (Order Code RL 32721), Congressional Research Service.

Parry, M., et al, 1998. Adapting to the inevitable. Nature. 395: 741. doi: 10.1038/27316

Peduzzi, P., 2005. Is climate change increasing the frequency of hazardous events? Environment and Poverty Times No. 3 p. 7. (Special Edition for World Conference on Disaster reduction, Kobe, Japan). 
Pelling M., 1997. What determines vulnerability to floods; a case study in Georgetown, Guyana. Environment and Urbanization, 9(1): 203-219.

Pelling, M., 1999. The political ecology of flood hazard in urban Guyana. Geoforum. 30: 249261.

Pereira, R., et al., 2014. Seasonal patterns of rainfall and river isotopic chemistry in northern Amazonia (Guyana): From the headwater to the regional scale. Journal of South American Earth Sciences, 52: 108-118, doi.org/10.1016/j.jsames.2014.02.005.

Persaud, E.R., 2014. Sea level rise and the coastline of Guyana. Faculty of Technology, University of Guyana. Guyana.

Peters, G.P., Hertwich, E. G., 2007. $\mathrm{CO}_{2}$ embodied in international trade with implications for global climate policy. Environmental Science and Technology, 42(5): 1401-1407. doi: $10.1021 / \mathrm{es} 072023 \mathrm{k}$

Pielke, Jr., R.A., 1998. Rethinking the role of adaptation in climate policy. Global Environmental Change, 8(2): 159-170

Preston, B.L., et al., 2011. Climate adaptation planning in practice: an evaluation of adaptation plans for three developed nations. Mitigation and Adaptation Strategies for Global Change, 16: 407- 438, doi.org/10.1007/s11027-010-9270-х

Promova, E., et al., 2014. Ecosystem services in the national adaptation programmes of action. Climate Policy, 12 (4), 393-409. doi: 10.1080/14693062.2011.647848

PROVIA, 2013: PROVIA Guidance on Assessing Vulnerability, Impacts and Adaptation to Climate Change. Consultation document, United Nations Environment Programme, Nairobi, Kenya, 198 pp.

Ramankutty, N., et al, 2007. Challenges to estimating forest carbon from tropical deforestation. Global Change Biology, 13: 51-66, doi: 10.1111/j.1365-2486.2006.01272.x

Roberts, E., 2012. Loss and damage in vulnerable countries. Germanwatch, United Nations University, ICCCAD, CDKN 
Rogelj, J., Meinshausen, M., 2010. Copenhagen Accord pledges are paltry. Nature, 464: 11261128.

Rohekar, J., 2014. China's per capita emissions surpasses EU's. Down to Earth, Science and Environment online, Retrieved on June, 2015.

Rosenzweig, C., et al., 2001. Climate change and extreme weather events-implications for food production, plant diseases and pests. NASA, Goddard Institute for Space studies

Sachs, J.D., 2015. The basic science of climate change in: The Age of Sustainable Development, pp: 393-433, Columbia University Press, NY, USA.

Schaap, B.F., et al., 2011. Impact changes of climatic extremes on arable farming in the North of the Netherlands. Regional Environmental Change, 11: 731-741, doi: 10.1007/s10113-011-0205-1

Schipper, L., \& Pelling, M., 2007. Disaster risk, climate change and international development: Scope for, and challenges to, integration. Disasters, 30(1), 19-38.

Schmidt, G., 2010. Carbon dioxide and the climate. American Scientist, 98(1): 1-2

Second National Communication (SNC), Guyana to the UNFCCC, 2012. Government of Guyana. Report supported by the UNDP and funded by the Global Environment Facility

Sem, G., Moore, R., 2009. The impact of climate change on the development prospects of the least developed countries and small island developing states. Office of the High Representative for Least Developed Countries, Landlocked Developing and Small Island Developing States (UN-OHRLLS).

Shaw, A.B., 1987. An analysis of the rainfall regimes on the coastal regions of Guyana. Journal of Climatology, 7: 291-302.

Sheargold, E., 2012. Doha COP Report: The Doha Climate Gateway. The Sabin Centre for Climate Change Law, Columbia Law School, NY, USA.

Smit, B., et al., 1999. The science of adaptation: A framework for assessment, Mitigation and Adaptation Strategies for Global Change. 4: 199-213. 
Smit, B., Wandel, J., 2006. Adaptation, adaptive capacity and vulnerability. Global Environmental Change, 16: 282-292, doi: 10.1016/j.gloencha.2004.12.006.

Solomon, S., et al., (editors), 2007, Climate Change 2007: The Physical Science Basis: Contribution of Working Group I to the Fourth Assessment Report of the Intergovernmental Panel on Climate Change. New York, United States: University Press and Geneva, Switzerland: IPCC.

Solomon, S., et al., 2009. Irreversible climate change due to carbon dioxide emissions. Proceedings, National Academy of Sciences, USA, 106(6): 1704-1709, doi: 10.1073/pnas.0812721106

Sovacool, B.K., 2011. Hard and soft paths for climate change adaptation. Climate Policy, 11: 1173-1183, doi: org/10.1080/14693062.2011.579315

Speranza, C.I., Scholz, I., 2013. Adaptation to climate change: analysing capacities in Africa. Regional Environmental Change, 13:471-435, doi: 10.1007/s10113-013-0467-x

Stehr, N., von Storch, H., 2008. Anpassung und Vermeidung oder von der Illusion der Differenz. GAIA - Ecological Perspectives for Science and Society, 17: 270-273.

Stern, N., 2006. The Stern review on the economics of climate change. HM Treasury, UK. Cambridge University Press.

Sutton-Grier, A.E., et al 2014. Incorporating ecosystem services into the implementation of existing U.S natural resource management regulations: operationalizing carbon sequestration and storage. Marine Policy, 43: 246-253, doi: 10.101b/i.marpol.2013.06.003

The REDD Desk, 2013. A programme of the Global Canopy Programme (Retrieved on June 2015.

Thomas, D.S.G., Twyman, C., 2005. Equity and Justice in climate change adaptation amongst natural-resource-dependent societies. Global Environmental Change, 15:115-124, doi:10.1016/j.gloenvcha.2004.10.001 
Thompson, A., 2014. April becomes first month with $\mathrm{CO}_{2}$ levels above $400 \mathrm{ppm}$. Climate Central,

Tol, R.S.J., et al., 2004. Distributional aspects of climate change impacts. Global Environmental Change, 14:259-272, doi: 10.1016/j.g/oenvcha.2004.04.007.

Travers, A., et al. 2014. Ecosystem based adaption guidance: moving from principles to practice. University of Sunshine Coast, Australia and UNEP, Division of Policy Implementation.

Trenberth, K.E., et al., 2014. Global warming and changes in drought. Nature Climate Change, 4: 17-22, doi: 10.1038/NCLIMATE2067

Turner, R., et al, 2009. Salt marshes and eutrophication: an unsustainable outcome. Limnology and Oceanography, 54(5): 1634-1642

Uittenbroek, C.J., et al., 2013. Mainstreaming climate adaptation into urban planning: overcoming barriers, seizing opportunities and evaluating the results IN TWO Dutch case studies. Regional Environmental Change, 13: 399-411, doi: 10.1007/s10113-012-0348-8

Uleberg, E., et al., 2014. Impact of climate change in agriculture in Northern Norway and potential strategies for adaptation. Climatic Change, 122: 27-39, d.o.i: 10.1007/s1013-013-04604

UNDP, 2015. Sustainable energy, climate change and disasters. Retrieved on June 2015

UNFCCC, 2013, Bonn, Germany

United Nations Framework Convention on Climate Change (UNFCCC). 2007. Impacts vulnerabilities and adaptation in developing countries. Bonn, Germany: UNFCCC

Vasileiadou, E., et al., 2014. Adaptation to extreme weather: identifying different societal perspectives in the Netherlands. 14:91-101, doi: 10.1007/s1013-013-0460-4

Vespa, M., 2009., Why 350? Climate policy must aim to stabilize greenhouse gases at the level necessary to minimize the risk of catastrophic outcomes. Ecology Law Currents, 36: 185-194 
Vignola, R., et al., 2012. Ecosystem-based adaptation to climate change: what role for policy makers, society and scientists? Mitigation and Adaptation Strategies for Global Change, 14(8): 691-696, doi: 10.1007/s11027-009-9193-6

Visseren-Hamakers, I.J., et al., 2012. Will REDD+ work? The need for interdisciplinary research to address key challenges. Current Opinion in Environmental Sustainability, 4:590-596, doi: 10.1016/j.cosust.2012.10.006

Waller-Hunter, 2003. Executive Secretary, UNFCC, Bonn, Germany

Wallack J.S., Ramanathan V., 2009. The other climate changers, Foreign Policy, Vol. 88 (5) 105- 108

Wayman, E., 2013. Science News, Magazine of the Society for Science and the Public, Washington D.C

Werners, S.E., et al., 2015. Method selection in adaptation research: the case of the Delta programme for the Dutch Wadden region. Regional Environmental Change (Open Access online), doi: 10.1007/s10113-015-0799-9

Wheaton, E.E., Maciver, D.C., 1999. A framework and key questions for adapting to climate variability and change. Mitigation and Adaptation Strategies for Global Change. 4:215-225.

Wigley, T.M.L., Raper, S.C.B., 1987. Thermal expansion of sea water associated with global warming. Nature, 330:121-131, doi: 10.1038/330127a0

Wolf, S., et al., 2012. Clarifying vulnerability definitions and assessments using formalisations. International Journal of Climate Change Strategies and Management, 5(1): 54-70, doi: $10.1108 / 17568691311299363$

World Bank, 2015. Climate Change, Health and opportunities for sustainable development. Retrieved on June 2015. 
WWF-Guiana, 2012. Living Guianas Report 2012: State of the Guianas drivers and pressures towards greener economies. WWF-Guianas and the Copernicus Institute, University of Utrecht, The Netherlands. 